\title{
MORFOLOGIA FLORAL E BIOLOGIA DA REPRODUÇÃO DE CINCO ESPÉCIES DE Controsema (DC.) BENTH. (LEGUMINOSAE - PAPILIONOIDEAE)
}

\section{ALICE BATTISTIN}

Orientador: Prof. Dr. PAULO SODERO MARTINS

Tese apresentada à Escola Superior de Agricultura "Luiz de Queiroz", da Universidade de São Paulo, para obtenção do título de Doutor em Agronomia. Área de Concentração: Genética e Melhoramento de Plantas.

PIR A C IC A B A

Estado de São Paulo - Brasil

Agosto = 1983 
.ii.

Aos meus pais (in memoriam), cuja lembrança me traz alegria $e$ incentivo de lutar e viver;

Aos meus irmãos, irmãs e demais familiares 
.iii.

Ao Prof. Dr. Paulo Sodero Martins, pela valiosa orientaça e amizade;

Ao casal,

Sra. Aracy Pontin Ducatti e

Sr. Alfredo Ducatti, pela

compreensão, carinho e amizade, OFEREÇO 


\section{AGRADECIMENTOS}

Sinceros agradecimentos a todos que contribuiram para a realização deste trabalho, particularmente:

- Prof. Dr. Paulo Sodero Martins;

- Prof. Dr. Ernesto Paterniani;

- Profa Dra. Maria Neysa Silva Stort;

- Profs. do Departamento de Genética da ESALQ/USP;

- Funcionärios do Departamento de Genética da ESAlQ/USP, em especial: Sra. Eisa A.A. César, Sra. Terezinha de Jesus Bar rete, Srta. Erica Spruck, Sr. Alaor de Oliveira, Sr. João Alcine e Ronaldo J. Rabello.

- Amigos e colegas de Pós-Graduação em especial Engo Agro Ita mar Soares de Mello e Maria Lidia S. Paterniani.

- Conselho Nacional de Desenvolvimento Cientifico e Tecnológi $\operatorname{co}(\mathrm{CNPq})$.

- Aos casais amigos:

Sra. Aracy Pontin Ducatti e Sr. Alfredo Ducatti, Sra. Angela Rossin Steagall e Sr. Eduardo Steagall. 
2. Revisão de literatura $\ldots \ldots \ldots \ldots \ldots \ldots \ldots \ldots \ldots \ldots \ldots \ldots \ldots \ldots \ldots$

2.1. Considerações gerais sobre o gênero Centrosema (DC. ) Benth. ....................... 5

2.2. Caracterização das espécies estudadas $\ldots \ldots . .7$

2.2.1. Centrosema pubescens Benth. ........ 7

2.2.2. Centrosema brasilianum (L.) Benth. ... 8

2.2.3. Centrosema virginianum (L.) Benth....99 9

2.2.4. Centrosema vexillatum Benth........ 9

2.2.5. Centrosema pascuorum (Mart.) Benth. ... 10

2.3. Biologia da reprodução $\ldots \ldots \ldots \ldots \ldots \ldots \ldots \ldots$

2.3 .1 . Flor $\ldots \ldots \ldots \ldots \ldots \ldots \ldots \ldots \ldots \ldots \ldots \ldots \ldots \ldots \ldots$

2.3 .2 . Inflorescēncia $\ldots \ldots \ldots \ldots \ldots \ldots \ldots \ldots \ldots \ldots$

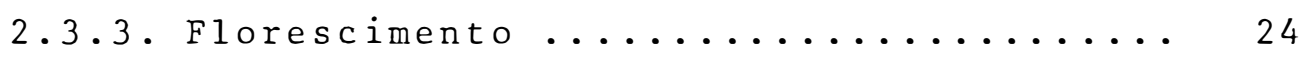

2.3.4. Número de óvulos e número de sementes. 27

2.3.5. Viabilidade do pólen ............. 29

2.3.6. Germinação do pölen $\ldots \ldots \ldots \ldots \ldots \ldots \ldots .31$

2.3 .7 . Modo de reprodução $\ldots \ldots \ldots \ldots \ldots \ldots \ldots$

3. MATERTAL E MÉTODOS $\ldots \ldots \ldots \ldots \ldots \ldots \ldots \ldots \ldots \ldots \ldots \ldots \ldots \ldots$

3.1. Preparo das sementes e semeadura ............ 39

3.2. Instalą̧ão dos ensaios ................ 40 
3.3. Anàlise qualitativa e quantitativa das partes

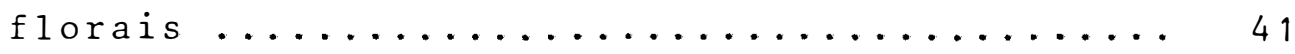

3.3.1. Anàlise para avaliar as caracteristicas morfolögicas florais $\ldots \ldots \ldots \ldots \ldots$

3.4. Ciclo de florescimento ............... 44 3.4.1. Cor das flores ............. 45

3.5. Relação: número de óvulos por ovảrio com número de sementes por vagem .............. 45

3.6. Viabilidade do pölen $\ldots \ldots \ldots \ldots \ldots \ldots$

3.7. Germinação do pólen em meio de cultura ..... 46

3.8 . Modo de reprodução ............... 47

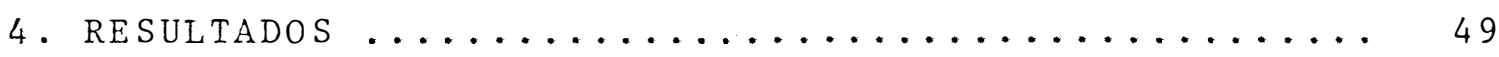

4.1. Anālise qualitativa e quantitativa das estrutu

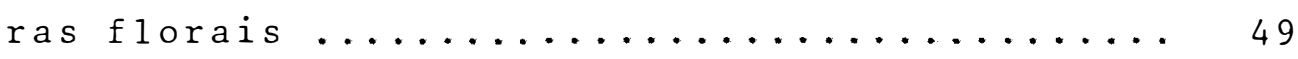

4.2. Ciclo de florescimento ................ 54

4.2.1. Cor das flores.................... 54

4.3. Relação entre número de óvulos por ovärio com número de sementes por vagem ............ 55

4.4. Viabilidade do pólen ................ 55

4.5. Germinação do pölen em meio de cultura ..... 56

4.6 . Modo de reprodução .................. 57

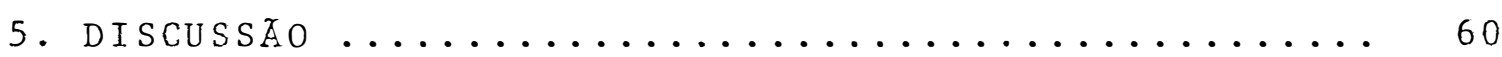


. vii.

pàgina

5.1. Análise qualitativa e quantitativa das estrutu

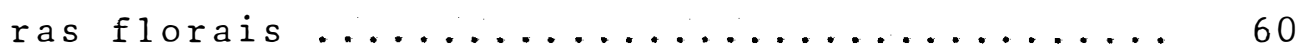

5.2 . Ciclo de florescimento ................ 72

5.3. Relação: número de óvulos por ovảrio com número de sementes por vagem ................ 75

5.4. Viabilidade do pölen .................... 77

5.5. Germinação do pólen em meio de cultura ...... 78

5.6 . Modo de reprodução .................... 80

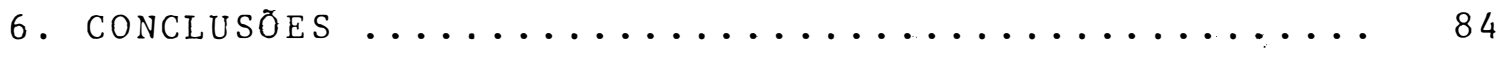

7. Literatura Citada $\ldots \ldots \ldots \ldots \ldots \ldots \ldots \ldots \ldots$

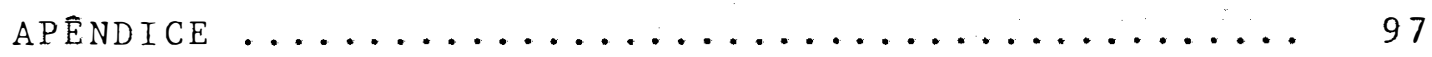


1. Médias estimadas de 22 caracteres morfológicos florais, em 5 espécies de Centrosema (DC.) Benth. $\ldots \ldots \ldots \ldots \ldots \ldots \ldots \ldots \ldots \ldots \ldots$

2. Coeficiente de Variação (\%) de 22 caracteres morfolögicos da flor de 5 espécies de Centrose

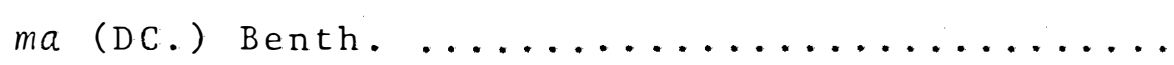

3. Resumo da Anālise da Variāncia para os caracte res mensuráveis (mm) analisados, de 5 espécies de Centrosema (DC.) Benth., usando 10 flores por espécies (GL. de Tratamento $=4$ e GL. do

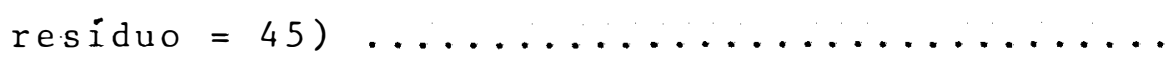

4. Valores de $\Delta$ para comparação entre as médias de cada caràter analisado, nas 5 espécies de Centrosema (DC.) Benth., pelo teste de Tukey a $5 \%$ de probabilidade com $n=5$ e $n^{\prime}=45$ graus de 1 iberdade, As médias com sinais iguais $(*$, - , $\mathbf{4}$, ) não diferem significativamente entre si

5. Início da primeira floraça de 5 espécies de Centrosema (DC.) Benth., em dois experimentos, montados em diferentes épocas do ano $(08.04 .82$ e 09.11.82). ESALQ/USP - Piracicaba - SP... 
6. Ciclo de florescimento de 5 espécies de Centrose ma (DC.) Benth., em dois experimentos, montados em diferentes épocas do ano: abril e novembro de

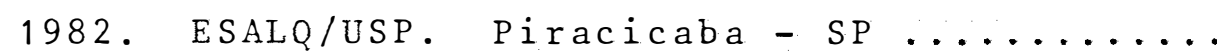

7. Variação na cor das flores, de 5 espécies do gēnero Centrosema (DC.) Benth.................. 104

8. Média e amplitude do nümero de óvulos por ovärio, em 10 ovārios, na fase de flor em botão e após a abertura da flor, em 5 espécies de Centrosema

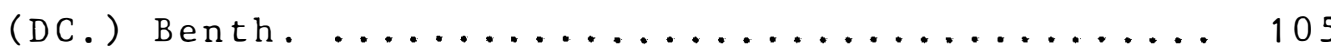

9. Média do nümero de sementes por vagem, após a ma turação, em 70 vagens, de cada espécie, em 5 espécies de Centrosema (DC.) Benth............ 106

10. Viabilidade do pólen de 5 espécies de Centrosema (DC.) Benth., coletado em condições de vasos...

11. Porcentagem de germinação do pólen, em diferentes meios de cultura, de 5 espécies de Centrose ma (DC.) Benth., em 2 ensaios de germinação, dü

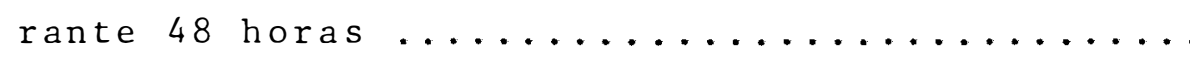


12. Nümero de botões isolados que continuaram o desenvolvimento normal até a formação da vagem, em 5 espécies de Centrosema (DC.) Benth. ........ 109 
1. C. pubescens Benth.: flor; estandarte; asas; qui lha; androceu; gineceu; cálice com bracteolas, unido ao pedicelo, bráctea e pedúnculo; cálice; bracteola; bráctea $\ldots \ldots \ldots \ldots \ldots \ldots \ldots \ldots$

2. C. brasilianum (L.) Benth.; flor; estandarte; asas; quilha; androceu; gineceu; cälice combracteolas, unido ao pedicelo, bräctea e pedúnculo;

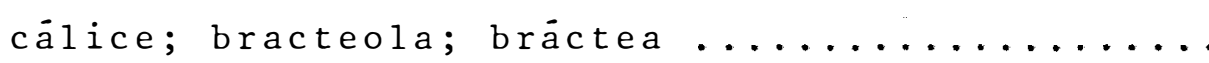

3. C. virginianum (L.) Benth.: flor; estandarte; asas; quilha; androceu; gineceu; cälice com bracteolas, unido ao pedicelo, bráctea e pedünculo;

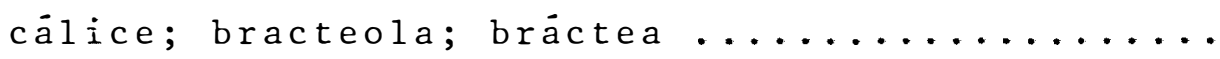

4. C. vexillatum Benth.: flor; estandarte; asas; quilha; androceu; gineceu; cálice combracteolas, unido ao pedicelo, bràctea e pedúnculo; cálice ; bracteola; bräctea $\ldots \ldots \ldots \ldots \ldots \ldots \ldots$

5. C. pascuorum (Mart.) Benth.: flor; estandarte; sas; quilha; androceu; gineceu; cálice combracteola, unido ao pedicelo, bráctea e pedúnculo;

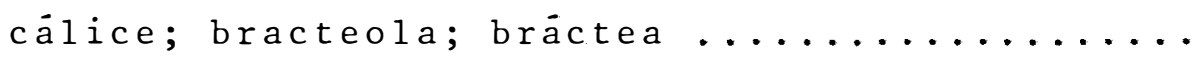


6. Vista dorsal (6.1) e ventral (6.2) das anteras de 5 espëcies do gēnero Centrosema (DC.) Benth.

7. Grãos de pölen, de 5 espécies do gênero Centro-

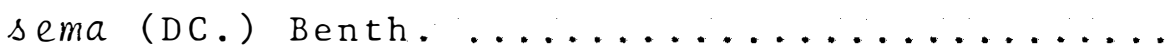

8. Óvulos, de 5 espécies do gēnero Centrosema (DC.)

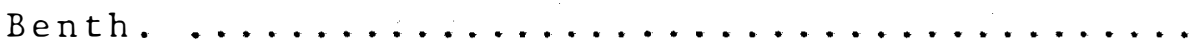

9. Cortes: longitudinal e transversal do ovärio de 5 espēcies do gēnero Centrosema (DC.) Benth. ..

10. Estígmas de 5 espëcies do gēnero Centrosema

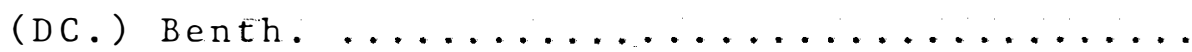

11. Distribuição dos caracteres florais: comprimento do estandarte (A); largura do estandarte (B); comprimento da asa (C); largura da asa (D); com primento da quilha (E); largura da quilha (F); comprimento do androceu (G); comprimento do estame vexilar livre (H); comprimento do gineceu ( I ); comprimento do ovärio ( $J$ ); comprimento do pedúnculo ( $K)$; comprimento do cälice ( $L$ ); diâme tro do cálice (M); comprimento da bracteola (N); largura da bracteola (0); comprimento da bràctea (P); largura da bräctea (Q); das espécies: 
- xiii.

Figura.

página

C. pubescens (-1, C. brasilianum (4), C. virgini nianum $1 \cdot 1, C$. vexillatum $(X)$ e C. pascuorum $(\sim)$. ESALQ/USP, Piracicaba - SP - $1983 \ldots \ldots \ldots \ldots$

12 Distribuiçáo dos caracteres florais; comprimento da antera (R); largura da antera (S); diâmetrodo grão de pólen (T); comprimento do óvulo (U); lax gura do óvulo (V); das espécies $C$. pubescens $(-1$, c. brasilianum (-), C. virginuanum (4), $c$. vexillatum $(x)$, c. pascuorum $(\sim)$. ESALQ/USP, Piracicaba - sp. $1983 \ldots \ldots \ldots \ldots \ldots \ldots \ldots$ 
MORFOLOGIA FLORAL E BIOLOGIA DA REPRODUÇĀO DE CINCO ESPECIES DE Centrosema (DG.) BENTH. (LEGUMINOSAE - PAPILIONOIDEAE)

\author{
Autora: ALICE BATTISTIN \\ Orientador: Prof. Dr. PAULO SODERO MARTINS
}

RESUMO

Esta pesquisa foi realizada com a finalidade de se obter informações bäsicas sob́re morfologia floral e bio logia da reprodução das espécies Centrosema pubescens Benth., Centrosema brasilianum (L.) Benth., Centrosema virginianum (L.) Benth., Centrosema vexillatum Benth. e Centrosema pascuo rum (Mart.) Benth.

A pesquisa foi conduzida em dois ensaios, montados em vasos e mantidos em condições climáticas normais. o primeiro ensaio, constituído de espécies multiplicadas no Campo Experimental, pertencente ao Departamento de Genética da ESALQ/USP, Piracicaba - SP, teve como objetivos: 1. analisar caracteres morfológicos qualitativos e quantitativos das flores de cada uma das cinco espécies; 2 . observar os fenómenos fenológicos: inicio da floração e periodo de florescimento; 3. relacionar o nümero de óvulos por ovärio com o nümero 
de sementes por vagem; 4. determinar a porcentagem de viabili dade do pólen. No segundo ensaio foram usadas sementes provenientes da EMBRAPA - Campo Grande - MS, com os seguintes ob jetivos: 5. observar a germinação do pölen, em meio de cultura; 6. observar em condições naturais os mecanismos de polini $z$ ação.

os resultados obtidos desta pesquisa permiti ram concluir que: a. na anälise qualitativa para os caracteres morfológicos da flor, suas partes constituintes: cálice, corola, androceu e gineceu, na sua constituicão, seguem os pa drões caracteristicos da sub-familia Papilionoideae; b. ocorreu variaça no tamanho dos 22 caracteres morfológicos mensurados, no número de flores por inflorescēncia, no nümero de lacínios do cālice, na cōr das flores e na forma dos grãos de pólen,entre as cinco espécies do gênero Centrosema (DC.) Benth., estudadas; c. número de lacinios do cälice e caracteres mensuráveis, cujas médias apresentaram o mesmo valor, são indicações de que as espécies C. brasilianum (L.) Benth., C: virginianum (L.) Benth. e C. pascuorum (mart.) Benth., possuem maior relacionamento filogenético entre si e maior grau de divergência com $C$. pubescens Benth. e C. vexillatum Benth., que por sua vez, guardam entre si, certo grau de proximidade filogenética; d. o período mais favorável ao florescimento das cinco espēcies de Centrosema (DC.) Benth., se extende de janeiro à junho; e. o número de óvulos por ovário fornece uma 
previsão do nümero de sementes que se desenvolvem por vagem; f. comparando a perda de óvulos por ovário com a porcentagem de sementes viáveis, parece ocorrer uma compensação pois, esta ūltima foi bastante alta em todas as espécies; g. a viabilidade do pólen foi alta em todas as espécies, existindo uma relação inversa entre grãos de pólen produzidos e quantidade de pólen viável, pois as espécies que apresentaram menor nüme ro de gräos de pólen, apresentaram maior porcentagem de viabilidade; h. novos testes, empregando diferentes meios de cultura, deverão ser efetuados, na tentativa de descobrir o meio mais adequado de cada espécie, para germinação do pólen "in vitro"; i. nos botões das flores de $C$. pubescens Benth., C. brasilianum (L.) Benth. e C. virginianuin (L.) Benth., devem existir um ou mais fatores que inibem a formação das vagens manifestando-se em condições especiais. Estes fatores poderão ser genéticos, fisiológicos ou ambientais; j. a morfo logia das flores, típica das Papilionoideae, indica serem espécies predominantemente autofecundantes; $k$. a presença constante de insetos do gênero Bombus sp. na flor e o seu comportamento, sugerem serem agentes que provocam a autofecundação nas flores e a existência de certa taxa de cruzamento externo. 
FLORAL MORPHOLOGY AND REPRODUCTION BIOLOGY OF FIVE SPECIES

OF centrosema (DC.) BENTH. (LEGUMINOSAE - PAPILIONOIDEAE)

\section{Author: ALICE BATTISTIN}

Adviser: Prof. Dr. PAULO SODERO MARTINS

SUMMARY

This paper was conducted to obtain basic information on floral morphology and reproduction biology of the species Centrosema pubescens Benth., Centrosema brasilianum (L.) Benth., Centrosema virginianum (L.) Benth., Centrose ma vexillatum Benth. and Centrosema pascuorum (Mart.) Benth.

The research was carried out in two trials. The first one, with species multiplied at the Experimental Field of the Department of Genetics of ESALQ/USP, Piracicaba-SP, with the following objectives: 1. to analyse qualitative and quantitative morphological characters of flowers of each one of five species; 2 . to observe the phenological phenomenons: beginning and period of flowering; 3 . to relate the number of ovules per ovary with the number of seeds per pod; 4. to determine the percentage of pollen viability. 
In the second trial, the seeds obtained from EMBRAPA - Campo Grande, MS, with the following objectives: 5. to observe the pollen germination in culture medium and 6. to observe, in nature, the pollination mechanisms.

The following conclusions can be formulated from the results herein analysed: a. the morphological characters of flower, such as: calyx, corolla, androecium, gynoecium, follow the chracteristic patterns of the Papilionoideae subfamilv; b. there was variation in size of the twenty-two morphological characters, in number of flowers per inflorescence, in number of lacinia of the calvx, in color of flowers and in shape of the pollen grains among the species of the genus Centrosema (DC.) Benth. studied; c. number of lacinia of the calyx and measurable characters whose averages presented the same value, indicate that the species C. brasilianum (L.) Benth., C. virginianum (L.) Benth. and C. pascuorum (Mart.) Benth., own larger phylogenetic relationship existing among them and larger degree of divergency with $C$. pubescens Benth. and $C$. vexillatum Benth., d. the more favorable period for the flowering of five species Centrosema, is January to June; e. the number of ovules per ovary furnishes a prevision of the number of seeds developed per pod; f. by comparison of the loss of ovules per ovary with the percentage of viable seeds, it seems to occur a compensation, because the percentage of viable seeds were very high in all species; g. the pollen viability was high 
in all the species, existing a inverse relation among pollen grains produced and amount of viable pollen, as the species that presented smaller number of pollen grains, presented higher viability percentage; h. new tests, using different culture medium, must be realized in attempt to find out the medium more suitable for "in vitro" pollen germination, for each species; $i$. in the buds of flowers of $C$. pubescens Benth., C. brasilianum (L.) Benth. and C. virginianum (L.) Benth., must exist one or more factors that inhibit the formation of the pods. These factors can be genetics, physiological or environmental; $j$. the flowers morphology, of the Papilionoideae, indicate to be predominantlv selffertilized species; $k$. the presence of the insects of the genus Bombus sp. visiting the flows, suggests their possible role as self-fertilizer agents, as well in promoting, some degree of outcrossing. 


\section{INTRODUÇAOO}

A família das leguminosas destaca-se das demais famílias, pelo elevado nümero de espécies úteis e pela variedade de produtos que fornece à economia humana. Além disso, as espécies que são usadas em pastagens, além de serem fontes fornecedoras de proteínas para os animais, fornecem o nitrogênio às gramíneas, quando em consorciação.

Atualmente a utilização de leguminosas na alimentação animal, é uma preocupação de âmbito internacional, de modo especial nos países onde a pecuäria representa uma fonte econômica significativa.

No Brasil e em outros países tropicais, a maior concentração de rebanhos ocorre em regiões de solos ácidos e de baixa fertilidade natural, refletindo-se num baixo nível nutricional dos animais em pastagem, constituindo este fato, 
o principal fator limitante da produção.

A baixa produtividade das pastagens e a tendẹn cia do mercado mundial de consumir cada vez mais, proteínas de origem animal, despertou entre pesquisadores e melhoristas a necessidade prioritāria de ampliar a produção de espécies for rageiras melhoradas em termos de qualidade e quantidade, já que na produção pecuária o fator mais importante é a alimenta ção do rebanho.

o Brasil possue grande nümero de leguminosas forrageiras, destacando-se entre elas quatro gêneros: Desmodium Desv., Zornia Gmel., Stylosanthes Sw. e Centrosema (DC.) Benth., considerados os mais promissores, em seleções feitas pelo Centro Internacional de Agricultura Tropical ( CIAT, $1976)$.

o gênero Centrosema (DC.) Benth., embora seja ainda bastante desconhecido, tem sido citado por vários pesquisadores (SCHOFIELD, 1941;GROF, 1970 ; RICHARDS, 1970 ; GROF e HARDING, 1970; SOUTO e LUCAS, 1973; CLEMENTS, 1974; SERPA, 1976; MONTEIRO, 1980 e MOGROVEJO-JARAMILLO, 1981), como promissor num programa de melhoramento, devido ao seu alto poten cial produtivo, boa compatibilidade com as gramíneas, alto va lor protéico, razoāvel palatabilidade, boa tolerância à seca e alta capacidade fixadora de nitrogênio. 

consequentemente aquelas que estão sendo mais exploradas devi do suas potencialidades são: C. pubescens Benth., C. brasilianum (L.) Benth. e C. virginianum (L.) Benth. (BOGDAN, 1977). Não excluindo porëm, a possibilidade de existirem outras espécies, menos conhecidas, de grande valor forrageiro, pertencentes ao gênero, jä que existem poucos trabalhos sobre o mesmo.

o conhecimento da biologia da reprodução de uma espécie, é de fundamental importância, pois indica a maneira pela qual a mesma, garante sua sobrevivência e perpetua ção ao longo dos tempos. Na condução de um programa de melho ramento, o conhecimento de como a espécie se reproduz, é indiscutivelmente o ponto básico na determinação dos métodos a serem usados para alcançar o sucesso, uma vez que os métodos de melhoramento variam na sua aplicação, conforme o sistema de reprodução da espécie.

Visando, portanto, a obtenção de informações básicas sobre morfologia floral e biologia da reprodução das espëcies C. pubescens Benth., C. brasilianum (L.) Benth., C. virginianum (L.) Benth., C. vexillatum Benth., e C. pascuorum (M. ) Benth., o presente trabalho tem os seguintes objetivos:

a. Analisar as características morfológicas qua litativas e quantitativas da flor de cada uma das espécies em 
estudo.

b. Observar os fenômenos fenológicos: início da floração e período de floração.

c. Determinar o nümero de óvulos por ovärio e relacionā-los com o nümero de sementes por vagem.

d. Verificar a viabilidade dos grãos de pólen.

e. Observar a germinação do pólen em meio de cultura.

f Observar em condições naturais, os mecanismos de polinização. 
2. REVISAAO DE LITERATURA

2.1. Considerações gerais sobre o gēnero Centrosema (DC.) Benth.

o gênero Centrosema (DC.) Benth., pertence a família Leguminosae, sub-família Papilionoideae e a tribo Pha seolae (BENTHAM, 1859). E característico das regiões tropicais e subtropicais, sendo adaptado a solos ácidos, de baixa fertilidade, baíxo conteüdo de fósforo e parecendo ser tolerante a níveis tóxicos de alumínio. As plantas são herbáceas ou subarbustivas, com häbito de crescimento trepador ou prostrado. Geralmente espécies deste gênero possuem sistema radi cular bem desenvolvido e profundo (ALCÂNTARA et alii.- 1977 ), sendo esta uma indicação de que têm bom potencial de produção, durante a estação seca.

Quanto a distribuição geogräfica, o gênero Cen 
trosema (DC.) Benth. é constituído de espécies distribuidas na América Central, Caribe, América do Sul e Austrälia (BoGDAN, 1977; CLEMENTS, 1977; TEITZEL e BURT, 1976). E bem representado na flora do Brasil, tendo aqui o seu centro de distribuição.

O gênero contém cerca de 40 a 50 espécies, sen do que no Brasil, foi constatada a ocorrência de 30 , das quais as mais conhecidas são: C. pubescens Benth., $C$. brasilianum (L.) Benth., C. virginianum (L.) Benth., C. plumieri Benth., C. venosum Mart., C. vexillatum Benth., C. arenarium Benth., C. bifidum Benth., C. coreaceum Benth., C. parviflora Benth., C. pascuorum (Mart.) Benth., C. grandiflora (Mart.) Benth. e C. rotundifolium Mart. (BARBOSA-FEVEREIRO, 1977).

As espécies apresentam um marcado polimorfismo e variação em seus caracteres morfölógicos, como, tamanho, for ma, dimensões e coloração das folhas, flores e frutos, ausência ou presença de pilosidade, tipo de cálice, häbito de cres cimento, etc. (BENTHAM, 1859 e DUCKE, 1949). Algumas das variações citadas ocorrem dentro da pröpria espécie, e, não raro na mesma planta, como è o caso da forma e côr dos folíolos e côr das flores. Esta variabilidade de caracteres, dentro das espécies tem sido causa de inümeros problemas no tratamen to taxonômico deste gênero.

Vulgarmente as espécies recebem värias denomi- 
nações: Jetirana, Cunhã, Feijão-de-mato, Feijão-bravo, Feijão-do-campo, Feijãozinho, Pau-de-rego, Babuia, Brinco-de-princesa, Cipó-das-feridas, Cabeça-de-galo, etc. (BARBosA FEVEREIRO, 1977 ).

Diversas espécies vem sendo utilizadas como forrageiras em pastagens consorciadas, em cobertura de solos em plantações de citros, seringueira, dendezeiro, coqueiro, cacaueiro, como plantas ornamentais e também como adubo verde (BARBOSA - FEVEREIRO, 1977 ).

2.2. Caracterização das espécies estudadas

2.2.1. Centrosema pubescens Benth.

E uma leguminosa nativa (BENTHAM, 1859) que se encontra dissiminada em vários Estados do Brasil, sendo atual mente considerada como uma das principais forrageiras por ser de fácil manejo, possuir boa palatabilidade (MATTos, 1973), boa produção de sementes, boa produção de matéria verde, sistema radicular bem desenvolvido e profundo, além de possuir ampla variação genética entre as populações para os caracteres: número de dias para o florescimento, intensidade de florescimento e número de vagens fertilizadas (MOgRovejo - JARAMILLO, 1981 e MONTEIRO, 1980). Se estabelece muito bem em so- 
los àcidos sem fertilizantes (ALCÂNTARA et arii, 1977).

WILLIAMS (1964), situou-a como uma das espécies que apresenta problemas no seu estabelecimento inicial, na Austrália, pelo fraco vigor de suas plântulas.

SERPA (1971), confirmou quando disse que, uma das principais deficiências desta leguminosa tropical, durante sua implantação no pasto, é a falta de vigor inicial. Porém TEITzEL e BURT (1976), afirmaram que desde sua introdução na Austrālia, hä uns 40 anos aträs, C.pubescens Benth., mostrou ser uma das es pécies de leguminosas mais versāteis nos trópicos úmidos do norte e do sul de Queesnland. HUTTON (1970, 1976), afirmou que esta espécie apresenta grande variabilidade para diversos caracteres morfológicos e agronômicos, sendo que diversos eco tipos foram evidenciados.

2.2.2. Centrosema brasilianum (L.) Benth.

E uma espécie um tanto similar a Centrosema pu bescens Benth., diferindo por seus ramos finos, foliolos tip i camente arredondados e glabros (GROF; 1970).

BURKART ( 1952 ), situou-a entre as leguminosas que podem ser utilizadas nas pastagens e como fixadora de solos, por possuir um forte häbito estolonífero. Na Austrália chegou a produzir 15 toneladas de matéria seca/hectare/ano, 
sendo que a maior parte desta produção é obtida no período se CO (BOGDAN; 1977$)$.

\subsubsection{Centrosema virginianum (L.) Benth.}

Centrosema virginianum (L.) Benth., è uma espẹ cie facilmente distinguível das demais, por seus ramos finos e volüveis com marcada tendência a enraizar (GROF, 1970). 0 enraizamento secundārio é uma característica de grande importância numa leguminosa de pastagem. As folhas apresentam polimorfismo bastante acentuado, chamando atenção dos taxonomis tas. Possue também abundante nodulação (SERPA, 1977) e, é ótima fixadora de dunas. CRONQUIST (1975-) encontrou alta her dabilidade em alguns caracteres analisados no $F_{2}$ de cruzamentos dialélicos. O fato desta leguminosa, não ter sido ainda aproveitada em pastagens, deve-se principalmente à quantidade mínima de sementes que produz. Sua capacidade estolonífera, no entanto, justifica-a como espécie promissora para forragens e pastagens.

2.2.4. Centrosema vexillatum Benth.

Segundo BARBOSA - FEVEREIRO (1977) esta espëcie, embora até agora não tenha sido utilizada em pastagens, 
demonstra ser muito útil como forrageira, devido a seus ramos volúveis, folhas grandes formando boa cobertura. Possue um desenvolvimento inicial mais räpido, quando comparada com outras espécies do mesmo gênero.

2.2.5. Centrosema pascuorum (Mart.) Benth.

o aspecto vegetativo e floral desta espécie a classifica como ornamental, além de possuir boas característi cas como forrageira: quantidade considerável de massa verde, bom enraizamento. HUTTON (1981) constatou ser esta espécie altamente intolerante a solos äcidos. Este é um dos pontos negativos para o uso da mesma em pastagens onde o solo é predominantemente àcido.

\subsection{Biologia da reprodução}

Segundo ALLARD (1971) a primeira etapa natural para se determinar o modo de reprodução de uma espécie, consiste no exame estrutural da flor, justificando que em algumas espécies isto é suficiente vara definir o modo de reprodução.

ORNDUFF (1969), estabeleceu uma série de carac terísticas florais típicas das plantas autógamas e alógamas. 
Estas características, com a evolução, foram sofrendo modificações diferenciando-as em autógamas e alógamas. Entre as ca racterísticas encontradas nas autógamas destacou: redução no tamanho das pétalas, redução nos tamanhos das flores, uniformização das cores, redução dos nectärios, poliploidia, as quais são evidenciadas em estudos de biologia floral.

CRUDEN (1977) em gramíneas, concluiu que o me1hor indicador para reconhecer o sistema de cruzamento de uma planta é a anālise da razão entre o nümero de grãos de pólen por flor e o número de óvulos da mesma flor (P/O). De acôrdo com este autor, altos valores desta relação indicam alogamia, enquanto que baixos valores são indicativos de endogamia, sen do que as flores cleistógamas teriam os menores valores.

\subsubsection{Flor}

Segundo Leppik (1966) citado em ARROYO (1981), as diferenciações ocorridas nas flores das leguminosas e consequentemente nos mecanismos da polinização, surgiram em resposta à forças seletivas responsāveis pela evolução desta famîlia.

As flores são estruturas que tem a mesma origem das folhas, porēm sofrem modificações no seu desenvolvimento evolutivo. O grau de semelhança entre a flor e a fo- 
1 ha, varia segundo as diferentes estruturas florais. Assim, as sépalas e as pétalas, são essencialmente folhas modificadas com função de proteger os örgãos reprodutivos e facilitar a fecundação, enquanto que o gineceu e o androceu são os responsāveis diretos pela reprodução (REYES - ZUMETA, 1963).

A constituição geral dos verticilos florais tem uma variação muito grande, constituindo um caräter de valor sistemätico importante na classificação das famïlias.

A familia das leguminosas em geral possue flores variadas, sempre cíclicas, de simetria radial até fortemente zigomorfas, como é o caso das papilionoideae, a qual pertence o gênero Centrosema (DC.) Benth. A zigomorfia das flores nas Papilionoideae, representa um avanço evolutivo maior em relação a Caesalpinioideae e Mimosoideae. As flores são diclamídeas, com cālice gamossépalo pentâmero ou tetrâmero. A corola é dialipétala, tetrâmera ou pentâmera, na maioria das vezes com pétalas muito desiguais (Papilionoideae). o androceu é formado de quatro a dez estames, livres ou solda dos entre si, todos férteis ou alguns transformados em estami nóides, abrindo-se por fendas ou por poros apicais. o ovário sempre súpero, unicarpelar e unilocular, às vezes dividido por falsos septos com muitos óvulos, raramente um sö (JOERGEN SEN, 1909; BURKART, 1952 e JOLY, 1975).

A forma floral mais difundida é $+k 5, C 5, A 5+5$, 
Gl, típico de flor hermafrodita, pentâmera e pentacíclica (di plostêmona).

A posição normal da flor das Papilionoideae em relação ao eixo è a seguinte: o estandarte é oposto à bráctea, e a sépala impar aderida a ela. 0 tamanho varia muito, mas todas elas tem flores vistosas, com predominância de cores amarelas, violáceas, vermelhas e roxas (BURKART, 1952).

No gênero Centrosema (DC.) Benth., segundo ALCÂNTARA e BUFARAH (1979), as cores variam de branco, rosa a violeta. As características das flores são ötimas para a atração de insetos polinizadores, embora quanto ao tipo de re produção, o gênero Centrosema (DC.) Benth., tenha sido enquadrado no grupo de plantas quase exclusivamente autofecundantes por HUTTON (1960).

\section{a. Corola}

Segundo STRASBURGER (1943) e REYES - ZUMETA (1963) no desenvolvimento filogenético do perianto, a corola se origina por modificações progressivas dos estames, surgindo as estruturas denominadas pétalas. Devido ao fato de exe cer duas funções importantes, ou seja, proteção aos órgãos re produtores e atração dos insetos polinizadores, a corola possue uma notável configuração e suas pétalas são em geral de cores vistosas. 
Segundo ARROYO (1981), o estandarte nas Papilionoideae está associado a atração dos insetos polinizadores enquanto que a quilha protege a coluna estaminal e, juntamente com as asas serve de plataforma de desembarque dos polinizadores. Estas estruturas funcionam em intercâmbio. Nas flo res resupinadas, como é o caso do Centrosema (DC.) Benth. e Periandra, o estandarte torna-se plataforma de pouso dos inse tos e a proteção é feita pela quilha invertida. O nectar des tas flores está localizado na base do estandarte (ARROYO, $1981)$.

BURKART (1952) e JOLY (1975) descreveram a corola das leguminosas da sub-familia Papilionoideae do tipo floral papilionoidea ou amariposada, com um pétala bem maior chamada estandarte ou vexilo, duas laterais livres que são as asas ou alas e duas inferiores soldadas ao longo da linha de contato cujo conjunto é denominado quilha ou carena. A quilha envolve e protege os órgãos sexuais da flor. Na ontogenia dos órgãos florais, as pétalas alcançam seu maior desenvolvimento depois das sépalas, gineceu e androceu. A pré-flo ração da corola é imbricada descendente.

As corolas das flores de C. pubescens Benth., säo grandes, vistosas, de coloração variando de branca, rosa a violeta (BARBOSA - FEVEREIRO, 1977 e ALCÂNTARA e BUFARAH, 1979). C. brasilianum (L.) Benth. e C. virginianum (L.) 
Benth., possuem estandarte, asas e quilha de coloração varian do de branca, violácea, azulada ou rosada (GRoF, 1970). Enquanto que, C. vexillatum Benth., possue a corola bem maior comparada com as três espécies citadas, de cor roxo - averme1 hada intensa e de cor branca segundo BARBOSA - FEVEREIRO (1977). As flores de C. pascuorum (Mart.) Benth., divergem das colorações citadas nas espécies mencionadas, pois suas pê talas são vermelho - escarlate intenso, como estandarte apre sentando pubescência acentuada, dando ao conjunto um aspecto ave ludado.

Nas cinco espécies mencionadas a corola é pubescente, sendo mais acentuada no C. pascuorum (Mart.) Benth., as as as são sigmóides em C. pubescens Benth. e C. vexillatum Benth. e, falcadas em C. brasilianum (L.) Benth, C. virginianum (L.) Benth. e C. pascuorum (Mart.) Benth. As carenas são semiorbiculares nas cinco espécies estudadas (BARBOSA-FEVEREI RO, 1977 ).

\section{b. Cărice}

o cálice de maneira geral exerce duas funções no conjunto floral ou seja, proteção e assimilação. Sua origem ocorre por transformações de "hipsofilos" que chegam até a regiãofloral. Suas sépalas variam na forma, tamanho, nüme ro e coloração, conforme a espécie. Podem estar concrescidas 
entre si, formando o cálice gamossépalo, ou livres formando o cālice dialissépalo (strasburger, 1943 e ReYes - ZUMETA, 1963). O cálice apresenta muitas variantes quanto a profundi dade de inserção, aspecto geral herbáceo ou membranoso, forma, duração, coloração, nümero de sépalas, etc.

BURKART (1952) descreveu o cálice das Papilionoideae como gamossépalo. Neste caso, a parte basal chamada tubo do cálice, em forma de funil ou cilindro, terminando por cinco lóbulos ou dentes (lacínios, BARBOSA - FEVEREIRO, 1977), separados, que representam a extremidade livre das sépalas. Estes dentes são de forma e tamanhos variados, conforme as espécies e podem se apresentar parcialmente unidos entre si. Na pré-floração as sépa las tem os lóbulos imbricados e valvares. Em C. pubescens Benth., C. brasilianum (L.) Benth., C. virginianum (L.) Benth., C. vexillatum Benth. e C. pascuorum (Mart.) Benth., o cálice é gamossépalo, de coloração verde e pubescente, apresentando variação quanto aos lacínios. Segundo BARBosA - FEVEREIRO (1977), os lacínios superiores podem ser triangulares, agudos ou obtusos, altamente unidos ou até quase a metade, os inferiores laterais sublanceolados e o central lanceolado, no C. pubescens Benth., dois 1 acínios superiores formando um läbio integro e emarginadono ápice, com formas triangulares unidas até a metade do comprimento, dois lacínios inferiores triangu lares e o mediano de ápice agudo e acuminado são caracteristi 
cos no cálice de C. brasilianum (L.) Benth., C. virginianum (L.) Benth. e da C. pascuorum (Mart.) Benth. Enquanto que em C. vexillatum Benth., os lacínios superiores são completamente unidos formando um lábio, truncado ou emarginado no ápice, sendo os inferiores triangulares.

Todos os cálices dessas cinco espécies são envolvidos lateralmente por duas bracteolas, de forma e tamanhos variados, conforme a espécie.

\section{c. Androceu}

E um órgão reprodutor masculino, constituído pe 10 conjunto de estames. Segundo REYES-ZUMETA (1963) o androceu se origina a partir de processos de diferenciação que ocorrem nas regiões meristemáticas, onde se formam as folhas. Portanto $\vec{e}$ uma folha modificada. O nümero básico de estames, tamanho e forma variam em função do gênero e da espécie. o estame é composto de uma antera, cuja função está ligada dire tamente à produção de pólen, um filamento (filete) estéril que mantém a antera unida ao conjunto floral e um conectivo que é o ponto de união entre a antera e o filete.

No androceu das leguminosas, os estames em geral são diadelfos, variando muito em nümero e disposição. o nümero básico é dez ou seja, dois ciclos de cinco estames cada um, de modo que a flor é diplostêmona e pentacíclica. o 
ciclo externo é epissépalo e o interno epipétalo. No caso de Centrosema (DC.) Benth., os estames são nove soldados entre si e um livre denominado estame vexilar livre. A soldadura dos filetes é um fenômeno muito generalisado na família. A parte inferior dos estames se une formando um tubo, por ëm as extremidades superiores são livres, onde se encontram as ante ras. Estas são geralmente elípticas, ovaladas ou retangulares. As tecas em geral, são dorsifixas e os grãos de pólen individualizados (BURKART, 1952 ).

FERGUSON e SKVARLA (1981), encontraram considerävel variação nos caracteres morfológicos do pólen, nas legu minosas papilionoideae; abertura da parede, tamanho, forma, escultura, etc.

Quanto ao tamanho dos grãos de pólen, os autores citados mencionaram que não existe classificação da varia ção, ocorrendo apenas alguns gêneros com pólen grande e outros gêneros com pólen pequeno. Entretanto, o tamanho máximo não ultrapassa a 50 milimicrons.

A forma em geral é esferoidal achatada nos polos ou triangular achatada em alguns tipos de pólen considera dos mais especializados. No caso de forma triangular a abertura, na germinação, ocorre na grande maioria, nas três extre midades do triângulo, como $\vec{e}$ o caso da Dumasia villosa e Camp tosema curiaceum, que pertencem a tribo Phaseoleae. A morfo- 
logia do pólen em Phaseoleae, possue caracteres bem específicos, sendo possível sua distinção das demais tribos, entretan to, é bastante difícil reconhecer a macromorfologia do pólen em cada gênero e em cada espécie, devido a constantes modificações secundārias surgidas ao longo dos tempos. Porém, é possível detectar no mesmo gênero, grupos com caracteres mnrfológicos do pölen altamente especializados, grupos com menor especialização e grupos com grandes tendências à especializaçãos bem como estabelecer relações entre grupos de gêneros di ferentes, atravēs de sobreposições e interrelações entre os mesmos (FERGUSON e SKVARLA, 1981 ).

\section{d. Gineceu}

E o örgão reprodutor feminino, formado pelo conju to de carpelos. Da mesma forma que o androceu, origina-se a partir de diferenciações que ocorrem nas regiões meristemáticas, onde se formam as folhas (REYES - ZUMETA; 1963). Os car pelos são formados pelas seguintes estruturas: ovário, onde se desenvolvem os óvulos, estígma que é uma estrutura especia lizada para receber o pólen, onde este germina e desenvolve o tubo polínico, cuja condução é feita pelo estilete o qual pos sue no seu interior um tecido especial formado de um ou mais canaliculos. 
pistilo é formado por uma única peça carpelar diferenciada em ovário, estilete e estïgma. As formas linear e bilateral são bastante constantes na familia Leguminosae (BURKART, 1952). Quanto a posição o gineceu é süpero, unicarpelar e unilocular. Forma-se por brotamento do ponto vegetativo da flor. o estilete é geralmente filiforme, glabro ou peludo, estando os pelos dissiminados ou reunidos debaixo do estígma em forma de barba. No caso de Centrosema (DC.) Benth., é endurecido, engrossado e dilatado em várias formas. A parte basal do estilete é envergada, formando àngulo reto em relação ao ovārio, o que constitui o tipo denominado campilótropo. O estígma e apical e nas papilionoideae è protegido, juntamente com o ová rio e os estames, pela quilha. Pode ser grosso, convexo e subgloboso, papiloso ou viscoso (BURKART, 1952), membranāceo, de ápice truncado ou emarginado, raro engrossado e glossiforme, barbado (BARBOSA - FEVEREIRO, 1977). o ovärio pode ser cilíndrico, lateralmente comprimido, deprimido, ovöide, etc. os óvulos estão inseridos numa fileira na sutura placentar ou ventral. A placentação é ünica e linear, caráter constante na família. Ao abrir longitudinalmente um ovário, nota-se que os óvulos se inserem na sutura placentar ou ventral que é geralmente a superior e corresponde a cavidade do estilete (BOU FEIL, 1947 ). 


\section{e. Receptäculo floral}

E a porção terminal do pedúnculo da flor, onde se inserem as peças florais. Portanto a sua existência é justificada pela função que exerce de sustentar o conjunto floral: gineceu, androceu, cälice e corola.

Nas Papilionoideae tem forma de um prato. Geralmente com flores perígenas. Isto é evidenciado, pelo espaço de separação existente na inserção do gineceu e androceu, que é considerado espaço permanente ou receptáculo cupiliforme (BURKART, 1952 ).

\subsubsection{Inflorescēncia}

Na maioria das angiospermas existe a tendência de se produzir um grande número de flores, as quais asseguram sua perpetuação. Em geral as partes do rebento que trazem flo res são diferentes daquelas que desempenham funções vegetativas e são denominadas inflorescências (REYEs - ZUMETA, 1963). Portanto, todo o sistema de ramificação que induz a formação de flores $\vec{e}$ considerado inflorescência. A inflorescência supõe uma ramificação e como esta, em geral, é constante para cada espécie vegetal, assume grande importância como característica taxonômica. Nos pedúnculos das inflorescências as folhas são muito reduzidas recebendo a denominação de bracteolas. 
Entre o desenvolvimento da inflorescência e de cada flor em particular, existem importantes correlações. Pode-se observar frequentemente que o aumento considerável do nụ mero de flores na inflorescência supõe uma redução no tamanho das mesmas (STRASBURGER, 1943).

Segundo REYES - ZUMETA (1963) a interpretação exat̀a da inflorescência é muito importante para conhecer as re lações genéticas das plantas entre si, quanto ao nümero, posição e dimensões das flores, bem como as simplificações morfoló gicas que podem ocorrer no conjunto.

Para BURKART (1952) as flores das leguminosas, em geral nunca são solitárias. Os agrupamentos das flores, for mando inflorescência são variados, porém, quase todas são do tipo racimoso ou indefinido, de floração centrípeta. Conside rou partes da inflorescência as seguintes estruturas: a) pedünculo, eixo que sustenta a inflorescência, unindo-a aos talos vegetativos, em geral axilar e às vezes terminal, breve ou al argado segundo a espécie; b) raquis, è uma continuação do pe dúnculo onde se inserem as flores, podendo ser simples ou rami ficado, distinguindo-se no $\vec{u} l t i m o$ caso em: primário, secundário, etc.; c) pedicelas, são pedúnculos menores que sustentam as flores, sendo aparentemente nulas nas espigas; d) brácteas, são diferenciações escamosas do pedūnculo em cuja axila nasee um pedünculo; e) bracteolas, são diferenciações escamosas ge- 
ralmente semelhantes às bräcteas, porēm menores, diferenciando-se delas pela posição: nascem no pedünculo, as vezes ao redor do receptáculo da flor; f) invólucro, formado por uma ou mais diferenciações do pecíolo reduzido, estípulas soldadas e dilatadas e folíolos mais ou menos reduzidos; g) flor, cuja posição è terminal sobre o pedicelo, porëm sempre axilar ao raquis.

CARLSON (1973) observou em algumas variedades de soja, que a inflorescência surgiu por brotamento da folha axilar trifoliada, que se manteve presa pela haste, desenvolvendo ao mesmo tempo duas bracteolas. Após a formação das bracteolas o meristema apical desenvolveu diretamente os órgãos florais. E acrescentou que a inflorescênria era composta de cachos contendo duas a trinta e cinco flores cada -.uma, enquanto PRAKASH e CHAN (1976) em outras variedades de soja, encontraram duas a sete flores por inflorescência.

LAWES (1972) afirmou que na soja e em outras le guminosas o nümero de flores por inflorescência e por planta, varia com a variedade e com o ambiente.

BARBOSA - FEVEREIRO (1977) mencionou que as inflorescências de C. pubescens Benth., são plurifloradas. Enquanto que em C. brasilianum (L.) Benth. as flores são solitärias e em C. pascuorum (Mart.) Benth., C. virginianum (L.) Benth. e C. vexillatum Benth., ocorrem respectivamente duas, quatro e cinco flores por inflorescência. 


\subsubsection{Florescimento}

Durante o desenvolvimento, toda a planta apresenta uma ou mais vezes o fenômeno da reprodução. Os örgãos reprodutores não permanecem durante toda a vida da planta. A passagem do estado vegetativo para o estado reprodutor depende de fatores internos e externos, da planta, que induzem a forma ção e posterior funcionamento dos órgãos.

STRASBURGER (1943) fez referência a värios fatô res mesológicos que influenciam na produção das flores. Entre eles destacou: fotoperiodismo, em relação ao qual as plantas reagem diferentemente, enquanto umas florescem precocemente quando recebem maior quantidade de luz, isto è em dias de fotoperiodismo mais longo, outras atuam em sentido inverso, florescendo quando submetidas a um regime diārio de luz bastan te curto. Em outras, o fotoperiodismo não exerce nenhuma influência sobre a antese das flores. Outros dois fatores impor tantes que exercem influência na floração são temperatura e nutrientes. 0 mesmo autor afirmou que são os fatores internos da planta que controlam as reações da mesma diante dos fatores externos.

Segundo COHEN (1976) o relacionamento entre o crescimento vegetativo e a reprodução é um problema muito importante no desenvolvimento de um organismo. 
CARLSON (1973) reforçou a afirmação de STRASBURGER (1943), quando observou que na soja o aparecimento da primeira flor depende do estágio de desenvolvimento da planta e das condições ambientais em que ela se encontra, incluindo o comprimento do dia e a temperatura. Verificou que o início da floração em algumas variedades, ocorre de cinco a seis semanas após o plantio. Enquanto PRAKASH e CHAN (1976) em outras variedades de soja, constataram a iniciaçãofloral trinta e oito a quarenta e dois dias após o plantio.

ALCÂNTARA et alii (1977), baseados em observações fenológicas realizadas em casa de vegetação constataram que a cultivar Deodoro de C. pubescens Benth., emitiu suas pri meiras flores aos noventa e quatro dias após o plantio, e, as populações IRI - 1346 é IRI - 1976, floresceram aos cento e vinte e cento e quarenta e dois dias respectivamente, apös o plantio. Enquanto BOWEN (1959) em condições de campo, realizä do nas regiões norte e sul de Queensland, verificou que o início do florescimento de $C$. pubscens Benth., ocorreu cento e quarenta a cento e cinquenta dias após o plantio, e, acrescentou que este caráter não está relacionado com o fotoperiodismo. MOGROVEjo - JARAMillo (1981) em vinte e uma populações de C. pubescens Benth., verificou a existência de diferenças entre populações e entre locais. Classificou as populações em precoces, intermediárias e tardias. As precoces no local Areião (Piracicaba), emitiram as primeiras flores numa amplitu- 
de de variação de cento e vinte e oito a cento e quarenta e quatro dias após a semeadura, enquanto que as mesmas populações no local Anhembi (Piracicaba), emitiram as primeiras flores, numa amplitude de variação de cento e quarenta e três a cento e cinquenta dias, após a semeadura. As intermediārias foram consideradas as populações que emitiram a primeira flora ção no período de cento e cinquenta a cento e sessenta e cinco dias após a semeadura, no local Areião e, cento e cinquenta e um dias a cento e setenta e nove dias as populações no local Anhembi. E, finalmente as populações consideradas tardias emi tiram as primeiras flores após a semeadura, no período de tempo de duzentos e dezoito a duzentos e oitenta e um dias as do local Areião, e, duzentos e treze a trezentos e trinta e oito dias as do local Anhembí. O mesmo autor concluiu que as populações classificadas como precoces tiveram uma produção maior e quase contínua de flores, enquanto que as populações tardias tiveram menor produção de flores e uma distribuição unimodal.

Vários autores são unâmimes em concordar que a época de florescimento está diretamente correlacionada com a produção de matéria seca e de vagens. Assim, CAMERON (1970), constatou em Stylosanthes humilis, que as populações de flores cimento tardio, apresentaram alta produção de matéria seca e pouca produção de vagens. O mesmo afirmou o Bank of New South Wales (1965), na Austrália quando considerou que o florescimento tardio de algumas leguminosas forrageiras tropicais è uma característica vantajo 
sa, desde que permite que o período vegetativo se prolongue du rante o outono. CLEMENTS (1977) mostrou que progênies de Centrosema (DC.) Benth., com florescimento precoce tem menor produção de matéria verde do que as tardias, e, acrescentou que populações com florescimento contínuo geralmente tem alta produção de sementes, porém baixo nūmero de vagens fertilizadas, pois a energia alocada para o florescimento é elevada e grande parte desta é perdida nas vagens chochas. KRETSCHMER na Flórida, não encontrou nenhuma correlação significativa entre produção de matéria verde e iñ́cio de florescimento nas po pulações de C. virginianum (L.) Benth. e C. plumieri Benth.

\subsubsection{Nümero de óvulos e nümero de sementes}

Nas Papilionoideae, o óvulo é do tipo campilótropo, o que é revelado pela forma da sementé. Em geral o nūmero de óvulos por ovário é elevado (BURKART, 1952).

KRESS (1981) afirmou que, nas angiospermas quantidade de grãos de pólen e o número de óvulos por ovārio, reflete a quantidade de sementes que se desenvolvem, existindo portanto uma relação entre o número de grãos de pólen e o núme ro de óvulos por ovário.

DATTEE (1972) postulou que, considerando a fertilização e a produção de sementes, em qualquer espécie, o nú- 
mero de óvulos por ovário é um caräter muito interessante, pois é potencialmente o limite da produção de sementes de uma flor. Concluiu também que o nümero de övulos por ovärio é transmitido de pais para filhos.

BARNES e CLEVELAND (1963), contando o nümero de óvulos por ovärio em Medicago, em plantas diplóides e tetraplóides, encontraram diferenças significativas de uma planta à outra, porém na mesma planta todas as inflorescências possuem o mesmo nümero de óvulos por flor. Observaram também que o nümero de óvulos por ovärio é governado por um sistema genético. AL - MUkHTAR (1981), na geração $F_{3}$ de Phascolus vulgaris, constatou que o número de óvulos por vagem, é controlado por um gen principal. Enquanto que DOKU (1976) constatou que o nü mero de óvulos por ovário e o nümero de sementes por vagem, nas variedades de soja "Ballaire" e "Ross", è um caräter altamente influenciado pelo ambiente, pois com fotoperiodismo mais longo, o numero de óvulos bem como o nümero de sementes produzidas $\vec{e}$ significativamente maior, quando comparado com a produção em fotoperiodismo mais curto.

NARAYANAN e MURTHY (1979), nas variedades de amendoim "Garapuri" e "GDM ", a diferença do nümero de ōvulos por ovärio e o nümero de sementes por vagem foi de $91,7 \%$ na variedade "Garapuri" e $87,8 \%$ na variedade "GDM_".

DATTÉE (1972) em värios cruzamentos sucessivos de Medicago, observou 
que o nümero médio de óvulos por oväriofoi igual a 10,4, enquanto que o número médio de sementes por vagem era apenas de 3,3. Isto indica a presença de fatôres limitantes que impedem o desenvolvimento de uma porcentagem de óvulos.

\subsubsection{Viabilidade do pōlen}

os grãos de pölen das Papilionoideae são indivi dualizados, de forma e escultura variada: esférica, elíptica, etc.; geralmente um pouco pesados e viscosos. Após o amadurecimento as anteras se rompem longitudinalmente, devido ao rompimento do endotécio, fenômeno resultante do turgor que se for ma no interior das células (BURkART, 1952).

São utilizados värios métodos para testar a via bilidade do pölen, porëm, uns são mais comumente usados como: Carmin acético e Iodo (ZHuChenko et alii, 1975). Estes métodos são recomendados, pelo fato de permitirem detectar o desen volvimento normal do citoplasma, e além disso os resultados são räpidos (KLEIN et alii, 1974). LASA (1975), considerou o "Bromo Tetrazólico", o método mais eficaz para avaliar a viabi lidade do pólen, principalmente em amostras armazenadas num pe ríodo maior de tempo. KILSON e FRANKE (1980) afirmaram que, vários métodos utilizados para testar a viabilidade do pólen são välidos, porëm, um dos métodos indiretos que merece maior 
confiança é aquele feito com aplicação de "Diacetato fluorescente". Os mesmos autores acrescentaram que a determinação in direta da viabilidade do pólen em cereais é feita com maior eficiência usando a técnica "Fluorocromática". O método envol ve a determinação da atividade da esterase nas células vegetativas particularmente no plasmalema. Usando este método, observaram no trigo, que o pólen das plantas da geração Fl resul tantes do cruzamento de octoplóides cruzadas com alopoliplói des, a viabilidade foi em torno de $56 \%$, enquanto que as plantas da geração F resultantes do cruzamento de hexaplóides com alopoliplóides mostraram uma viabilidade do pólen em torno de $82 \%$.

Plantas de Raphanus sativus e Brassica campestri, quando polinizadas artificialmente produziram apenas $61,5 \%$ de frutos, quando comparadas com plantas de polinização normal que possuem uma taxa de $95 \%$. Para verificar a viabilidade do pólen foram feitos testes em laboratório, utilizando "Metanol". Este método só mostrou eficiência em Raphanus satí uus, enquanto que para Brassica campestri, foi ineficiente (SASTRI e SHIVANA, 1980). Isto indica que cada espécie exige um método adequado para poder desencadear reaçóes nas células germinativas.

Outro método de fácil aplicação, foi usado por Jovancevic (1962) citado em STANLEY e LINSKENS (1974) nas 
espécies P̉icea omorica e Salix alba, fázendo observação direta ao microscópio, identificando os grãos de pólen não viäveis, pelo tamanho, forma e cor da exina que se apresentam diferentes dos grãos de pólen normal. Acrescentou que outro teste rá pido, para averiguar a viabilidade do pólen é observar a germi nação "in vitro".

BLONDON et alii (1981), correlacionarama porcentagem de pólen fértil com a quantidade de pólen produzido por flor, em clones de Medicago sativa, para verificar a varia ção da fertilidade do pólen em função da temperatura. Conclui ram que existe uma correlação entre grãos de pólen produzidos por flor com a quantidade de pólen viável.

\subsubsection{Germinação do Pólen}

Vários são os fatôres que influenciam o crescimento do pólen "in vitro" e "in vivo": tipo de pólen, tempo de coleta, estação do ano, método de coleção, secreção do estígma, substâncias químicas produzidas pelo övulo que desencadeiam a formação do tubo polínico, etc. (STANLEY e LINSKENS, 1974 e PRAKASH e CHAN, 1976). Porém, a capacidade do crescimento do pólen depende sobretudo da composição química do mesmo .

o critério usado para comparar a capacidade de 
germinação do pólen "in vitro" e em condições naturais, às vezes é muito arriscada, porque amostras de pólen com alta capacidade de germinação "in vitro", às vezes em condições naturais não desenvolvem um tubo polînico de comprimento suficiente para atingir o saco embrionário onde se dá a fecundação. Resultados tambem indicaram que, pólen armazenado, mostrando baixa taxa de germinaçäo, "in vitro", nem sempre pode ser viável, pois pólen de Gossypium e Penissetum, testado "in vitro" não é viável, entretanto, usado na polinização, apresenta uma taxa satisfatória de fecundação. Em outros casos, a porcentagem de germinação "in vitro" è mais alta após alguns dias de armazenamento do pólen, comparado com o pólen coletado após a abertura da antera (STANLEY e LINSKENS, 1974).

Alguns autores sugeriram para determinadas espé cies, um meio ótimo para a germinação do pólen. Assim, para Beta vulgaris o meio ótimo de germinação do pólen é aquele constituído de $40 \%$ de Beta - sacarose, $6 \%$ de gelatina, pH 5.6 e mantido numa temperatura de $20^{\circ} \mathrm{C}$ (Glënk et a $i$ i, 1969 , citado em STANLEY e LINSKENS, 1974). Para Nicatiana alata, o meio mais eficiente é aquele que contém 10\% de Beta - sacarose,água e uma temperatura de $30^{\circ} \mathrm{C}$ (Hoekstra, 1972 , citado em STANLEY e LINSKENS, 1974). O pólen de Eucalyptus, germina bem num meio com $20 \%$ de Beta - sacarose, $1,5 \%$ de ägar, numa temperatura de $30^{\circ} \mathrm{C}$ (Boden, 1958, citado em STANLEY e LINSKENS, 1974). Já HONG - QI e CROES (1982) consideraram o "Glicol Polietile- 
no" (PEG) 400, um meio superior à sacarose para germinação do pólen de Petunia hybrida. O PEG - 400, è um estimulante que age rapidamente no crescimento do tubo polínico.

Em Nymphaea spp., o boro è um elemento estimulante.na germinação do pólen, pois o estígma no momento em que está receptívo, possue alta taxa de boro, e, substituindo a secreção do estígma pelo boro, não ocorreu alteração na taxa de germinação do pölen. Porēm, isto não é välido para todas as espécies (Schmuchler, 1932, citado em STANlEY e LINSKINS, $1974)$.

HUTTON (1960), estudando a polinização e desenvolvimento do tubo polínico em Centrosema pubescens Berith., con cluiu que o desenvolvimento do tubo polínico ocorre de 4.5 horas antes da abertura da flor.

2.3.7. Modo de reprodução

o sucesso evolutivo e ecológico das leguminosas, deve-se em grande parte a modificações biológicas reprodü tivas ocorridas dentro da familia ao longo dos tempos. Entre estas modificações biológicas salienta-se o mecanismo da polinização e suas implicações comportamentais em relação aos dife rentes sistemas desenvolvidos (ARROYO, 1981). 
Nas leguminosas Papilionoideae, as adaptações nas estruturas florais associadas com o sistema de cruzamento são bem evidenciadas. As que possuem autofecundação, em geral possuem flores de tamanhos reduzidos. As cleistógamas exibem precocidade de germinação do pölen, isto é a germinação ocorre no período da flor em botão e algumas espécies não possuem corola, como é o caso da Lespedeza. Nestas espécies a temperatü ra é um fator influente na determinação do tipo de flor. A Lespedeza só produz flores cleistögamas em temperaturas frias e noites longas, enquanto que Ononis alopecurioides, produz flo res chasmögamas no verão e flores cleistógamas no outono (ARROYO, 1981 ).

GRANT (1958 e 1963) e STEBBINS (1950) defenderam a idéia de que as plantas que apresentam autofecundaçãoten dem formar populações geneticamente homogêneas, enquanto aquelas de fecundação cruzada possuem maior variação dentro das populações. Desta forma conhecendo-se a maneira pela qual uma espécie se reproduz (autofecundação ou fecundação cruzada) podemos prever a variação a ser encontrada dentro das populaçóes que elas formam.

A evolução organogräfica floral nas leguminosas $\vec{e}$ caracterizada pela maximização e economia do pólen e do nectar. Esta tendência no desenvolvimento evolutivo é manipulada por um processo gradual de seleção favorecendo vetores especia 1 izados (ARROYO, 1981$)$. 
A posição dos estames diadelfos ao redor do gineceu facilita a autofecundação, pois o pólen é lançado dire tamente sobre o estígma, resultando uma alta taxa de autofecun dação (WIlliams, 1964). A maior parte da polinização ocorre com a flor fechada (CARLSON, 1973).

HUTTON (1960) mostrou que é necessärio um mecanismo eficiente na transferência do pólen das anteras para o estígma do qual depende a quantidade de sementes que se formam. Nas papilionoideae os mecanismos que promovem a autofecundação são diferentes nos diferentes gêneros.

Para LEVIN (1971) o vetor de pólen é um agente seletivo e, $\vec{e}$ a este agente que o mecanismo floral responde. Portanto, existe uma correlação evolutiva entre o mecanismo floral e o agente polinizador. A constância floral de uma espēcie e a especificidade dos seus polinizadores, ē vantajosa pa ra as plantas porque aumentam a segurança de polinização, redu zem a perda de gametas os quais podem limitar a produção de sementes e diminuir a incidência de hibridação. e, ao mesmo tempo minimizar o gasto de energia dispendida por unidade de alimento acumulado e, reduz a competição interespecífica do pó len. Ambos, constância floral e especificidade do polinizador, são respostas plásticas sujeitas a modificaçóes pelas circunstâncias imediatas.

Segundo ARROYO (1981), no desenvolvimento dos 
mecanismos de polinização ocorrem muitas variantes entre as tribos, porēm alguns mecanismos já são conhecidos: o mecanismo de escova, em que o pólen é transportado da antera para o estígma através dos pelos da quilha; mecanismo de bomba, em que o pólen é conduzido ao estígma sob pressão; mecanismo explosivo, ocorre pela explosão das anteras.

Para BURKART (1952), a polinização em Centrosema (DC.) Benth. ocorre através do mecanismo de alavanca, isto é, quando o inseto pousa na asa ou na quilha, as mesmas abaixam aparecendo então as anteras e o estígma. As anteras depositam o pólen no corpo do inseto e o estígma do mesmo modo recebe o pólen estranho. Ao retirar-se o inseto, a as a e a quilha voltam ao lugar, cobrindo novamente os órgãos sexuais. Es ta é uma maneira de ocorrer fecundação cruzada nestas plantas. Nas espécies do gênero Centrosema (DC.) Benth., ocorrem também flores cleistógamas, que se caracterizam por corola incompleta, poucos estames e autofecundação obrigatória, antes da abe tura do cälice. Porém, sempre ocorrem além dessas, na mesma espécie, flores chasmögamas.

JOERGENSEN (1909), afirmou que nas leguminosas os insetos heminópteros são os que fazem a maior parte da fecundação cruzada.

As abelhas são os insetos que se destacam, entre os demais insetos, como agentes polinizadores, pelo fato 
de sua habilidade discriminativa entre diferentes flores, quan to a cor, forma, tamanho e perfume. As diferenças preferenciais entre as abelhas polinizadoras à determinadas caracterís ticas florais contribui para uma rápida evolução na formação de barreiras de isolamento reprodutivo etológico (LEVIN, 1971 ).

A discriminação pelos polinizadores lepidópteros atravēs da cor é bem conhecida. Entretanto, a base fisiolögica é pouco estudada. Segundo Goldsmith (1969) citado em LEVIN (1971), a composição fisiolögica de Colias eurytheme, contēm duas ou mais classes de receptores de mäxima sensibilidade às cores violeta e vermelho-laranja.

Na família Leguminosae a maior parte da polini- zação é feita pelas abelhas. De acôrdo com Watmough (1974) ci tado em ARROYO (1981), as plantas dos gêneros Centrosema, Cana valia e Harpalyce, no sul da África, são polinizadas por espēcies do gênero Xylocopa. Sendo este gênero bastante comum como polinizador na tribo Phaseoleae. 


\section{MATERIAL E METODOS}

Cinco espécies de Centrosema (DC.) Benth., fo ram utilizadas para o desenvolvimento deste trabalho:

C. pubescens Benth.

C. brasilianum (L.:) Benth.

C. virginianum (L.) Benth.

C. vexillatum Benth.

C. pascuorum (Mart.) Benth.

o trabalho foi conduzido em dois ensaios monta dos em vasos. No primeiro ensaio as sementes usadas foram pro cedentes da EMBRAPA - Campo Grande-MS, multiplicadas no campo experimental pertencente ao Departamento de Genética da ESALQ/ USP, Piracicaba-SP. Esta etapa abrangeu coleta de dados e anālise dos seguintes parâmetros:

a. Anālise qualitativa' e quantitativa das par- 
tes florais.

b. Ciclo de florescimento.

c. Relação: nümero de óvulos por ovário com nūmero de sementes por vagem.

d. Viabilidade do pólen.

No segundo ensaio, foram usadas sementes provenientes da EMBRAPA - Campo Grande - MS, sendo analisados os seguintes parāmetros:

e. Germinação do pólen.

f. Modo de reprodução.

3.1. Preparo das sementes e semeadura

a. Preparo das sementes

As sementes utilizadas para o plantio, foram submetidas ao processo de escarificação manual através da uti1 ização de 1 ixas.

\section{b. Semeadura}

As sementes foram colocadas em caixas de germinação, com papel filtro, umidecido com ägua destilada, e pos- 
tas a germinar em germinador de bandeja a $25^{\circ} \mathrm{C}$, no escuro. A medida que as plântulas das sementes germinadas, dotadas de ra dícula e dois cotilëdones, atingiam mais ou menos cinquenta mm de altura foram transferidas para copos de plástico, permanecendo na casa de vegetação durant: dez dias. Após este período, as plantulas foram transplantadas para vasos individuais, permanecendo até a última coleta de dados.

\subsection{Instalação dos ensaios}

O delineamento utilizado foi inteiramente casua lisado, para os dois ensaios, sendo o primeiro montado com dez plantas de cada espécie correspondendo a um total de cinquenta plantas. O segundo, com apenas cinco plantas de cada espécie perfazendo um total de vinte e cinco plantas. Os vasos fo ram distribuídos ocupando um espaço individual de $1 \mathrm{~m}^{2}$, numa Zrea livre, sob condições atmosféricas normais.

o período experimental estendeu-se cla data do plantio até a data da coleta dos ültimos dados correspondendo respectivamente 08/04/82 a 30/01/83 para o primeiro ensaio e, 09/11/82 a 30/06/83 para o segundo ensaio. 
3.3. Anāitise qualitativa e quantitativa das partes florais

$$
\text { Cada parte da flor: estandarte, asa, quilha, }
$$
gineceu, androceu, cálice, bracteola, bräctea e pedünculo, foi desmontada do conjunto floral, fixada numa ficha de cartolina com "Con-Tact" e analisada separadamente, quanto a forma, disposição, nūmero tamanho e cor, seguindo a classificação botânica de BARBOSA - FEVEREIRO (1977). Também cada parte da flor foi fotografada isoladamente.

Em cada espécie foram feitas dez mensurações nos seguintes caracteres:

$$
\begin{aligned}
& 1 \text { - comprimento do estandarte } \\
& 2 \text { - largura do estandarte } \\
& 3 \text { - comprimento da asa } \\
& 4 \text { - largura da asa } \\
& 5 \text { - comprimento da quilha } \\
& 6 \text { - largura da quilha } \\
& 7 \text { - comprimento do pedúnculo } \\
& 8 \text { - comprimento do cálice } \\
& 9 \text { - diâmetro do cälice } \\
& 10 \text { - comprimento da bracteola } \\
& 11 \text { - largura da bracteola } \\
& 12 \text { - comprimento da bräctea } \\
& 13 \text { - largura da bräctea } \\
& 14 \text { - comprimento do androceu }
\end{aligned}
$$




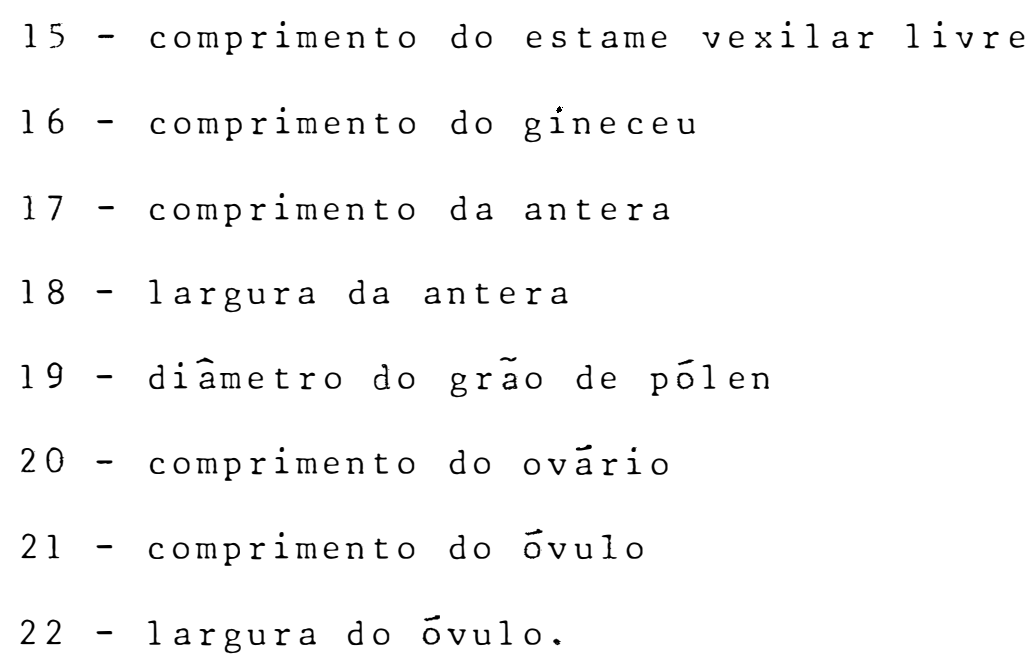

Todas as mensurações dos caracteres morfológicos dos órgãos florais, do item l ao item l6, com exceção do diâmetro dó cálice, foram feitas com o auxílio de uma rëgua mi limetrada comum, tomando sempre o ponto de maior dimensão do órgão, tanto para o comprimento como para a largura. o diâmetro do cálice foi medido com auxilio de uma fita métrica. Do Item 17 ao ítem 22, as mensurações foram feitas com uma ocular micromëtrica, ao microscópio "Zeiss" usando aumento de $80 x$.

3.3.1. Anālise para avaliar as características morfoló gicas florais

A anālise da variância para os caracteres morfo lógicos, foi realizada com o objetivo de termos uma idéia da amplitude de variação que ocorre em cada caräter dentro da espécie e o grau de diversificação entre as espécies, a partir das amostras colhidas de cada uma. 
Para cada caráter dentro de cada espécie foi calculado o coeficiente de variação, utilizando a fórmula:

$$
C V .=\frac{100 . s}{m}
$$

Onde:

Cv : coeficiente de variação do caráter dentro da espēcie.

s : desvio padrão (variação aleatória) em relä çào à média.

m: média aritmética dos dados.

Para a anālise conjunta da variância dos caracteres morfológicos entre plantas dentro das espécies, foi utilizado o seguinte modêlo linear:

$$
Y_{i j}=m+t_{i}+e_{i j}
$$

Onde:

$$
\begin{aligned}
& Y_{i j:}: \text { mensuração de um dado caräter, na planta } \\
& \quad \text {, repetição } j . \\
& \quad: \text { média geral } \\
& t_{i} \quad: \text { efeito do tratamento } \\
& e_{i j:}: \text { efeito do tratamento + repetição. }
\end{aligned}
$$


De acôrdo com este modêlo a anālise da variância de cada caräter entre as espécies, obedece o seguinte esquema:

\begin{tabular}{cccc}
\hline F.V. & G.L. & Q.M. & F \\
\hline Espécie & $E-1$ & $Q_{1}$ & $Q_{1} / Q_{2}$ \\
Resíduo & $E(r-1)$ & $Q_{2}$ & \\
\hline
\end{tabular}

Total

$$
(\operatorname{Er}-1)
$$

Com as médias de cada caräter foram construídos gráficos comparativos entre as cinco espécies, segundo o esque ma de polígonos (BENSON, 1962).

\subsection{Ciclo de florescimento}

o início de florescimento, foi determinado contando-se o número de dias a partir da semeadura até o aparecimento da primeira flor. A partir da emissão das primeiras flo res atê o término da floração, foi considerado período de floração. 


\subsubsection{Cor das flores}

Dez flores de cada espécie foram colhidas e ana lisadas quanto a coloração de suas partes: estandarte, asas e quilha. Foi feita uma comparação entre as flores de diferentes espēcies.

3.5. Relação: nūmero de ōvulos por ovārio com nūmero de sementes por vagem

Com o auxílio da lupa e do microscópio, foram feitos cortes longitudinais em dez ovários de cada espécie, e, contado o nümero de óvulos em cada ovário. o processo foi fei to no estágio de botão e no estágio de flor aberta. Para relacionä-los com o nümero de sementes por vagem, foram contadas as sementes de setenta vagens em cada espécie.

3.6. Viabilidade do pōien

A viabilidade dos grãos de pölen das flores das cinco espécies, foi verificada empregando-se a técnica de colo ração pelo "Carmin Acético". Para cada espécie foram tomadas dez flores, ao acaso. A contagem dos grãos viáveis e inviäveis foi feita em microscópio "Zeiss", em campos ao acaso, 
usando o critério de coloração, forma e tamanho diferencial.

3. 7. Germinação do pólen em meio de cultura

Com intuito de obter informações sobre germinação do pólen "in vitro", das cinco espécies de Centrosema (DC.) Benth. em estudo, foram montados ensaios, sendo que em cada um deles foram utilizadas diferentes concentrações de sacarose e de agar, sob diferentes temperaturas.

o primeiro ensaio constou de seis diferentes concentrações de sacarose $(0,5-1,0-2,0-3,0-4,0$ e 5,0 gramas), sendo cada uma delas diluída em $100 \mathrm{ml}$ de ägua destí 1ada. Para cada concentração foram utilizadás dez placas de "Petri", com duas repetições de pólen de cada espécie, perfazendo um total de sessenta placas. Uma repetição de cada espẹ cie e de cada concentração foi mantida, durante 48 horas, no germinador à $25^{\circ} \mathrm{C}$, num ambiente com $100 \%$ de umidade relativa. A outra repetição foi mantida na temperatura nor mal do ambiente externo correspondendo a uma variação entre 24 à $28{ }^{\circ} \mathrm{C}$, em $100 \%$ de umidade relativa, durante 48 horas.

o segundo ensaio, foi montado seguindo o mesmo esquema e condições do primeiro ensaio, usando a mesma quantidade de material, diferindo apenas o meio de cultura, que foi o seguinte: 
Concentração de sacarose (g)

$$
\begin{aligned}
& 0,5 \\
& 0,5 \\
& 0,5 \\
& 1,0 \\
& 1,0
\end{aligned}
$$

Concentração de agar $(g)$

1,0

1,5

2,0

1,0

2,0

No terceiro e no quarto ensaios, as condições ambientais, o esquema e a quantidade de material foi igual ao primeiro e segundo ensaios, com as seguintes variações nos meios de cultura:

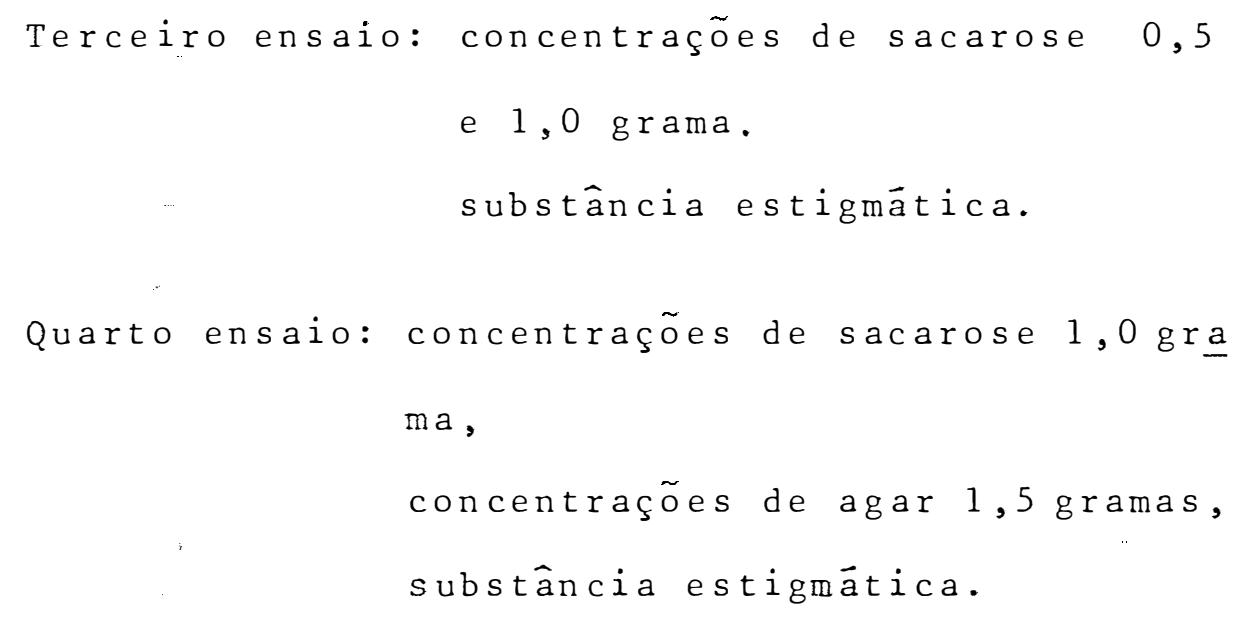

3. 8. Modo de reprodução

Afim de verificar a quantidade.de flores que de senvolveram vagens, quando isoladas, um número variável de bo- 
tões, de cada espécie foi envolvido com saquinhos de papel transparente. Os saquinhos foram retirados após o aparecimento da vagem ou a queda da flor.

Diariamente, durante 15 dias, no período das 7:00 às 9:00 horas da manhä, foram feitas observações diretas nas plantas com a finalidade de verificar os tipos de insetos que pousavam nas flores. 
4. RESULTADOS

4.7. Anālise qualitativa e quantitativa das estruturas florais

Levando em consideração a forma, o nümero e a disposição das partes da flor, de cada uma das cinco espécies de Centrosema Benth., os resultados obtidos foram os seguintes :

Inflorescência: Blores agrupadas em número de 5 a 6 (C. pubescens Benth.), 3 a 4 ou isoladas ( $C$. brasilianum (L.) Benth.), 2 a 3 ou isoladas (C. virginianum (L.) Benth., C. vexillatum Benth. e C. pascuorum (Mart.) Benth.)

Flor: Nas cinco espécies as flores são zigomorfas, papilionoideas, com uma pétala maior que é o standarte, 2 laterais 1 i- 
vres que são as asas e 2 inferiores soldadas ao longo da linha de contato, cujo conjunto é denominado de quilha ( Figuras $1,2,3,4$ e 5 ).

Cấlice: O cálice é gamossépalo nas 5 espécies, ocorrendo varia ção quanto aos lacínios. Estas variações estão assim distribuídas:

C. pubescens 4 lacínios, sendo:

1 maior, alongado e pontiagudo,

2 médios e pontiagudos;

1 ovalado, com leve bifurcação final for mando a metade do tamanho do diâmetro ( Figura 1).

C. brasilianum 5 lacínios, todos pontiagudos, sendo:

C. Virginianum 1 mais $10 \mathrm{ngo}$,

C. pascuorum 2 médios iguais entre si,

2 menores iguais entre si (Figura 2, 3 e 5 ).

C. vexillatum 4 lacínios, sendo:

1 de forma arredondada ocupando metade do diâmetro do cälice,

1 pontiagudo,

2 mucronados, iguais entre si (Figura 4). 
Duas bracteolas saem do receptáculo floral externamente ao cálice, cobrindo-o de ambos os lados, sendo que no C. vexillatum Benth. estas bracteolas são bem desenvolvidas, envolvendo toda a parte externa do cálice (Figuras 1, 2, 3,4 e 5).

Androceu: E formado de 10 estames, sendo 9 soldados entre si, com a parte superior livre onde se encontram as ante ras, e, um estame vexilar 1ivre. 0 tubo formado pelos 9 estames, envolve o estilete e o ovário do gine ceu (Figuras 1, 2, 3, 4 e 5).

As anteras de forma ovóide, possuem as tecas subdivididas longitudinalmente em 4 sacos polínicos, cuja deis cência do pólen é feita por fendas longitudinais. As 5 espécies de Centrosema ( $D C$. ) Benth., estudadas, apresentaram diferenciação quanto ao tamanho das mesmas e mantiveram constante sua forma (Figura 6.1). A inserção do filete é mesofixa (Figu ra 6.2.).

os grãos de pólen são individualizados. Ao microscópio foram observadas 2 formas: esférica e triangular, em cada uma das espécies, ocorrendo variação apenas quanto ao tamanho (Figura 7).

Gineceu: E unicarpelar, com óvulo campilótropo, com ovárió süpero apresentando acentuada pilosidade na parede externa, nas 5 espécies (Figuras $1,2,3,4$ e 5 ). 
Ovärio: Em corte longitudinal e transversal (Figura 9), o ovärio apresenta-se em forma de um tubo alongado, unilocu 1 ar onde se inserem os óvulos dispostos em fileiras. Externamente $\bar{e}$ recoberto por pilosidade e apresenta um sulco longitudinal.

os óvulos (Figura 8) são de forma oval-alongada, apre sentando uma pequena concavidade na região do hilo.

Estigma: E apical, achatado com bordos ovais e piloso, apresen tando viscosidade e um sulco longitudinal, que é uma continuação do sulco longitudinal do ovário.

Estilete: Apresenta-se achatado, piloso, com pelos disseminados. A parte basal do estilete é envergada formando um ângulo reto em relação ao ovārio, o que constitue o tipo denominado campilótropo.

Os Coeficientes de Variação obtidos das mensura ções para os 22 caracteres morfológicos florais das cinco espé cies do gênero Centrosema (DC.) Benth., encontram-se na Tabela 2 .

os valores estão indicando a ocorrência de variabilidade em todos os caracteres analisados, destacando-se o comprimento do pedünculo com Coeficiente de Variação mais elevado, comparando com os demais caracteres entre as cinco espécies analisadas. Comprimento da asa e comprimento da quilha 
foram os dois caracteres que apresentaram Coeficientesde Varia ção mais baixos em relação aos demais caracteres.

Os valores e significâncias dos Quadrados Médios e os respectivos coeficientes de Variação obtidos na analise da variância entre as espécies para os caracteres estudados, encontram-se na Tabela 3 .

Observa-se nesta Tabela, que todos os caracteres florais analisados, apresentaram alta significância para o efeito dos mesmos, aos níveis de $1 \%$ e $5 \%$, indicando que as espécies diferem significativamente entre si, com relação aos ca racteres.

Na Tabela 4, encontram-se as médias obtidas de cada caräter, com seus respectivos valores de $\Delta$ (Tukey, $5 \%$ ) e as comparações de cada caráter entre as espécies.

Pelos valores obtidos, observamos que as espécies apresentaram diferenças bem acentuadas na média de seus caracteres florais mensurāveis, indicando divergência. morfológica entre as mesmas. As espécies C. brasilianum (L.) Benth. e C. Virginianum (L.) Benth., no entanto apresentaram maior nü mero de médias semelhantes entre si, indicando maior proximida de morfológica entre essas espécies.

Com as médias de cada carāter, para as diferentes espécies (Tabela 1), foram construídós grä́icos comparati- 
vos, nos quais os caracteres foram distribuídos segundo o esquema de polígonos de BENSON (1962), (Figuras 11 e 12). Na Figura 11 constam os caracteres cujas medições foram feitas diretamente em mm, enquanto que na Figura 12 foram coloca dos os caracteres cujas medidas foram tomadas ao microscópio (micras) e transformadas em $\mathrm{mm}$.

\subsection{Ciclo de florescimento}

De acôrdo com os resultados da Tabela 5, houve uma variação do comportamento de cada uma das espécies em rela ção ao inäcio da floração, para as duas diferentes épocas de plantio: abril e novembro.

Na Tabela 6, estão representados os meses do ano em que cada espécie teve seu ciclo de floração, bem como o mês em que cada uma atingiu seu pico máximo de florescimento.

\subsubsection{Cor das flores}

o caräter morfolögico: coloração das flores está representado na Tabela 7. Este caráter apresentou uma variação bastante acentuada entre as espécies, e em algumas espē cies dentro da prōpria espécie. 
4.3. Relação entre nūmero de óvulos por ovārio com nūmero de sementes por vagem

\begin{abstract}
De acôrdo com as Tabelas 8 e 9 , o nūmero de óvu los que desenvolveram sementes variou em cada espécie, sendo maior a variação nas espécies $C$. pubescens Benth. e $C$. virginianum (L.) Benth. cuja média de óvulos perdidos por ovário foi de 6 e 5 respectivamente. Seguindo, C. brasilianum (L.) Benth., C. vexillatum Benth. e C. pascuorum (Mart.) Benth., com perda respectiva de 4,2 e 1 óvulos por ovário. Comparando a perda de óvulos por ovário com a porcentagem de sementes viáveis, parece ocorrer uma compensação pois, esta ültima foi bastante alta em todas as espécies.
\end{abstract}

4.4. Viabilidade do pólen

Os resultados obtidos do estudo da viabilidade do pólen pela técnica do "Carmin Acético", nas 5 espécies do gênero Centrosema (DC.) Benth., encontram-se na Tabela 10. Pa ra este caráter, em todas as espécies estudadas, a porcentagem de pōlen viável mostrou-se bastante alta. 
4.5. Germinação do pōien em meio de cultura

os resultados dos 4 ensaios para germinação do pölen em diferentes meios de cultura, encontram-se nas Tabelas $11.1,11.2,11.3$ e 11.4 .

Na Tabela 1l.1, constam os dados do ensaio em que foi usado o meio de cultura: sacarose 0,5 gramas e agar 1,0 grama. Embora a porcentagem de germinação tenha sido ba xa, todas as espécies com exceção de C. virginianum Benth., tiveram uma resposta à germinação do pólen em temperatura variável de 24 a $28^{\circ} \mathrm{C}$. Enquanto que numa temperatura constante de $25^{\circ} \mathrm{C}$ não ocorreu germinação em nehuma espécie.

os resultados do ensaio como meio de cultura contendo 0,5 gramas de sacarose e 1,5 gramas de agar (Tabela 11.2) mostraram uma germinação superior em temperatura variävel entre 24 a $28^{\circ} \mathrm{C}$, do que em temperatura constante de $25^{\circ} \mathrm{C}$, com exceção da espécie C. vexillatum Benth. que mostrou ser ligeiramente mais eficiente $(0,07 \%)$ em temperatura à $25^{\circ} \mathrm{C}$.

No meio de cultura (Tabela 11.3) contendo 0,5 gramas de sacarose e 2 gramas de agar, ocorreu uma variação na germinação do pólen, tanto em temperatura constante $25^{\circ} \mathrm{C}$, como em temperatura variável 24 a $28^{\circ} \mathrm{C}$. Ocorrendo uma exceção com a espécie C. vexillatum Benth., cujo pólen não germinou a $25^{\circ} \mathrm{C}$.

o meio de cultura que mostrou maior eficiência 
entre os meios testados, embora considerado baixo, foi o que continha em seu meio além de sacarose e agar, substância retirada do próprio estígma (substância estigmática), (Tabela 11.4).

Com os restantes meios de cultura usados, não ocorreu nenhum indício de germinação do pölen, nas 5 espécies testadas.

4.6. Modo de reprodução

os resultados obtidos do isolamento dos botões (Tabela 12), em cada espécie, para o caräter desenvolvimento do botão até a formação da vagem, variaram entre as espécies. A maior porcentagem ocorreu nas espécies $C$. vexillatum Benth. e C. pascuorum (Mart.) Benth., cujos resultados positivos foram respectivamente 96 e $92 \%$. C. brasilianum (L.) Benth. e C. pubescens Benth., foram as que apresentaram menor indice de formação de vagens, com apenas $20 \%$ e a espécie C. virginianum (L.) Benth. com $22 \%$.

Com relação aos insetos visitantes, seu comportamento e sua adaptabilidade para a polinização, as observações foram as seguintes:

Durante o período de 15 dias consecutivos, na época da floração, foram feitas diariamente observações minuciosas para identificar a presença do tipo de inseto nas flo- 
res. Constatamos que a presença de insetos do gênero Bumbus sp. parece ser bastante significativa nas flores do gênero Cen trosema (DC.) Benth. No horärio compreendido entre 7:30 horas às 9:00 horas da manhã, insetos do gênero citado, pousavam sobre o estandarte das flores, pressionando o conjunto floral asa e quilha, para cima, afim de sugar o néctar. Sob estapres são, a quilha abre a parte terminal distal da inserção no receptáculo, e, deixa sair os estames e o estígma. Uma certa quantidade de pólen fica depositada no dorso e na cabeça do inseto. Com as patas anteriores o inseto fecha novamente a quilha e voa para outra flor, onde repete o mesmo processo.

os insetos deste gênero, parecem ter uma certa preferência sobre as flores de Centrosema (DC.) Benth., em re1 ação às 5 espécies estudadas. Os insetos de coloração mais escura, pousavam nas flores de C. pubescens Benth., C. brasilianum (L.) Benth., e C. virginianum (L.) Benth., enquanto que os insetos claros pousavam nas flores de $C$. vexillatum Benth. Nenhuma presença de inseto, foi observada nas flores de $C$. pascuorum (Mart.) Benth.

Foi observado também, que os insètos, na mesma visita pousavam nas flores da mesma planta, em flores de plantas diferentes da mesma espëcie e em plantas de diferentes espécies (C. brasilianum (L.) Benth. e C. virginiamum (L.) Benth.). 
.59.

Outra observação importante neste ítem, foi que o inseto durante 15 dias de observação, apenas repetiu o processo descrito durante três dias, porëm não consecutivos. Os restantes 12 dias, apenas sugou o nëctar, pousando na flor em sentido oposto ao citado, portanto não pressionando o conjunto floral asas e quilha, mas de certa forma neste movimento poderá pressionar a parte basal do androceu e gineceu. 
5. DISCUSSAOO

5.1. Análise qualitativa e quantitativa das estruturas florais

o grau de diversificậão de uma espécie, é o re sultado da soma acumulativa de modificaçóes morfológicas, biológicas e funcionais que são incorporadas geneticamente ao longo dos tempos em resposta as diferentes modificações ambientais. Cada espécie usa estratégias específicas para manutenção, perpetuação e aperfeiçomento de seus indivíduos. Em consequência disto, ca da espécie biológica apresenta maior ou menor grau de variação em alguns de seus caracteres florais, enquanto que, outros ca racteres mantem certa uniformidade, garantindo, desta forma, características semelhantes que padronizam os indivíduos dentro da espécie a qual pertencem.

Nas cinco espécies de Centrosema (DC.) Benth. 
analisadas, os caracteres florais que não apresentaram variação quanto ao nümero, disposição e forma, foram: estandarte, asas, quilha, gineceu, androceu, forma do cálice (gamossépalo), número de bräcteas e bracteolas (Figura 1, 2, 3, 4 e 5), forma das anteras (Figura 6) e forma e disposição dos óvulos (Figuras 8 e 9).

Sobre estes caracteres, provavelmente age a seleção canalizadora cuja função é forçar todos os genótipos do caräter considerado, na direção de um ūnico fenótipo, especifi camente adaptado às condições ambientais existentes.

A constância no nümero, forma e disposição dos caracteres florais mencionados, serviu de base para os classificadores botānicos, BURRART (1952), JOLY (1975) e BARBOSA FEVEREIRO (1977), para incluir as espécies de gênero Centrosema (DC.) Benth. na família Leguminosae e sub-familia Papilionoideae.

Os mesmos caracteres mencionados, apresentaram variabilidade quanto ao tamanho, dentro e entre as espécies. Isto foi constatado pelos resultados obtidos através de mensurações feitas (Tabela 1, 2 e 3, e Figuras 6, 7, 8, 9, 10, 11 e 12 ) .

Os Coeficientes de Variação representados na Ta bela 2, mostram valores diversificados entre os caracteres: e 
entre as espëcies. Comprimento do pedúnculo de C. vexillatum Benth., foi o caráter que se destacou dos demais, atingindo um valor de $49,49 \%$. Isto indica que entre os 22 caracteres anali sados, foi o caráter que apresentou maior amplitude de variação.

Tomando por base o carāter comprimento do pedūn culo de C. vexillatum Benth., podemos reunir os caracteres flo rais em três grupos quanto a variação que apresentaram: alta, com Coeficiente de Variação acima de $30 \%$, média, os que possuiram Coeficientes de Variação compreendidos entre 15 a 30\%, e, baixa, quando os valores dos Coeficientes de Variação foram inferiores a $15 \%$. Desta maneira teremos a seguinte distribuição:

- Caracteres que apresentaram valores altos para Coeficientes de Variação: comprimento do pedúnculo com exceção de C. pascuorum (Mart.) Benth., comprimento da antera em C. brasilianum (L.) Benth., largura da antera em C. brasilianum (L.) Benth. e C. pascuorum (Mart.) Benth., diâmetro do grão de pölen em C. pubescens Benth., C. brasilianum ( L. ) Benth. e C. pascuorum (Mart.) Benth.

- Caracteres que apresentaram valores médios pá ra Coeficientesde Variação: 1 argura da asa em $C$. virginianum (L.) Benth. e C. vexillatum Benth., comprimento do pedúnculo em 
C. pascuorum (Mart.) Benth., diāmetro do cálice em C. pascuorum (Mart.) Benth.; comprimento e largura da bracteola em C. virginianum (L.) Benth., comprimento da bractea em $C$. pubescens Benth., C. virginianum (L.) Benth. e C. vexillatum Benth., largura da bractea em C. brasilianum (L.) Benth. e C. virginia num (L.) Benth., comprimento da antera em C. pubescens Benth. e C. pascuorum (Mart.) Benth., largura da antera em C. pubescens Benth., C. virginianum (L.) Benth. e C. vexillatum Benth., diâmetro do grão de pólen em C. virginianum (L.) Benth. e C. vexillatum Benth., comprimento do gineceu em

c. virginianum (L.) Benth., comprimento do ovärio em C. pubescens Benth., $C$. brasilianum (L.) Benth. e C. vexillatum Benth., comprimento do óvulo em C. pubescens Benth. e C. brasilianum (L.) Benth., lar gura do óvulo em C. pubescens Benth., C. brasilianum Benth. e C. pascuorum (Mart.) Benth.

\section{- Caracteres que apresentaram baixos valores} para Coeficientes de Variação: comprimento do estandarte, largura do estandarte, comprimento da asa, comprimento e largura da quilha, comprimento do cálice, comprimento do androceu, com primento do estame vexilar livre, apresentaram Coeficientes de Variação baixos, nas cinco espécies; largura da asa em C. pubescens Benth., C. brasilianum (L.) Benth. e C. pascuorum (Mart.) Benth., diāmetro do cālice em C. pubescens Benth., $C$. brasilianum (L.) Benth., C. virginianum (L.) Benth., e C. vexillatum Benth., comprimento da bracteola em $C$. pubescens 
Benth., C. brasilianum (L.) Benth., C. vexillatum Benth. e C. pascuorum (Mart.) Benth., largura da bracteola em C. pubescens Benth., C. brasilianum (L.) Benth., C. vexillatum Benth. e C. pascuorum (Mart.) Benth., comprimento da bráctea em C. brasilianum (L.) Benth. e C. pascuorum (Mart.) Benth., largura da bractea em C. pubescens Benth., C. vexillatum Benth. e C. pas cuorum (Mart.) Benth., comprimento da antera em C. virginianum (L.) Benth. e C. vexilla.tum Benth., comprimento do gineceu em C.pubescens Benth., C. brasilianum (L.) Benth., C. vexillatum Benth. e C. pascuorum (Mart.) Benth., comprimento do óvulo em C. virginianum (L.) Benth., C. vexillatum Benth..e C. pascuorum (Mart.) Benth., largura do óvulo em C. virginianum Benth. e C. vexillatum Benth.

Diante dos resultados obtidos, podemos verificar que todos os caracteres florais analisados, apresentaram variabilidade quanto ao tamanho (Tabela 2, Figuras 6, 7, 8, 9 , 10, 11 e 12), variando conforme o grau de aperfeiçoamento que o caráter atingiu na evolução da espécie. Os que possuem menor variabilidade provavelmente estão mais próximos ao ponto mäximo de desenvolvimento e diferenciação dentro da espécie, e, consequentemente mais afastados do caráter ancestral. Os que possuem maior variabilidade retida, provavelmente estão longe do ponto máximo de desenvolvimento e diferenciação e, mais pró ximos ao caräter ancestral. 
Com base nos resultados do teste de Tukey (Tabe la 4), foi possível detectar a existência de espécies que tem o mesmo valor médio em alguns caracteres florais, demonstrando o grau de maior ou menor aproximação filogenética entre os mesmos .

O relacionamento entre as espécies através dos caracteres florais que possuiram médias semelhantes está repre sentado no esquema que segue. Os números representam o número de caracteres cujas médias não diferiram significativamente en tre si.

C. pubescens

c. brasilianum

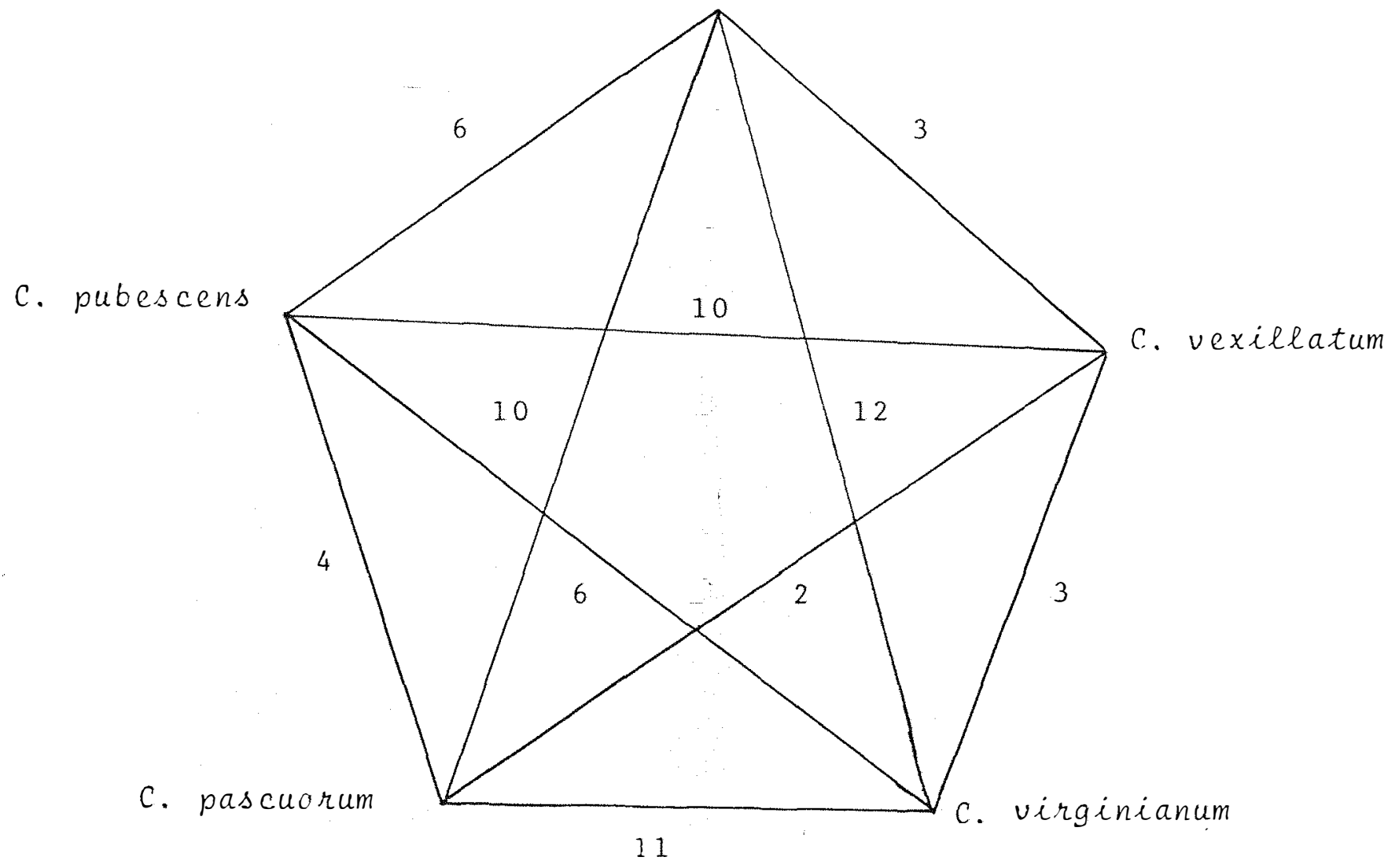


Assim, C. brasilianum (L.) Benth. e C. virginia num (L.) Benth., foram as duas espécies que apresentaram um maior nümero de médias (12) que não diferiram significativamen te entre si, para os caracteres: comprimento do estandarte, do pedúnculo, da bráctea, da bracteola, do gineceu, do ovário, do óvulo, largura da quilha, bräctea, bracteola, do óvulo e diāme tro do grão de pólen. Seguindo C. brasilianum (L.) Benth. mos trou menos divergēncia com C. pascuorum (Mart.) Benth., pois suas médias não apresentaram variação significativa nos seguin tes caracteres: comprimento do pedúnculo, do androceu, da ante ra, do gineceu e do ovário, largura do estandarte, da quilha, da antera, do óvulo, e diàmetro do grão de pólen. Enquanto que com C. pubescens Benth. mostrou semelhança nas médias das mensurações em 6 caracteres: largura da asa e da bracteola, com primento do pedúnculo, da bracteola, do ovário e diāmetro do pólen. Com C. vexillatum Benth., apenas nảo variou nas médias para diámetro do cálice, comprimento do ovārio e do óvulo.

C. virginianum (L.) Benth., também apresentou semelhança em suas médias com C. pascuorum (Mart.) Benth. nos caracteres: comprimento da asa, da quilha, do pedúnculo, do ovārio e do óvulo, largura da asa, da quilha, da antera, do óvulo, diāmetro do cálice, diāmetro do grão de pólen. Entre C. pubescens Benth., e C.virginianum (L.) Benth., ocorreram 6 médias semelhantes que foram: comprimento do pedúnculo, da bracteola, da antera, do ovärio, largura da antera e diāmetro 
.67.

do grão de pólen. Enquanto que com C. vexillatum Benth. as médias semelhantes foram: diâmetro do pólen, comprimento do ovário e do ōvulo.

Comprimento do estandarte, da quilha, do androceu, do estame vexilar livre, da antera, do gineceu e do ovário, largura da antera, diâmetro do câlice e diâmetro do grão de pólen, foram as características morfológicas que apresentaram semelhança de mëdias entre as espëcies: C. pubescens Benth. e C. vexillatum (Mart.) Benth.

C. pascurum (Mart. Benth. e C. pubescens Benth. tiveram médias semelhantes nos caracteres: comprimento do pedúnculo, da bräctea, do ovärio e diâmetro do grão de pölen.

Entre C. pascuorum (Mart.) Benth. e C. vexillatum Benth. apenas duas médias foram semelhantes: comprimento e largura do óvulo.

Nas Figuras 11 e 12 , observa-se que a distribui ção dos caracteres morfolögicos florais, seguem linhas uniformes de distribuição, embora conservando bem nítida a variabili dade individual de cada espëcie.

Variações encontradas nos caracteres morfológicos florais qualitativos que mais se destacaram foram: nümero de flores por inflorescência; nümero de lacínios do cálice, co loração das flores e forma dos grãos de pólen. 
Nas cinco espécies estudadas, foram encontradas flores solitärias, porém foram encontradas também flores agrupadas formando inflorescências. C. pubescens Benth., foi a espécie que apresentou maior nümero de flores por inflorescência, sendo de 5 a 6 para cada grupo. C. brasilianum Benth., mostrou inflorescências com 3 a 4 flores, enquanto que C. virginianum (L.) Benth., C. vexillatum Benth. e C. pascuorum (Mart.) Benth., possuíam apenas 2 a 3 flores por inflorescência.

Embora REYES - ZUMETA (1963), tenha postulado que a inflorescência é constante quanto ao número de flores, para cada espécie vegetal assumindo grande importância como ca racterística taxonômica, verificamos que existe variação para este caráter nas espēcies de Centrosema (DC.) Benth., bem como em outras espécies, como é o caso da Glycine max, onde CARLSon (1963) em algumas variedades encontrou de 2 a 35 flores por in florescência, e, PRAKASH e CHAN (1976), que constataram a ocor rência de 2 a 7 flores por inflorescência. LAWES (1972) afirmou que na soja e em outras leguminosas, o nümero de flores por inflorescência e por planta, varia com a variedade e como ambiente. As nossas observações concordaram com as observações dos autores citados, justificando que, as espécies mencionadas pos suem uma razoável plasticidade em relação ao caräter número de flores por inflorescência, cuja finalidade importante é a produção de maior número de sementes que se traduz num maior núme- 
ro de descendentes produzidos na próxima geração, os quais asseguram a perpetuação da espécie.

Um caräter que merece também atenção é o nümero e a forma dos lacínios do cālice. Nas cinco espécies estudadas, 3 delas apresentaram o mesmo nümero e a mesma forma de lacinios, que foram: C. brasilianum (L.) Benth., C. virginianum (L.) Benth. e C. pascuorum (Mart.) Benth. Os lacínios são todos pontiagudos, sendo um mais longo, dois médios iguais entre si e dois menores também iguais entre si (Figuras 2, 3 e 4), va riando apenas a coloração em C. pascuorum (Mart.) Benth. que é vermelho escuro, enquanto que nas outras duas espécies citadas a coloração é verde. C. vexillatum Benth. e C. pubescens Benth., possuem o mesmo nümero de lacínios, isto é quatro para cada cálice, porém com variação quanto a forma, sendo um maior alongado e pontiagudo, dois médios e pontiagudos, um ovalado, com leve bifurcação final ocupando metade do diâmetro do cálice (Figura I) no C. pubescens Benth. e, no C. vexillatum Benth. os lacínios se apresentam com a seguinte forma: um arredondado ocupando metade de diâmetro do cälice, um pontiagudo e dois mucronados, iguais entre si (Figura 4).

o cālice sendo orgão de proteção e assimilação (REYES - ZUMETA, 1963) da flor, apresenta plasticidade fenotípica em seus lacínios, conforme a necessidade adaptativa da e pécie em proteger e assimilar substâncias nutritivas para os 
órgãos reprodutores (gineceu e androceu), jā que são eles que garantem a sobrevivência e perpetuação da espécie.

Quanto a coloração das flores, concordamos com BARBOSA - FEVEREIRO (1977), ALCÂNTARA e BUFARAH (1979) e GROF (1970), que são dotadas de colorações vistosas e variadas. Es tas cores variam entre as espécies (Tabela 7) e em algumas de1 as dentro da própria espécie, como foi observado em C. brasilianum (L.) Benth. e C. virginianum (L.) Benth. cuja tonalidade de cores variou desde roxo-claro até roxo-escuro. E ressante notar que em cada espécie com exceção de C. pascuorum (Mart.) Benth., tem estrias coloridas na parte central do estandarte, e, estas estrias são típicas para cada espécie, não apresentando variação.

As diferentes colorações nas flores, provavelmente são mecanismos usados pelas plantas para atração dos an mais polinizadores, concordando com LEVIN (1971) quando confi $\underline{r}$ mou que existe uma correlação evolutiva entre o mecanismo floral e o agente polinizador, sendo as abelhas os insetos que se destacam entre os demais insetos polinizadores, pelo fato de possuirem uma melhor habilidade discriminativa quanto a cor. As diferenças preferenciais das abelhas polinizadoras à determinados caracteres florais, contribuìram para uma rāpida evolução na formação de barreiras de isolamento reprodutivo etológico. 
Comparando as Figuras 11 e 12 , com o esquema re presentativo, descrito, das médias dos caracteres entre as espécies e o número de lacínios do cálice, as cinco espécies estudadas têm tendência a formar dois grupos quanto a semelhança na distribuição de seus caracteres. C. brasilianum Benth., C. virginianum (L.) Benth e C. pascuorum (Mart.) Benth., mostraram maior nümero de caracteres com médias semelhantes entre si, nümero e forma de lacínios iguais e uma distribuição mais uniforme em seus caracteres quantitativos, indi cando uma maior aproximação filogenética. Enquanto que as espécies C. pubescens Benth. e, C. vexillatum Benth., seguem $1 \underline{i}$ nhas de divergência maior, comparadas com as outras três espécies, quanto a distribuição de seus caracteres quantitativos, nümero e forma de lacínios do cälice e médias de seus caracteres florais.

Portanto, na escala evolutiva as espécies C. brasilianum (L.) Benth., C. virginianum (L.) Benth. e C. pascuorum (Mart.) Benth. guardam maior grau de parentesco entre si, e maior grau de divergência com $C$. pubescens Benth. e $C$. vexillatum (Mart.) Benth. Isto é uma indicação da existência de um maior isolamento reprodutivo entre as três primeiras espécies citadas e as duas ültimas, implicando num aumento cada vez maior de dificuldades de cruzamento entre as mesmas . 
A variação observada na forma dos grãos de pölen, provavelmente representa diferentes estágios de formação, pois forma redonda ocorreu com maior frequência em botóes mais novos, enquanto que forma triangular foi observada em botões mais próximos a abertura da flor, ou seja, num ciclo de amadurecimento mais adiantado. Segundo FERGUSON e SKVARLA ocorrem consideräveis variações na forma do pólen, embora a forma mais geral é esférica ou triangular em alguns tipos de pólen considerados mais especializados. Se a idéia proposta pelos dois autores mencionados for välida, o pólen das espécies de Centrosema (DC.) Benth., já atingiu o grau de especialização mais elevado dentro da família Leguminosae.

\subsection{Ciclo de florescimento}

Na Tabela 5, verificamos uma variação bastante acentuada no número de dias para o florescimento, tanto entre as espécies como dentro de cada espécie, em diferentes épocas do ano.

o início da floração, dá uma idéia da maior ou menor rapidez no ciclo de desenvolvimento, diferenciação e crescimento de cada espécie. Com exceção da C. brasilianum (L.) Benth., as demais espécies estudadas demonstraram acentua da dependência das condições ambientais, para o referido cará- 
ter, concordando com CARLSON (1973) quando afirmou que o apare cimento da primeira flor é relativo ao estägio de desenvolvimento da planta que, depende da variedade e das condições ambientais, e com STRASBURGER (1943), quando mencionou que o fo toperiodismo, a āgua, temperatura, nutrientes e fatores internos controlam a floração das espécies vegetais.

Dois podem ter sido os possiveis fatores limitantes, no desenvolvimento normal das plantas, além dos mencio nados: o meio ambiente e a época de plantio. As plantas em va sos estão sujeitas ao "stress" muito mais acentuado do que as plantas no campo. Algumas espécies podem ter uma constituição fisiológica mais sensível às diferentes épocas do plantio, manifestando um atraso no período de desenvolvimento, como-" aconteceu com C. pubescens Benth. e C. virginianum ( $L$. ) Benth., cujo atraso de dias para oflorescimento foi de 45 e 65 dias respectivamente, para as plantas germinadas em abril, sendo e te período considerado desfavorável, em relação as plantas ge minadas em novembro. Para outras espécies, como ocorreu com C. brasilianum (I.) Benth., as diferentes épocas de plantionão tiveram influência significativa sobre o início da floração. Por outro lado, encontram-se espécies que são influenciadas pẹ lo período de semeadura, como aconteceu com (Mart.) Benth., que suas plantas não floresceram, quando semea das em abril. Porém as semeadas em novembro tiveram uma flora ção normal. 
Plantas de C. vexillatum Benth., germinadas em abril, emitiram a primeira floração num período mais curto de tempo (22 dias), do que as plantas germinadas em novembro.

Estas discrepâncias que ocorreram para este caráter, foram mencionadas também por värios autores consultados como ALCÂNTARA et alii (1977) que constataram entre populações de Centrosema pubescens Benth., uma diferença de floração de 94, 120 e 142 dias após o plantio enquanto que BOWEN (1959) ob servou em condições de campo que a mesma espécie floresceu 140 a 150 dias após o plantio, quando plantada em diferentes épocas do ano. MOgRovejo - JARAMIllo (1981) em 21 populações de Centrosema pubescens Benth., verificou diferenças de floração entre populações e entre locais. Estas diferenças que ocorrem mostram de uma certa forma a individualidade comportamental de cada espécie, decorrente de uma sensibilidade e variabilidade específicas.

Em termos de reprodução, estas variedades e populações, indicam pertencer a uma espécie autógama, já que para polinização cruzada, diferentes épocas de florescimento são um fator de isolamento reprodutivo.

No que diz respeito ao período de floração, cada espécie tem seu pico máximo de florescimento e período de duração, variando conforme a época do plantio (Tabela 6), sendo maior ou menor a intensidade dependendo da espécie. Este 
caráter mostrou variação entre as espécies e dentro de cada espécie, em diferentes épocas do ano, embora tenha sido observado que a intensidade de floração ocorrida em todas as espécies, coincidiu com as plantas germinadas em novembro, e, cujo pico de floração máxima aconteceu após o período de maior precipitação de chuvas, ocorrido nos meses de dezembro, janeiro e fevereiro. Uma prova disto, são as plantas que semeadas em abril, tiveram sua segunda floração no mesmo período das espécies semeadas em novembro.

A época e a duração do ciclo de florescimento são fatores importantes na biologia da reprodução pois indicam maior ou menor isolamento reprodutivo que ocorre entre espécies pertencentes a um mesmo gênero. Entre espécies cujos ciclos de florescimento diferem quanto a época não pode ocorrer cruzamento natural, pois existe entre elas uma barreira sazonal. Porém, o mesmo não ocorre entre espécies cujos ciclos de florescimento coincidem, pois os mesmos favorecem ocorrênciade cruzamentos naturais.

5.3. Relação: nūmero de ōvulos por ovārio com nūmero de sementes por vagem

o nümero de óvulos por ovário, é um caráter mui to interessante, pois fornece uma previsão da quantidade de se 
mentes que vai ser produzida, concordando com DATTEEE

quando afirmou que o número de óvulos por ovário é potencialmente o limite da produção de sementes de uma flor, como também pode indicar a presença de fatores que impedem o desenvolvimento de uma porcentagem de óvulos em algumas espécies, como acontece em plantas do gênero Medicago.

Nas cinco espēcies de Centrosema (DC.) Benth. estudadas, comparando as médias do nümero de óvulos por ovärio, tanto na fase de botão como na fase deflor aberta, com a média de sementes por vagem (Tabelas 8 e 9), a porcentagem de óvulos que são perdidos é relativamente baixa na maioria das espécies, sendo a mais alta ocorrência de perda de óvulos, em média por ovário, constatada em C. pubescens Benth. 6 , e 4 em C. virginianum (L.) Benth. Porém tal perda parece ser compensada pelo elevado nümero de sementes viáveis, pois em $C$. pubes cens Benth. a porcentagem chegou a $91,34 \%$ e em C. virginianum (L.) Benth. $88,8 \%$.

As cinco espécies estudadas, alocaram uma grande parte de sua energia, na produção de sementes, garantindo assim, maior nümero de indivíduos que serão produzidos na prōxima geração. Assumindo a teoria dos estrategistas $r$ e $k$, as espēcies apresentaram um equilíbrio para as duas estratégias, pois ocorreu uma distribuição uniforme de energia tanto para a parte vegetativa como para a parte reprodutiva. 
5.4. Viabilidade do pólen

A viabilidade do pólen (Tabela 10) detectada pelo emprego do "Carmin Acético", mostrou ser bastante elevada, nas cinco espécies estudadas, sendo a mais alta porcentagem en contrada no C. brasilianum (L.) Benth., com 99,49\%, e, a mais baixa no C. pubescens Benth. com $93,66 \%$.

As observações feitas em anteras, concordaram com as observações feitas por BLONDON et alii (1981) quando correlacionaram a porcentagem de pólen fértil com a quantidade de pólen produzido por flor, concluindo que existe uma correla ção entre grãos de pólen produzidos por flor com a quantidade de pölen viável. Na realidade, nas espécies analisadas as que apresentaram menor número de grãos de pölen foram aquelas que apresentaram porcentagem mais alta de viabilidade, foi o caso de C. brasilianum (L.) Benth. e C. virginianum (L.) Benth.

Comparando as Tabelas 8,9 e 10 , os dados concordaram com a afirmação de KRESS (1981), que nas angiospermas a quantidade de grãos de pölen e o nümero de óvulos por ovario, refletem a quantidade de sementes que se desenvolvem, exis tindo portanto uma relação entre número de grãos de pólen e o número de óvulos por ovärio. 
5.5. Germinação do póten em meio de cultura

Referente aos estudos de germinação do pólen em meio de cultura, podemos observar pelos dados das Tabelas 11.1, $11.2,11.3$ e 11.4 , que ocorreu uma desuniformidade bastante as centuada entre e dentro das espécies em função dos meios de cultura usados e da temperatura.

Na tentativa de descobrir qual o meio mais favo rável à germinação do pólen em meio de cultura, entre 4 ensaios efetuados, usando 14 meios contendo diferentes concentra ções de sacarose - agar e substância estigmática, apenas em 4 meios obtivemos respostas das 5 espécies testadas.

Quanto ao fator temperatura, todas as espécies responderam com uma maior germinação de pólen quando as temperatudas foram variáveis de 24 a $28^{\circ} \mathrm{C}$, com exceção de C. brasí lianum (L.) Benth. que em meio de cultura contendo sacarose ( 1,0 grama), agar ( 1,0 grama) e substância estigmática, mostrou maior preferência para germinar seu pólen, quando mantido em temperatura constante de $25^{\circ}$. C.

o meio de cultura que mostrou ser mais favoravel, entre todos os meios testados, foi aquele que conteve sacarose (1,0 grama), agar (1,0 grama) e substância estigmática, com exceção de C. vexillatum Benth., que teve resposta mais baixa do que em meio contendo apenas sacarose $(0,5$ gramas $)$ e 
agar $(1,0$ grama $)$.

Diante dos dados obtidos, podemos concordar com STANLEY e LINSKENS (1974) e PRAKASH e CHAN (1976) quando afirmaram que värios são os fatores que influenciam no crescimento do pölen "in vitro": tipos de pölen, tempo de coleta, estação do ano, método de coleta, secreção estigmätica, substâncias químicas produzidas pelo óvulo que desencadeiam a formação do tubó polínico.

Como todas as espécies devem ter seu meio ótimo que induz o desencädeamento do processo da germinação do pölen, acreditamos que o principal fator do insucesso tenha sido, a falta de conhecimento sobre um meio mais eficiente que as espécies exigem para germinar seu pölen. Talvez tenha faltado o elemento(s) químico(s) estimulante(s) da germinação, a exemplo do que acontece em Nymphaea spp., que para ocorrer a germinação do pölen deve ser adicionado ao meio o elemento boro, ou PEG-400 (Schmuchker, 1932 citado em STANLEY e LINSKINS, $1974)$.

Tambēm pode ter ocorrido uma quebra nas vias me tabölicas, inibindo a produção de hormónios que controlam o de senvolvimento normal do tubo polínico, no momento da coleta do pólen. Enfim, uma série de outros fatores poderiam ser citados como possíveis inibidores da germinação do pólen "in vitro", nas espëcies de Centrosema (DC.) Benth. 
Diante do fato, sugerimos que vários outros tes tes sejam efetuados, com o objetivo de encontrar o meiótimo para cada espécie, ou talvez chegar a conclusão de que pólen das 5 espécies de Centrosema ( $D C$. ) Benth. estudadas, não germi na "in vitro", como acontece com algumas espécies dos gêneros Gossypium e Pennisetum, segundo STANLEY e LINSKENS (1974).

\subsection{Modo de reprodução}

As respostas das espēcies ao isolamento dos botões com a finalidade de observar o desenvolvimento normal dos mesmos até formar vagens, foi bastante variada entre as espécies. Enquanto que, em C. vexillatum Benth. e C. pascuorum (Mart.) Benth. foram desenvolvidas 24 e 23 vagens respectivamente em 25 botões isolados, sendo considerada uma porcentagem bastante alta, nas espécies C. pubescens Benth., C. brasilianum (L.) Benth. e C. virginianum (L.) Benth. ocorreu uma porcentagem significativamente baixa na formação de vagens, sendo formadas apenas 5,10 e 11 vagens respectivamente de 25,50 e 50 botões isolados.

os dados das três ültimas espécies citadas, indicaram a presença de um ou mais fatores, com uma atuação bastante expressiva, impedindo o desenvolvimento das vagens. Es tes fatores poderão ter sido genéticos, ambientais ou fisioló- 
gicos.

No i solamento dos botões, em saquinhos, poderá ter ocorrido a formação de um microclima diferente, tornando- se a causa da não formação das vagens, devido a mudança das condições ambientais. Estas novas condições do ambiente criaram fatores inibitórios bloqueando passos metabólicos no desen volvimento normal da vagem, pelo fato destas espécies apresentarem maior sensibilidade aos fatores citados.

o fator de ordem fisiológica pode estar relacio nado à polinização. Embora estas plantas sejam consideradas autögamas, não significa que não necessitem de algum agente ex terno para ocorrer a autopolinização. ARROYo (1981) observou que o sucesso evolutivo das leguminosas deve-se em grande parte a modificações biológicas reprodutivas e entre estas modifi cações salientou o mecanismo da polinização e suas implicações comportamentais em.relação aos diferentes sistemas desenvolvidos. E, as modificações que ocorrem são manipuladas pela sele ção favorecendo vetores especializados.

Como foi observada a presença de insetos do g $\widehat{e}-$ nero Bombus sp. com bastante frequência nas flores, para sugar o nëctar, estes poderão ser agentes causadores da autopolinização, destas plantas, através de uma pressão que exercem na base dos órgãos sexuais, quando pousam na flor. HutTon (1960) 
mostrou que, é necessário um mecanismo eficiente na transferên cia do pólen das anteras para o estígma do qual depende a quan tidade de sementes que se formam.

E interessante acrescentar que nas observações feitas, referentes a visita de insetos nas flores, durante 15 dias, foi observada a frequência constante dos insetos do gêne ro Bombus sp: Isto sugere a ocorrência de uma taxa de fecundação cruzada, sendo os insetos citados os responsáveis pela polinização. Observações feitas por watmough (1974) citado em ARROYO (1981) no sul da África, plantas de värios gêneros entre eles de Centrosema (DC.) Benth. são polinizadas por insetos do gênero xylocopa.

HUTTON (1960) afirmou que em C. pubescens Benth. a polinização ocorre de 4 a 5 horas antes da antese da flor; classificando-a como planta cleistógama. Embora nesta espécie e na espécie C. pascuorum (Mart.) Benth., foram observadas tam bém flores cleistógamas, isto é vagens se desenvolveram sem ocorrer a abertura do botãofloral, indicando a ocorrência de autofecundação na fase de botão, este fato não exclui a possibilidade de ocorrer nestas espécies uma pequena taxa de fecundação cruzada, já que nestas plantas a maior parte das flores abrem normalmente.

BURKART (19.52) observou que na polinização das leguminosas Papilionoideae, ocorre o mecanismo da alavanca, e 
as anteras depositam o pólen no corpo do inseto e o estígma re cebe do mesmo modo o pólen estranho. Ao retirar-se o inseto, a asa e a quilha voltam a posição normal cobrindo novamente os órgãos sexuais. Nossas observações, nas flores das plantas e tudadas, divergem das observações de BURKART (1952) quanto a maneira de pouso do inseto sobre a flor. Para BURKART o inseto pousa na asa e na quilha, as mesmas abaixam aparecendo então as anteras e o estígma. Nas flores que observamos, o inseto pousa no estandarte, pressiona o conjuntofloral asa e quilha para cima, afim de sugar o néctar. Sob esta pressão a quilha abre na parte distal terminal à inserção no receptácu10, e, deixa sair, as anteras e o estígma. Ao retirar-se, o in seto carrega pólen no seu dorso.

A divergência quanto ao modo de polinização, se gundo LEVIN (L971) e ARROYO (1981), é comum ser encontrada entre Leguminosae pois no desenvolvimento dos mecanismos de poli nização, ocorrem muitas variantes, entre as tribos e entre os prōprios gêneros e espécies de leguminosas, sendo constância floral e especificidade do polinizador, respostas plásticas su jeitas a modificações impostas por. circunstâncias imediatas. 
6. CONCLUSOEES

Os resultados obtidos, analisados e discutidos na presente pesquisa, permitiram as seguintes conclusões:

a. na anālise qualitativa para os caracteres morfológicos da flor, suas partes constituintes: cálice, corola, androceu e gineceu, na sua constituição, seguem os padrões característicos da sub-família Papilionoideae;

b. ocorre variação no tamanho dos 22 caracteres mensuráveis, no nūmero de flores por inflorescência, no nūmero de lacínios do cálice, na cor das flores e na forma dos grãos de pólen, entre as cinco espécies do gēnero centrosema (DC.) Benth., estudadas;

c. nümero de lacínios do cälice e nümero de ca- 
racteres mensurāveis, cujas médias apresentaram o mesmo valor, são indicações de que as espécies C. brasilianum (L.) Benth., C. virginianum (L.) Benth., e C. pascuorum (Mart.) Benth., possuem maior relacionamento filogenético entre si e maior grau de divergência com $C$. pubescens Benth. e C. vexillatum (Mart.) Benth., que por sua vez, guardam entre si, certo grau de proximidade filogenética;

d. o período mais favorável ao florescimento das cinco espëcies de Centrosema (DC.) Benth., se extende de janeiro à junho;

e. o número de óvulos por ováriofornece uma previsão do nümero de sementes que se desenvolvem por vagem;

f. comparando a perda de óvulos por ovário com a porcentagem de sementes viáveis, parece ocorrer uma compen sação pois, esta última foi bastante alta em todas as espëcies;

g. a viabilidade do pólen foi alta em todas as espécies, existindo uma relação inversa entre grãos de pólen produzidos e quantidade de pólen viável, pois as espécies que apresentaram menor número de grãos de pólen, apresentarammior porcentagem de viabilidade; 
.86

h. novos testes, empregando diferentes meios de cultura, deverão ser efetuados, na tentativa de descobrir o meio adequado a cada espécie, para germinação do pólen "in ví tro";

i. nos botões das flores de C.pubescens Benth., C. brasilianum (L.) Benth. e C. virginianum (L.) Benth., devem existir um ou mais fatores que inibem a formação das vagens, manifestando-se em condições especiais. Estes fatôres poderão ser genéticos, fisiológicos ou ambientais;

j. a morfologia das flores típica das Papilionoideae, indica serem predominantemente autofecundantes;

k. a presença constante de insetos do gênero Bombus sp. na flor e o seu comportamento, sugerem seremagentes que provocam a autofecundação nas flores e a existência de certa taxa de cruzamento. 
7. LITERATURA CITADA

ALCÂNTARA, P.B.; V. de G.B. ALCÂNTARA; J.M.M. SIGRIST e F.S. PULZ, 1977. Caracterização de cinco introduções de Centrosema pubescens. Bolm. Industr. Anim., Nova odessa, SP., $34(1): 103-111$.

ALCÂNTARA, P.B. e G. BUfARAH, 1979. Plantas Forrageiras: Graminias e Leguminosas. São Paulo, Nobel, 150 p.

ALLARD, R.W., 1971. Principios do melhoramento genético das plantas. Agência Norte-Americana para o Desenvolvimento In ternacional - USAID - Rio de Janeiro, 381 p.

AL - MUKhTAR, F., 1981. Genetics of ovule numbers por pod, flowering, and association of several traits in Phaseolus vulgaris $L$. crosses. Dissertation Abstracts International, 41(9): 3306 B - 3307 B - Neb. Univ., Lincoln, USA. In: Plant breeding abstracts, 52 (2): 152, February. 1982. (Abstracts, 1719 ) 
ARROYO, K.M.T., 1981. Breeding systems and pollination

biology in Leguminosae. In: R.M. POLHLL \& P.H. RAVEN. Advances in legume Systematic, 2: 722-769.

BANK OF NEW SOUTH WALES, 1965. Pasture legumes and grasses: a guide to the identification and use of selected for pasture Improvement. Sydney, $76 \mathrm{p}$.

BARBOSA - FEVEREIRO, V.P., 1977. Centrosema (A.P. De Candolle) Benthan do Brasil - Leguminosae - Faboideae. Rodriguésia, revista do Jardim Botānico XXIX (42): 159-202.

BARNES, D.K. e R.W. CLEVELAND, 1963. Inheritance of ovule number in diploide alfalfa. Crop Science, 3: 499-504.

BenthaM, G., 1859. Leguminosae. In: Martius, K.F.P. De Flora Brasiziensis. Weiheim - Cramer, 15(1): 124-134. (Ed. Nova, $1976)$

BENSON, L., 1962. Plant taxonomy. Methods and Principles. The Ronald Press Company, New York. 494 p.

BLONDON, F.; M. GHESQUIERE e P. GUY, 1981. Variation de 1 a fertilité pollinique en fonction de la température chez luzernes de différentes origines (Medicago sativa L. et Medicago media Pers.) Agronomie, 1(5): 383-388. In: Plant breeding abstracts, 52(1): 44. January, 1982. (Abstracts, $498)$. 
BOGDAN, A.V., 1977. Tropical pasture and fodder plants:

Grasses and Zegumes. London and New York, Logman 330-335.

BOUFEIL, E., 1947. Biologie Ecologie et selection de L'arachide au sénégal. Buzzetin Scientifique no 1. Ministére de Za France. D'outre Mer.

BOWEN, G.D., 1959. Field studies on nodulation and growth of Centrosema pubescens Benth. Queensz. J.Agric. Sci., Brisbane, 16(4): 253-265.

BURKART, A., 1952. Las leguminosas argentinas sizvestres e cultivadas. ACME AGENCY, Soc. de Resp. Ltda. Suipacha 58, Buenos Aires. 569 p.

CAMERON, D.F., 1970. Townsville lucerne (Stylusanthes humilis): a comparison of introductions from Brazil and Mexico with naturalized ecotypes. In: Proceedings of the XI International Grassland Congress, Queensland, Austrälia, p. $184-187$.

CARLSON, J.B., 1973. Morphology. In: soybeans Improvement, production, and uses. American Society of Agronomy, Inc. Publisher Madison, Wiscosin, USA. 16(2): 17-95.

CENTRO INTERNACIONAL DE AgRiCULTURA TROPICAL, Cali, 1976. Informe Anual: 1976, Cali, Colombia, CIAT, 286 p. 
CLEMENTS, R.J., 1974. Centrosema species. Report CSIRO. Brisbane. p. 75-76.

CLEMENTS, R.J., 1977. Agronomic variation in Centrosema virgi nianum in relation to it's use as a subtropical pasture plants. Austr. J. of Exper. Agric. and Anim. Husb., Victoria, 1 I $(86): 435-444$.

COHEN, D., 1976. The optimal timing of reproduction. The American Naturalist, 110(975): 801-807.

CRONQUIST, A., 1975. Some thoughts on angiosperm phylogeny and taxonomy. Annals of the Missouri Botanical Garden, USA, $\underline{62}(3):$ 517-520. In: Plant breding abstracts, $47(2)$ : 92-93, February, 1977. (Abstracts, 937).

CRUDEN, R.N., 1977. Pollen-ovule ratios: a conservative irdicator of breeding systems in flowering plants. Evolution, $31(1): 32-46$.

DATTEE, Y., 1972. Héréditè quantitative du nombre d'ovules par ovaire dans quelques familles de luzerne cultivae (Medicago sativa I.). Annales de L'amelioration des plants. 22(2): 201-209.

DOKU, E.V., 1976. Grain abortion in soybean. Journal of Agricultural Science, $\underline{9}(1): 49-54$. 
DUCKE, A., 1949. Notas sobre a flora neotrópica II. As leguminosas da Amazônia brasileira, 2 a Ed. Bolm. Técn. Inst. Agron., Norte, Belém, 18: 212-214.

FERGUSON, I.K. e J.J. SKVARLA, 1981. The pollen morphology of the subfamily Papilionoideae (Leguminosae). In: R.M. POLHLL \& P.H. RAVEN. Advances in Legume Systematic, $2: 859-896$.

GRANT, V., 1958. The regulation of recombination in plants. Col. Spring Hard Symp. quant. Biol., 23: 357-363.

GRANT, V., 1963. The origen of adaptation - New York, Columbia University Press. 606 p.

GROF, B., 1970. Interespecific hybridization in Centrosema: Hybrids between C. brasilianum, C. virginianum and C. pubescens. Queenszand J. Agric. Anim. Sci., Brisbane, 27: $385-390$

GROF, B. e W.A.T. HARDING, 1970. Yield attributes of some species and ecotypes of Centrosema in north. Queensland. Queensland J. Agric. Anim. Sci., Brisbane, 27: 237-243.

HONG - QI, Z. e A.F. CORES, 1982. A new medium for pollen germination in vitro. Acta Bol. Neerl. 31(1/2): 113-119. 
HUTTON, E.M., 1960. Flowering and polination in Indigofera spicata, Phaseolus lathyroides, Desmodium uncinatum and some other tropical pasture legumes. Emp. J. Exp. Agric. 28: $235-243$.

HUTTON, E.M., 1970. Australian research in pasture: introduction and breeding. In: Proceedings of the XI International Grasszand Congress, Queenslarid, Australia, p. $1-72$.

HUTTON, E.M., 1976. Selection and breeding tropical pasture plants. Span, London, $19(1): 21-24$.

HUTTON, E.M., 1981. Breeding Centrosema pubescens better adapted to the acid infertile soils of South America. Proceedings of the XIV International Grass land Congress.

JOERGENSEN, P., 1909. Veobachtung uber Blumenbesuch, Biologia, Verbreitung usw. da Bienen von Mendonza. Dentsche Estomor. 1: $53-65, y$ 2: $211-227$.

JOLY; A.B., 1975. Botânica-Introdução à taxonomia vegetal. Companhia Editora Nacional. 2! Ed. São Paulo, 777 p. KILSON, H.U. e R. FRANKE, 1980. (The determination of pollen viability) Zur Bestimmung der lebensfahigkeit von pollen. Archiv. fur Zuchtungsforschung, 10(3): 171-177. In: Plant breeding abstracts, 51(1): 12, Jannuary, 1981 (Abstracts, 22). 
KLEIN, M.; W. KOSERA e B. MICHALIK, 1974. Investigations of the usefulness of various methods for estimation of pollen fertility in carrot. (Daucus carota L.). Buzletim de L'Académie Polonaise des sciences, 22(6): 417-420. In: Plant breeding abstracts, 45(4): 247, April, 1975. (Abstracts, 3133 ).

KRESS, W.J., 1981. Sibling competition and evolution of pollen unit, ovule number, and pollen vector in angiosperms. Systematic Botany, 6(2): 101-112.

KRETSCHMER, A.E. Jr., 1977. Production of annual and perennial tropical legumes in mixtures with pangolagrass and other grasses in Florida. In: Proceedings of the XI Internacional Grasszand congress, Queenszand, Australia, p. 149-153.

LASA, J.M., 1975. (Tetrazolium bromide and pollen viability in sugar beet, (Beta vulgaris L.). Annales de Za Estación Experimental de Auza Dei, 13(1/2): 111-121.

LAWES, D.A., 1972. The development of self-fertile fields Beans. Report of weesh plant breeding, station, p. 163-176. LEVIN, D.A., 1971. The origen of reproductive isolating mechanisms in flowering plants. Taxon, 20(1): 91-113. 
MATTOS, H.B., 1973. Características agronômicas de algumas le guminosas forrageiras de clima tropical. In: Curso de Pós-graduą̧̃o de Nutrifão Animal e Pastagens, disciplina : Manejo e pastagens. Piracicaba, SP., ESALQ/USP, 18 p.

MOGROVEJO-JARAMILLO, E.A., 1981. Comportamento e variabilidade de caracteres agronômicos em populações de Centrosema pu bescens Benth. (Leguminosae). Piracicaba, ESALQ/USP, 116 p. (Tese de Mestrado).

MONTEIRO, W.R., 1980. Estudo da variabilidade e correlações entre caracteres agronômicos em populações de Centrosema pú bescens Benth. Piracicaba, ESALQ/USP, 71 p. (Tese de Mestrado).

NARAYANAN, A. e S.R.K. MURTHY, 1979. Studies on the yield potential of pods in groundnut (Arachis hypogea L.). Indian Agriculturist $23(2): 85-94$.

ORNDUFF, R., 1969. Reproductive biology in relation to systematics. Taxon, 18(2): 121-151.

PRAKASH, N. e Y.Y. CHAN, 1976. Embryology of Glycine max. Phytomorphology. In: International Journal of Plant Morphology, 26(3): 302-309. 
REYES-ZUMETA, H. 1963. Apuntes de Botanica General. Publication Didactica Mimeografiada no 2. Facultad de Agro nomia - Venezuela, 173 p.

RICHARDS, J.A., 1970. Productivity of tropical pastures in the Caribean. In: Proceedings of the XI International Grassland Congress, Queensland, Australia, p. 49-56.

SASTRI, D.C. e K.R. SHIVANNA, 1980. Efficacy of mentor pollen in overcoming intraspecific incompatibility in Petunia, Raphanus and Brassica. Journal of Cytology and Genetics, 15(2): 107-112. In: Plant breeding abstracts, 52(6): 481 , June, 1982. (Abstracts, 5269).

SCHOFIELD, J.L., 1941. Introduced legumes in North Queensland. Queensland Agricultural Journal, Brisbane, 56: 378-388.

SERPA, A., 1971. A influência do meio na permeabilidade das sementes de Centrosema pubescens. Pesq. Agrop. Bras., Ser. Agro. 6: 151-153.

SERPA, A., 1976. Alguns fatores que afetam a velocidade inicial de crescimento em Centrosema sp. In: Anais XIII Reunĩ̃o da Sociedade Brasizeira de Zootecnica, Salvador, p. $316-318$

SERPA, A., 1977. Hibridação interespecífica entre Centrosema pubescens e Centrosema virgirianum. Pesq. Agrop. Bras., Rio de Janeiro, 12: $35-40$. 
SoUto, S.M. e D.E. de LUCAS, 1973. Avaliação premilinar, no período seco de leguminosas forrageiras tropicais. Pesq. Agrop. Bras. Ser. Zootec., 8: 55-59.

STANLEY, F.G. e H.F. LINSKENS, 1974. Polzen Biology, Biochemistry and Managemer.t. Springer - Verlag Berlin Heidelberg New York. Germany. 307 p.

STEBBINS, G.L., 1950. Variation and evolution in plants. Columbia Univ. Press, New York, 643 p.

STRASBURGER, E., 1943. Tratado de Botānica. Manuel Marín Editor, 3. Edición Española - Barcelona, 736 p.

TEITZEL, J.K. e R.L. BURT, 1976. Centrosema pubescens. In: Australia Toxp. Grassed. Brisbane, 10(1): 5-14.

WILLIAMS, R.J., 1964. Plant and introduction. In: Some concepts and methods in sub-tropical pasture research. Commonw Bur. Past. Fla. Crops, Bull. 47, 60-78.

ZHUCHENKO, A.A.; V.G. GRATI; V.K. ANDRYUSHCHENKO; M. I. GRATI a L.I. SAFRONOVA, 1975. Comparative evolution of different methods ed measuring pollen viability in tomatoes. In: Metody selektsii ovoshch. Kul'tur., Kishinev, Moldavian SSR; Stiinca 63 - 70. In: Plant breeding abstracts, $48(2)$ : 158, February, 1978. (Abstracts, 1768). 
.97 .

APENDICE 


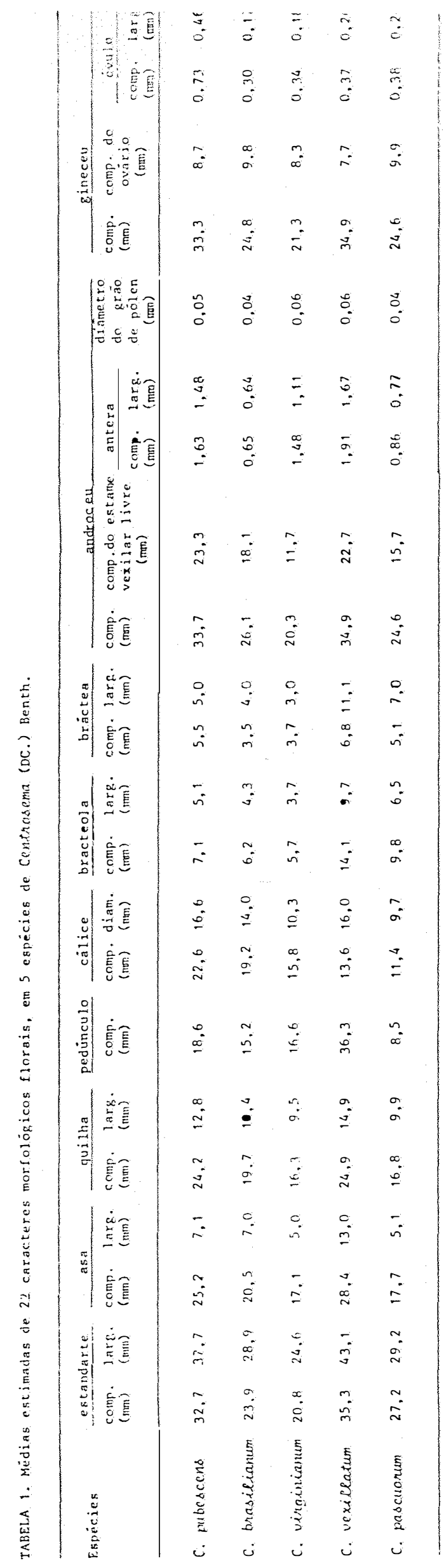




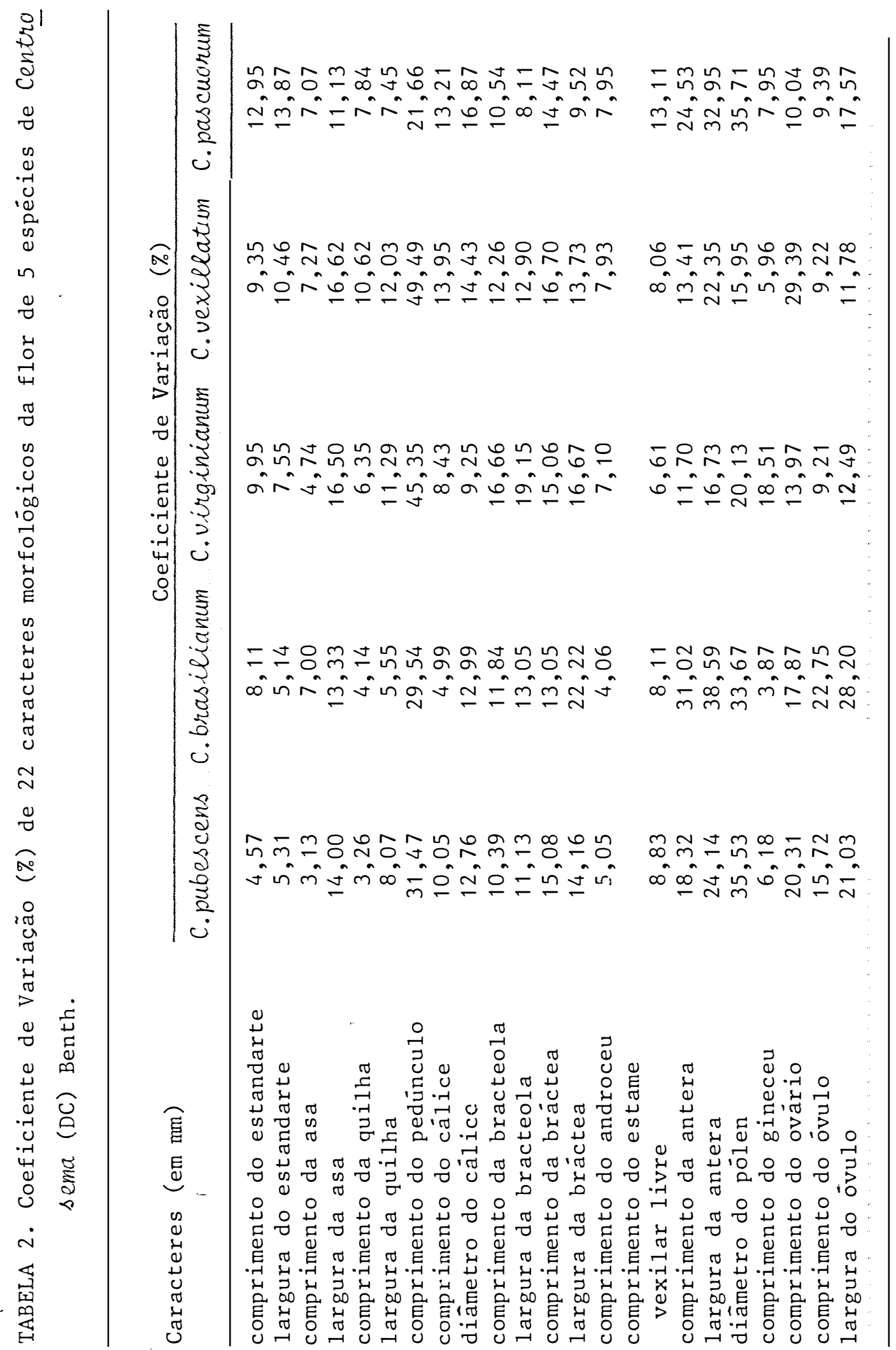


TABELA 3. Resumo da Anälise da Variāncia para os caracteres mensuräveis (mm) analisados, de 5 espécies de Centrosema (DC.) Benth., usando 10 flores por espécie (G.L. de Tratamento $=4$ e G.L: do residuo = 45).

\begin{tabular}{|c|c|c|c|}
\hline Caräter (em mm) & $\mathrm{Q} \cdot \mathrm{M}$. & $\mathrm{F}$ & $\therefore \mathrm{CV} \%$ \\
\hline comprimento do estandarte & 361,67 & $53,11 * *$ & 9,35 \\
\hline largura do estandarte & 563,65 & $59,84 * *$ & 9,39 \\
\hline comprimento da asa & 239,27 & $135,18 * *$ & 6,11 \\
\hline largura da asa & 106,63 & $68,79 * *$ & 16,73 \\
\hline comprimento da quilha & 162,37 & $71,53 * *$ & 7,40 \\
\hline largura da quilha & 52,55 & $40,42 * *$ & 9,91 \\
\hline comprimento do pedúnculo & 1074,73 & $12,44 * *$ & 48,81 \\
\hline comprimento do cälice & 198,52 & $69,66 * *$ & 10,22 \\
\hline diāmetro do cálice & 101,57 & $31,64 * *$ & 13,45 \\
\hline comprimento da bracteola & 120,27 & $98,58 * *$ & 12,87 \\
\hline largura da bracteola & 57,08 & $92,06 * *$ & 13,44 \\
\hline comprimento da bráctea & 23,29 & $39,47 * *$ & 16,09 \\
\hline largura da bráctea & 132,36 & $145,45 * *$ & 15,20 \\
\hline comprimento do androceu & 386,32 & $104,41 * *$ & 6,89 \\
\hline comprimento do estame vexilar livre & 236,80 & $83,67 * *$ & 9,19 \\
\hline comprimento da antera & 2,81 & $52,12 * *$ & 17,80 \\
\hline 1 argura da antera.. & 1,94 & $22,77 * *$ & 25,76 \\
\hline diâmetro do grão de pölen & 0,005 & $29,05 * *$ & 27,10 \\
\hline comprimento do gineceu & 355,37 & $52,11 * *$ & 9,40 \\
\hline comprimento do ovário & 9,12 & $3,34 *$ & 18,65 \\
\hline comprimento do óvulo & 0,31 & $73,46 * *$ & 15,37 \\
\hline 1 argura do óvulo & 0,14 & $49,41 * *$ & 21,10 \\
\hline 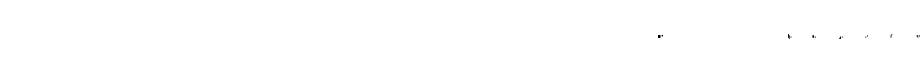 & & & \\
\hline
\end{tabular}




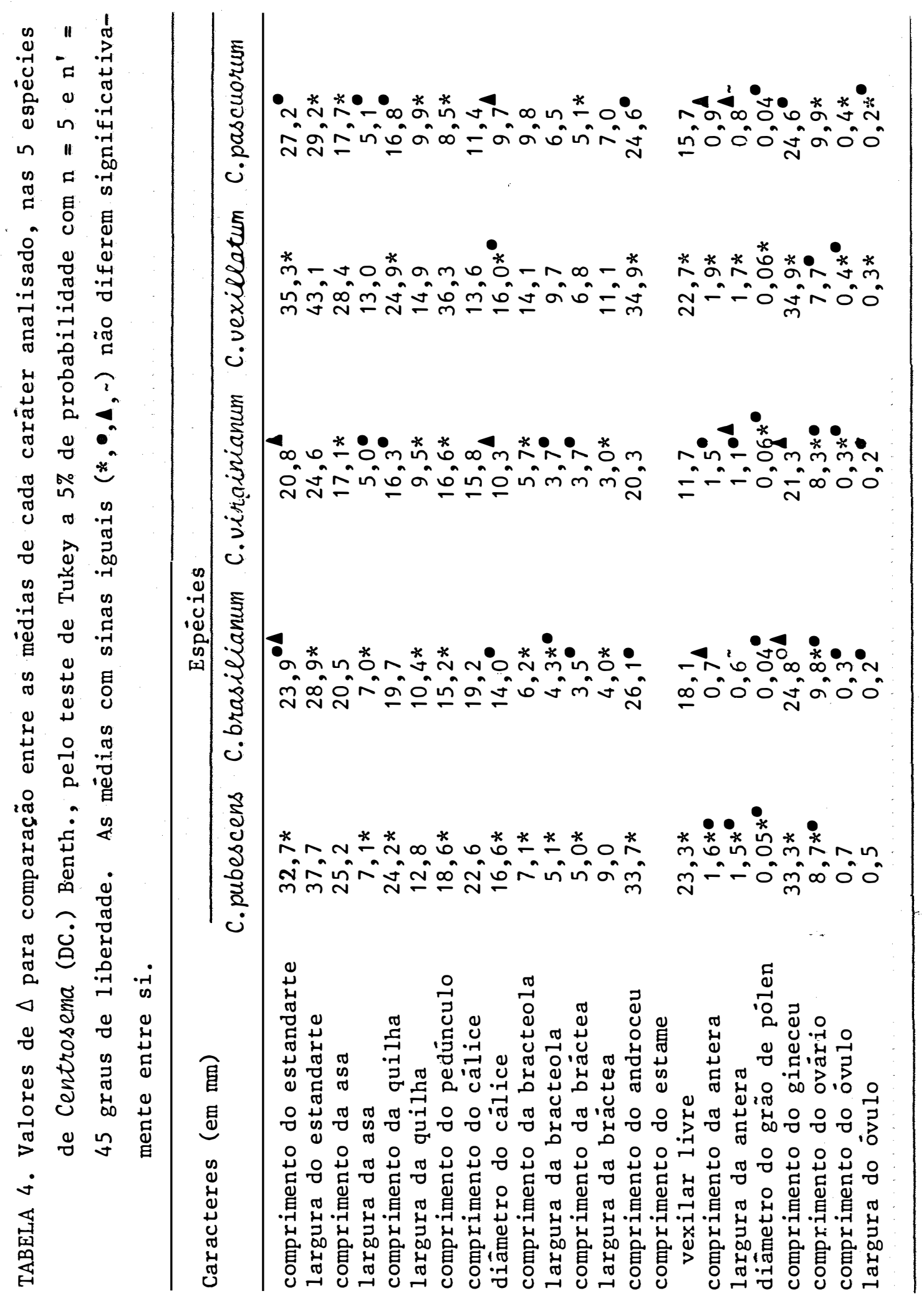




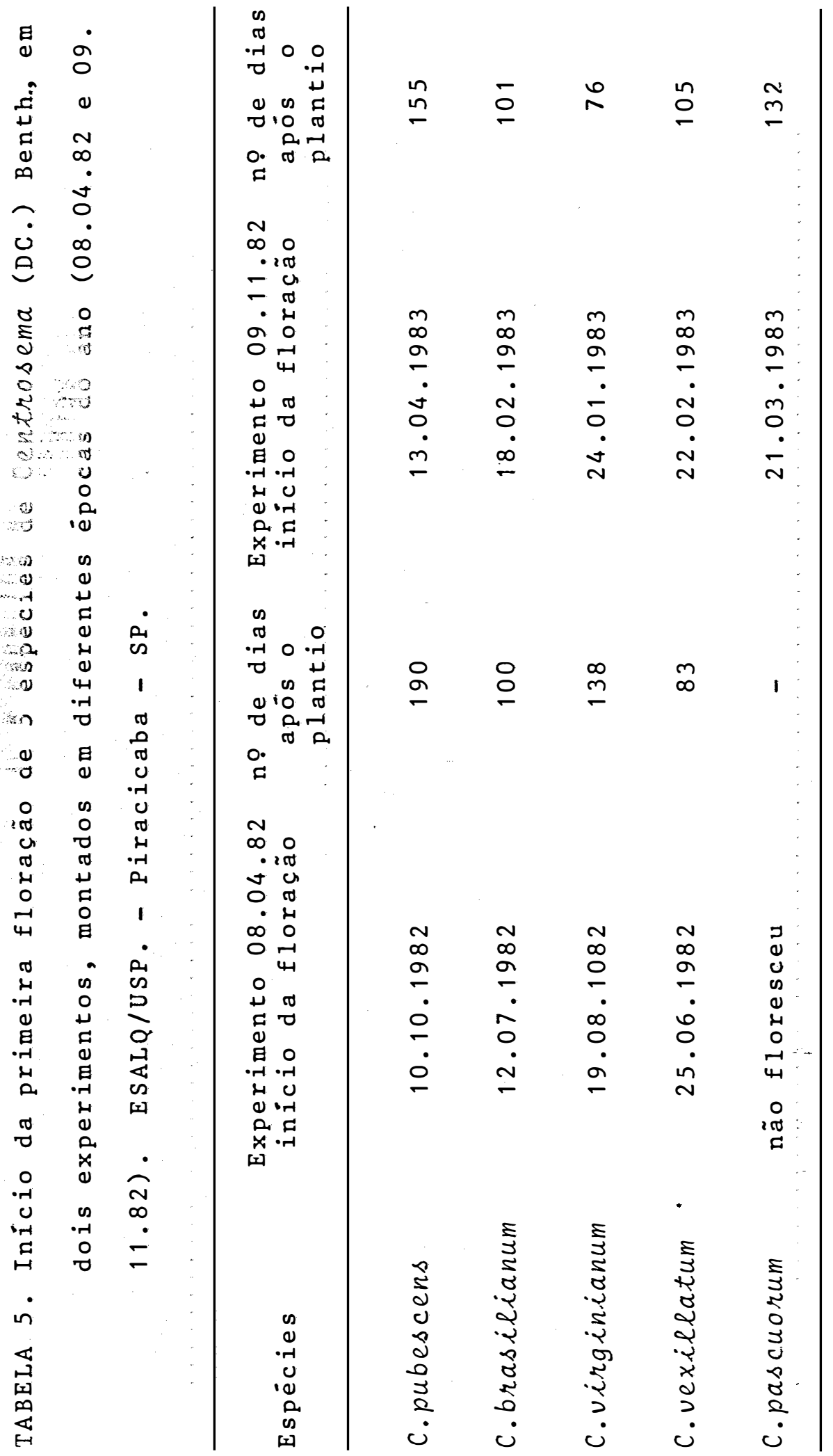


.103.

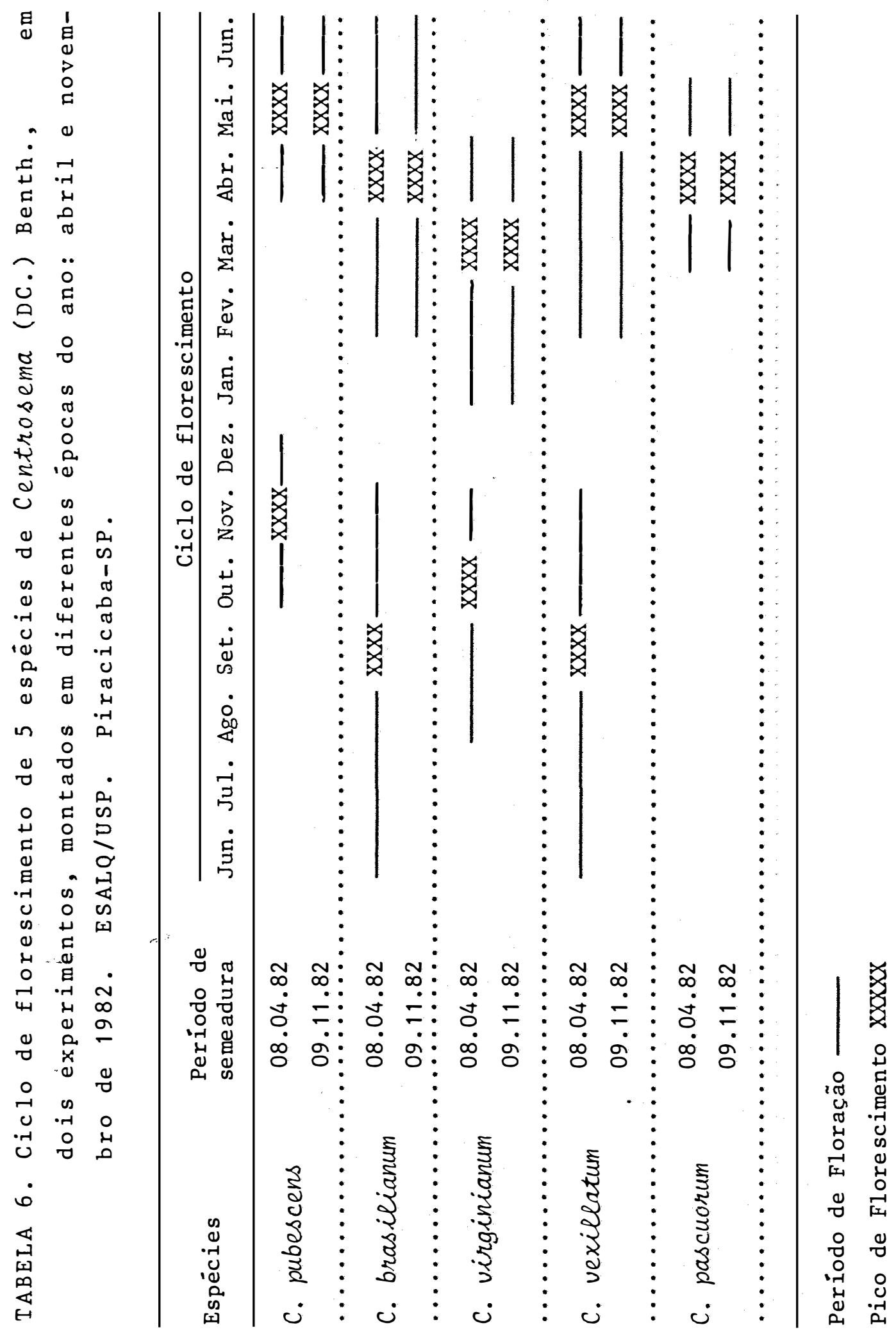




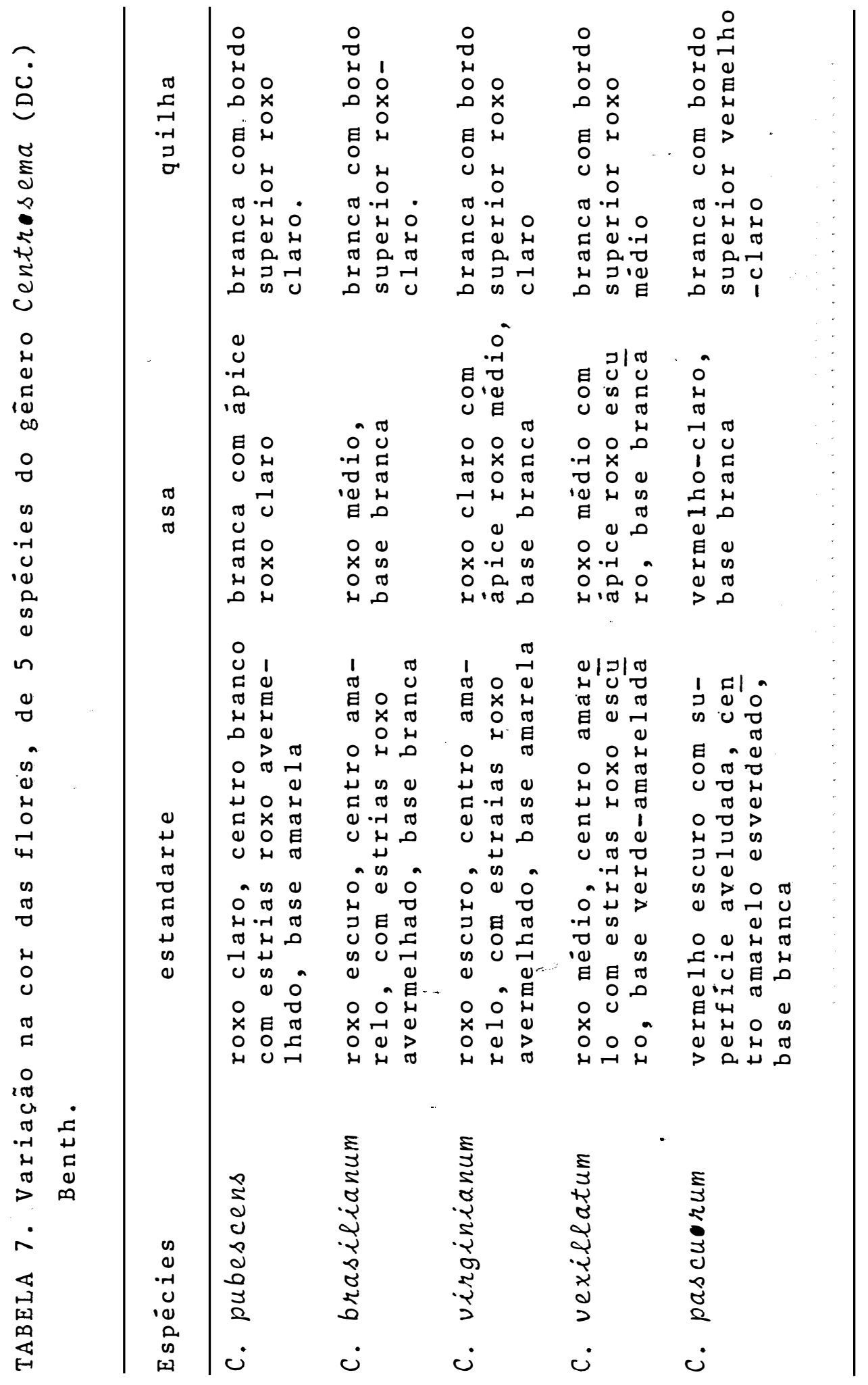


.105.

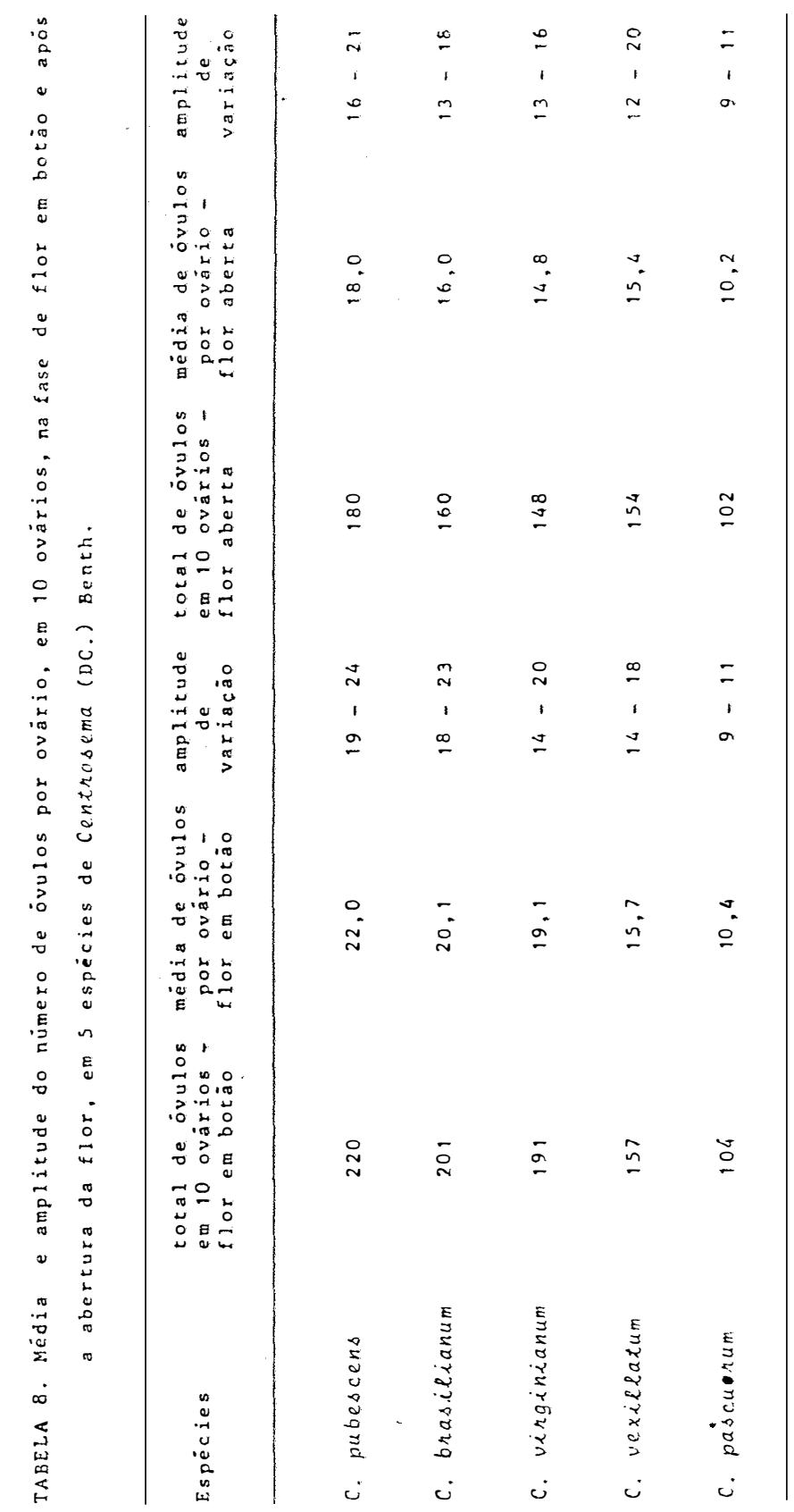


.106.

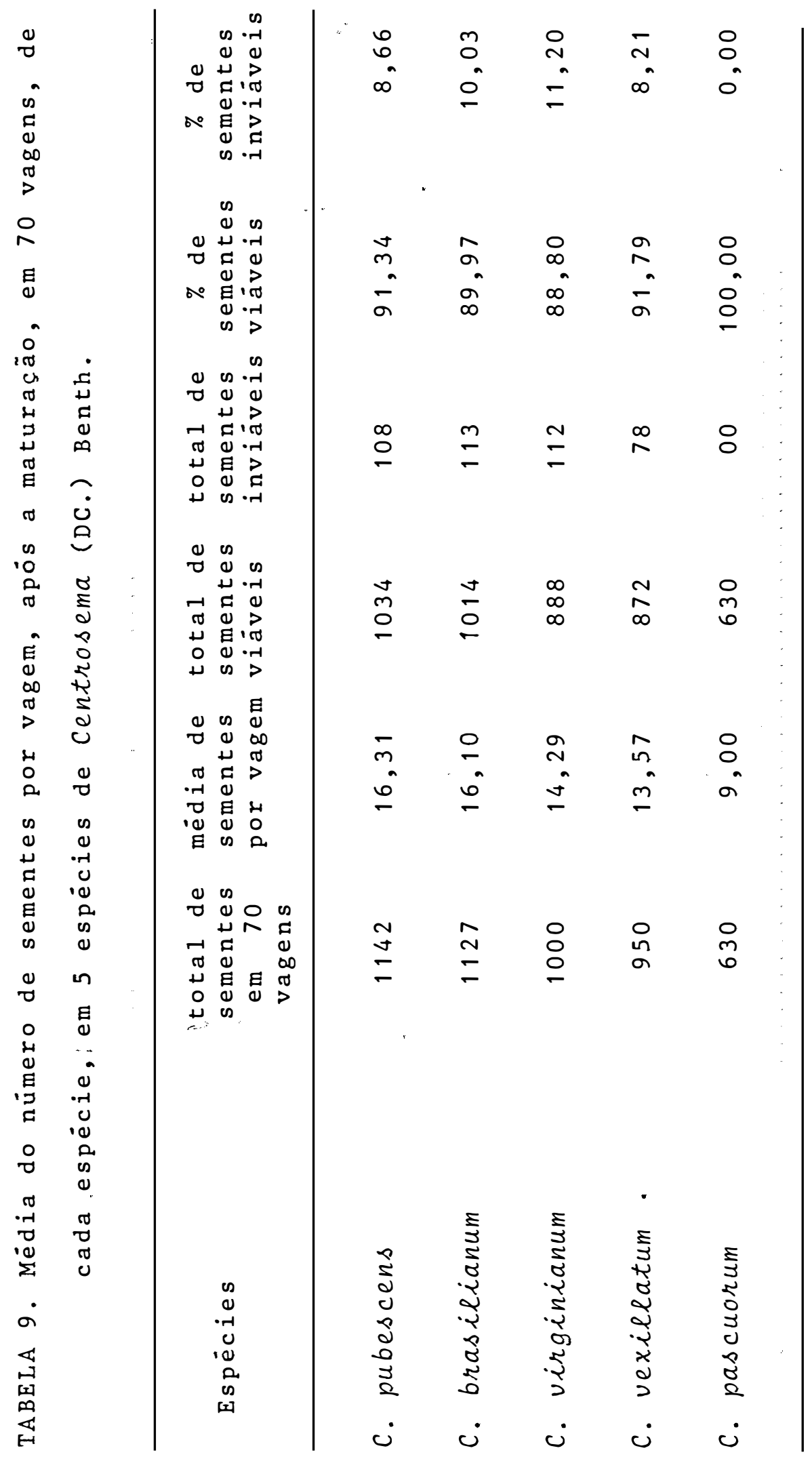


TABELA 10. Viabilidade do pólen de 5 espécies de

(DC.) Benth, coletado em condições de vasos.

Espëcies

Total de grãos de \% de grãos pölem observados de pölen viàveis
\% de grãos de pólen inviáveis
C. pubescens

C. brasilianum

C. virginianum

C. vexillatum

C. pascuorum
4.256

3.308

3.131

3.428

3,792
6,34

93,66

0,51

99,49

98,50

1,50

97,64

2,36

96,18

3,82 
TABELA 11. Porcentagem de germinaço do pölen, em diferentes meios de cultura, de 5 espécies de Centrosema (DC.) Benth., em 2 ensaios de germinacão, durante 48 horas.

11.1. Meio de cultura: sacarose (0,5 gramas) e agar (1,0 grama)

\begin{tabular}{|c|c|c|}
\hline Espécies & $\begin{array}{l}\text { variacào de temperatura } 24 \text { a } 28^{\circ} \mathrm{C} \text {, } \\
\text { porcentagem de germinacào }\end{array}$ & $\begin{array}{l}\text { temperatura constante } 25^{\circ} \mathrm{C} \text {, } \\
\text { porcentagem de germinacào }\end{array}$ \\
\hline C. pubescens Benth. & 1,25 & 0,00 \\
\hline C. brasilianum (L.) Benth. & 0,00 & 0,00 \\
\hline C. virginianum (L.) Benth. & 1.57 & 0,00 \\
\hline C. vexillatum Benth. & 1,00 & 0,00 \\
\hline
\end{tabular}

11.2. Meio de cultura: sacàrose (0,5 gramas) e agar (1,5 gramas)

\begin{tabular}{|c|c|c|}
\hline Espécies & $\begin{array}{l}\text { variacào de temperatura } 24 \text { a } 28^{\circ} \mathrm{C} \text {, } \\
\text { porcentagem de germinacào }\end{array}$ & $\begin{array}{l}\text { temperatura constante } 25^{\circ} \mathrm{C}, \\
\text { porcentagem de germinacáo }\end{array}$ \\
\hline C. pubescens Benth. & 1,96 & 1,05 \\
\hline C. brasilianum (L.) Benth. & 6,10 & 3,50 \\
\hline C. vinginianum (L.) Benth. & 2,91 & 1,00 \\
\hline C. vexillatum Benth. & 6,25 & 6,32 \\
\hline C. pascuorum (M.) Benth. & 10,70 & 0,03 \\
\hline
\end{tabular}

11.3. Meio de cultura: sacarose (0,5 gramas) e agar (2,0 gramas)

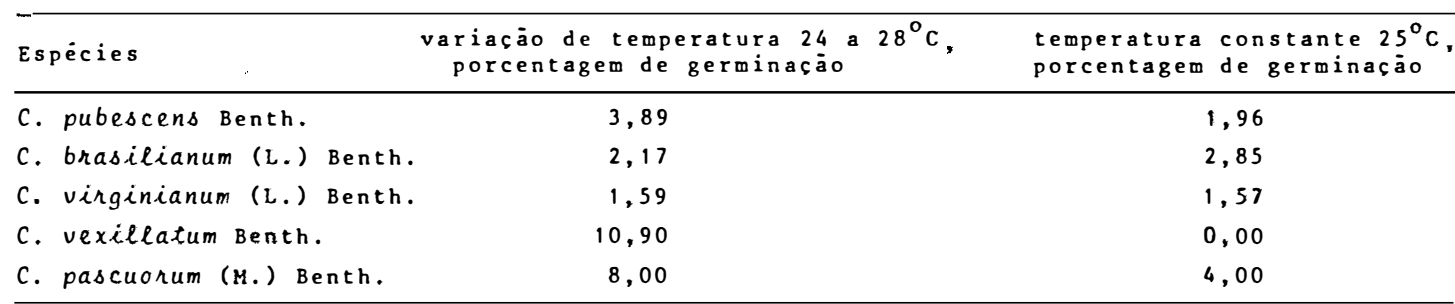

11.4. Meio de cultura: sacarose (1,0 grama), agar (1,0 grama) e substäncia estigmätica

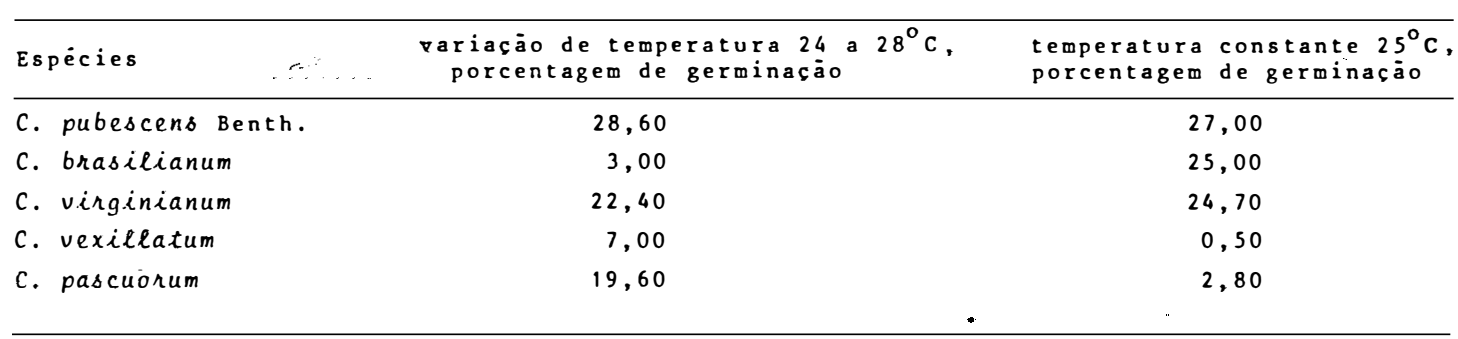


TABELA 12. Nümero de botões isolados que continuaram o desenvolvimento normal até a formação da vagem, em 5 es pécies de Centrosema (DC.) Benth.

\begin{tabular}{|c|c|c|c|}
\hline Espécies & $\begin{array}{l}\text { no de } \\
\text { botões } \\
\text { isola- } \\
\text { dos }\end{array}$ & $\begin{array}{l}\text { no de vagens que } \\
\text { chegaram a } \\
\text { maturação }\end{array}$ & $\begin{array}{c}\text { \% de vagens que } \\
\text { chegaram a } \\
\text { maturação }\end{array}$ \\
\hline
\end{tabular}

C. pubescens

25

5

20

c. brasilianum

50

10

20

c. virginianum

50

11

22

c. vexillatum

25

24

96

c. pascuorum

25

23

92 


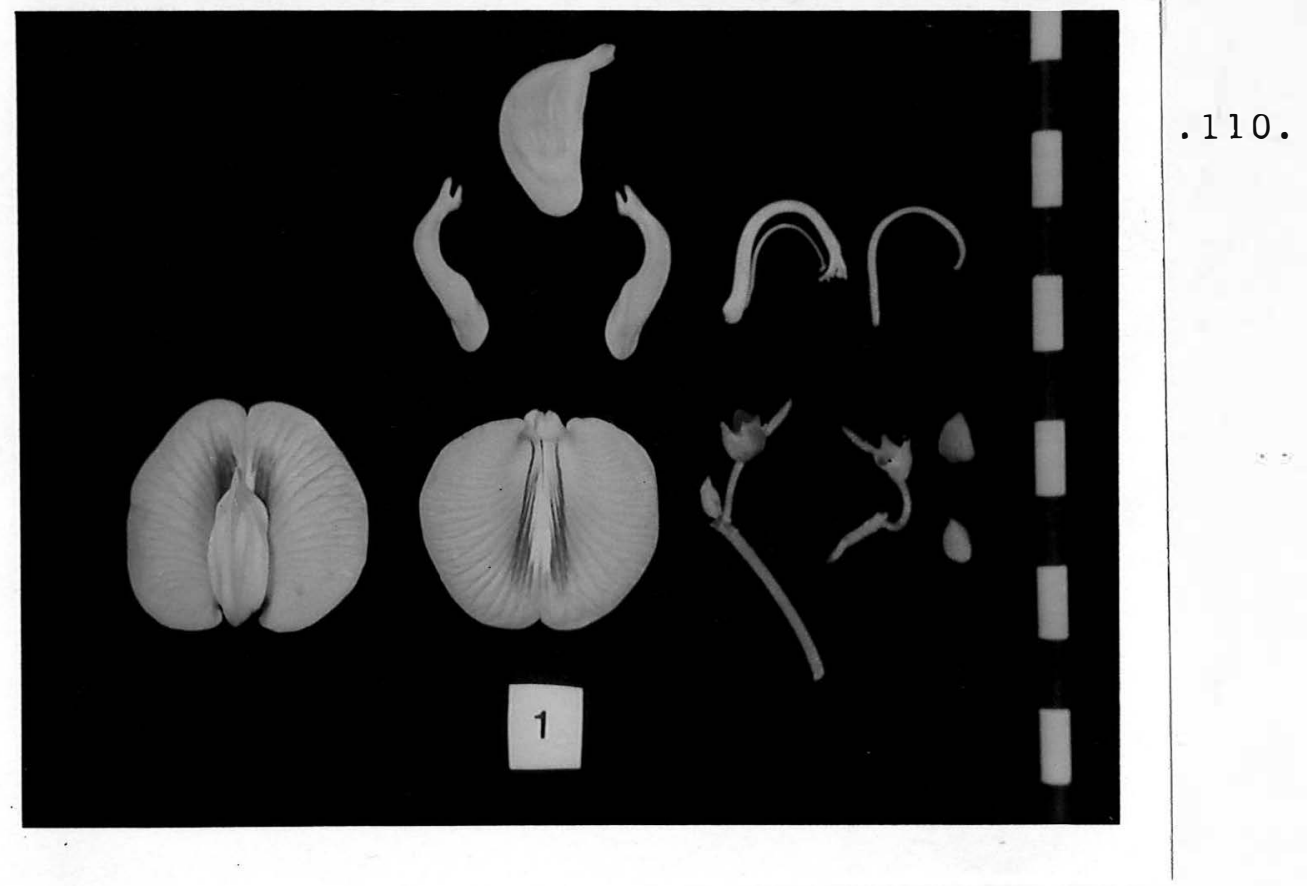

Figura 1. C. pubescens Benth.: Flor; estandarte; asas; quilha; androceu; gineceu; cálice combracteolas, unido ao pedicelo, bráctea e pedúnculo; cálice; bracteola; brāctea.

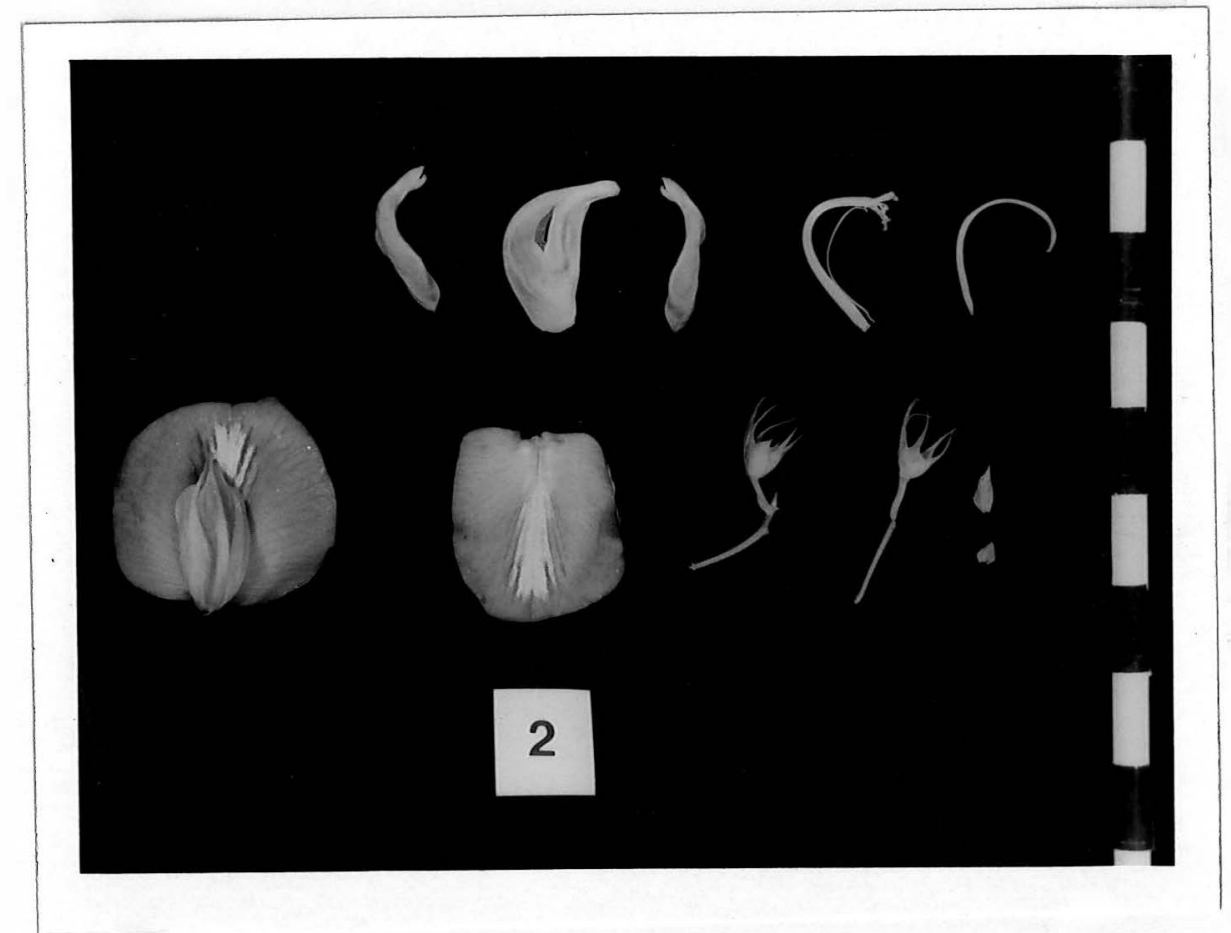

Figura 2. C. brasilianum (L.) Benth.: flor; estandarte; as as; quilha; androceu; gineceu; cálice com bracteolas, unido ao pedicelo, brāctea e pedúnculo; cālice; brac teola; bráctea. 


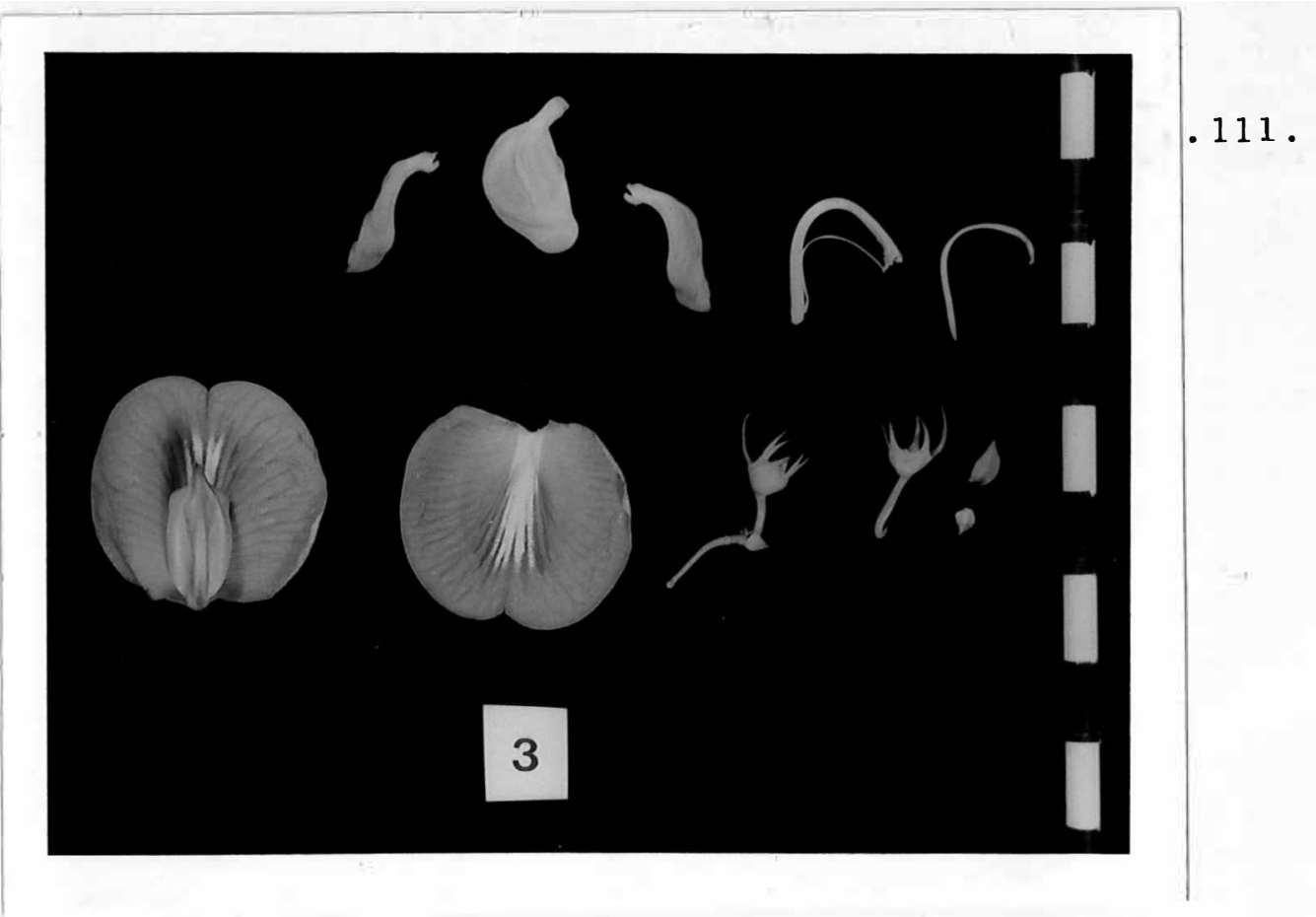

Figura 3. C. virginianum (L.) Benth.: flor; estandarte; asas; quilha; androceu; gineceu; càlice com bracteolas, uni do ao pedicelo, bráctea e pedúnculo; cálice; bracteo 1a; bräctea.

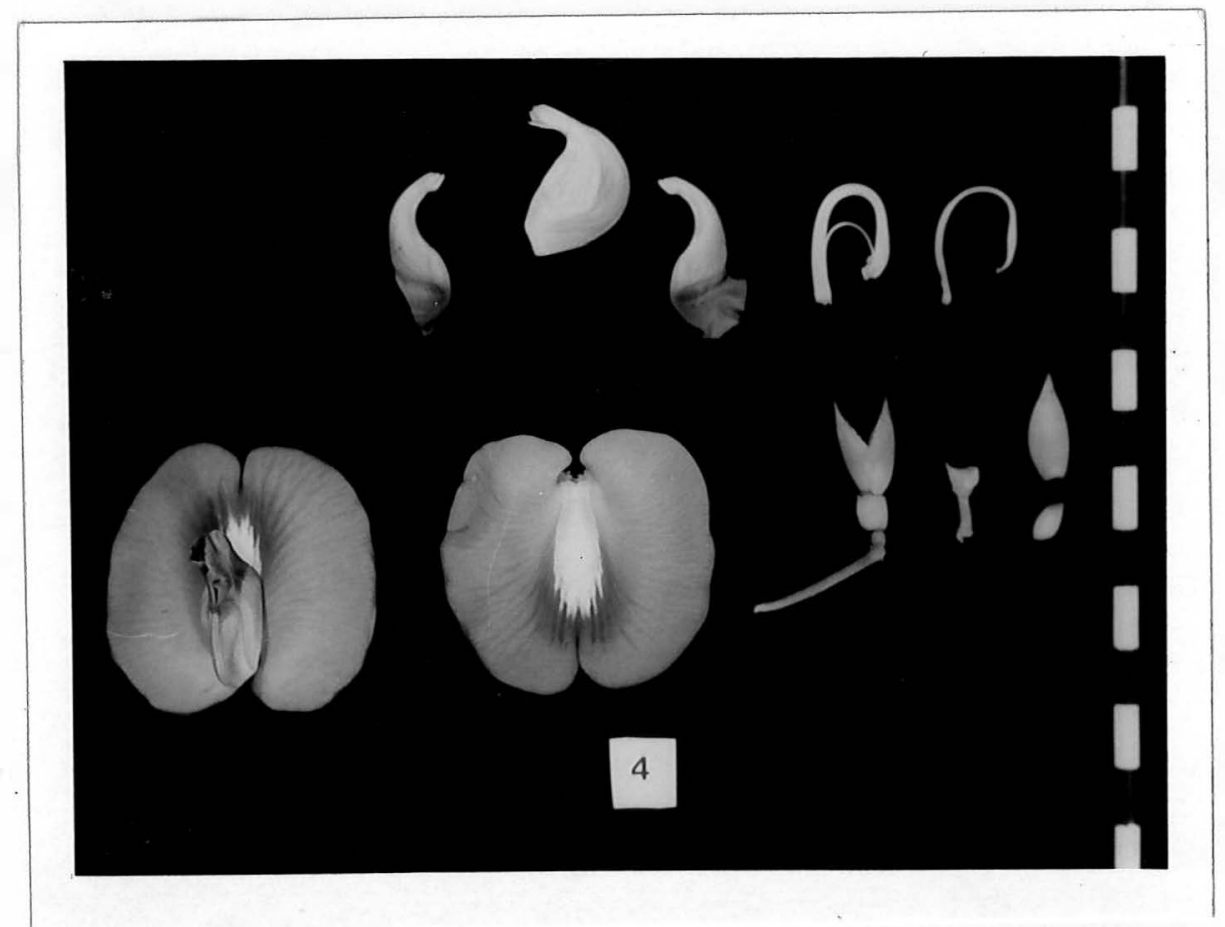

Figura 4. C. vexillatum Benth.: flor; estandarte; asas; qui1ha; androceu; gineceu; cálice combracteolas, unido ao pedicelo, bráctea e pedúnculo; cálice; bracteola; bráctea. 
.112 .

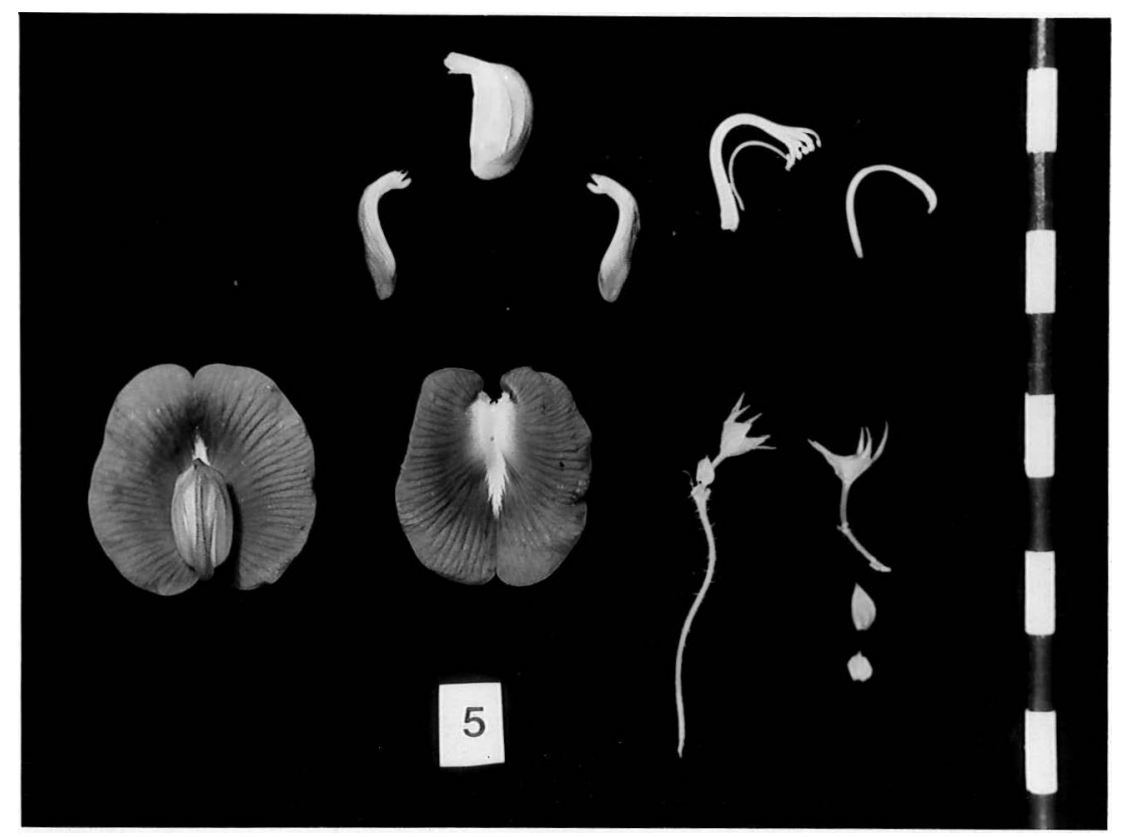

Figura 5. C. pascuorum (Mart.) Benth.: flor; estandarte; asas; quilha; androceu; gineceu; cālice com bracteolas, unido ao pedicelo, bráctea e pedúnculo; cálice; brac teola; bráctea. 


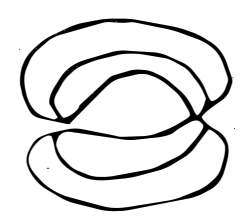

ํㅜㄹ

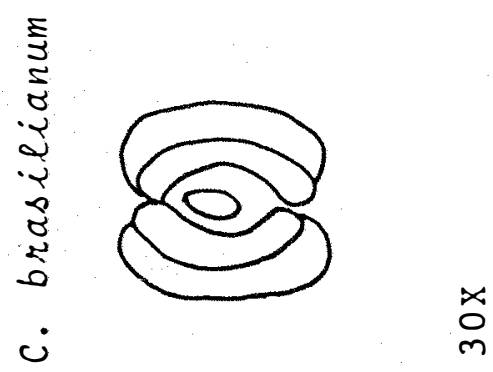

.113.
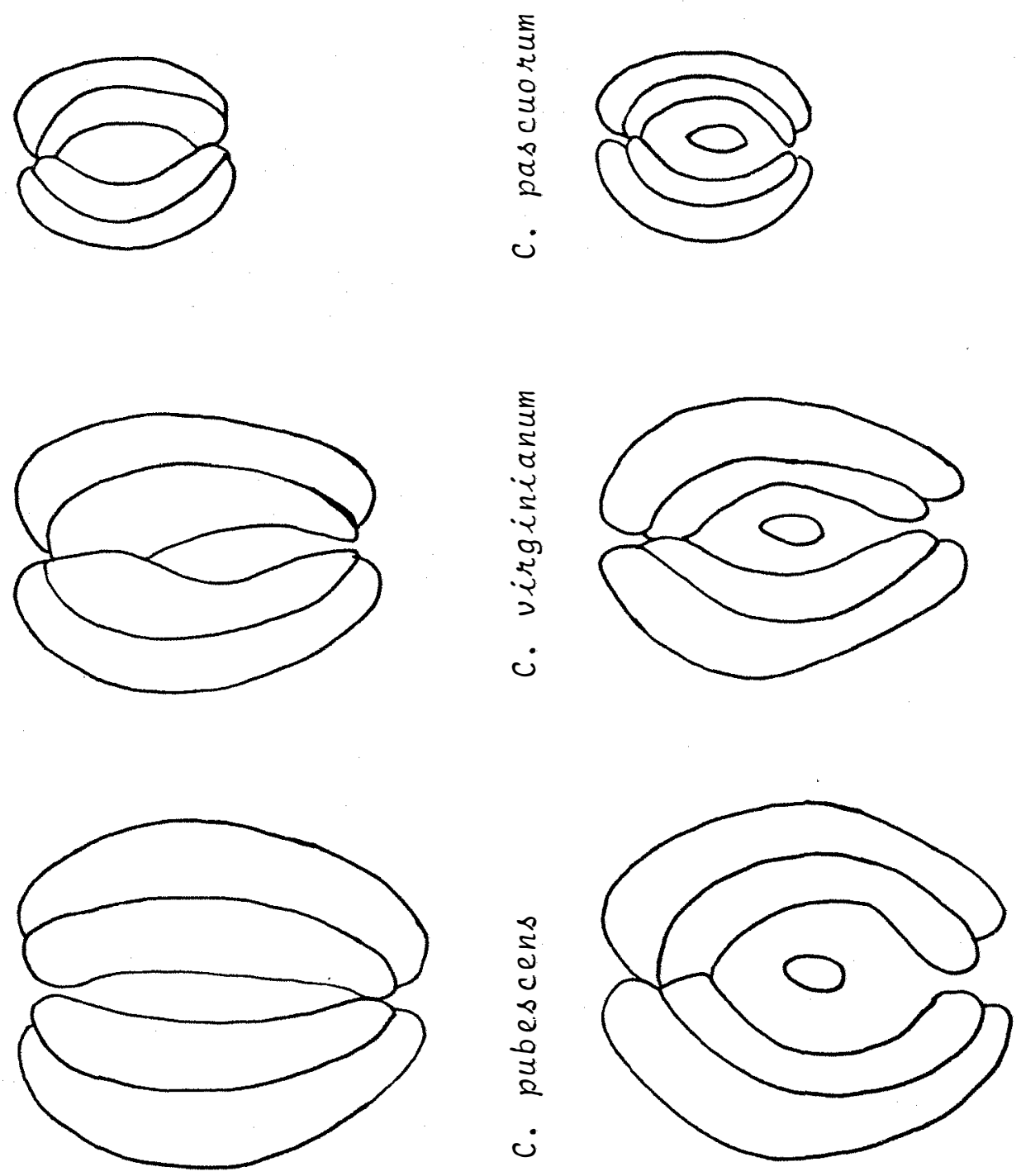

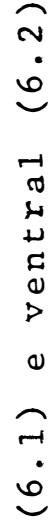
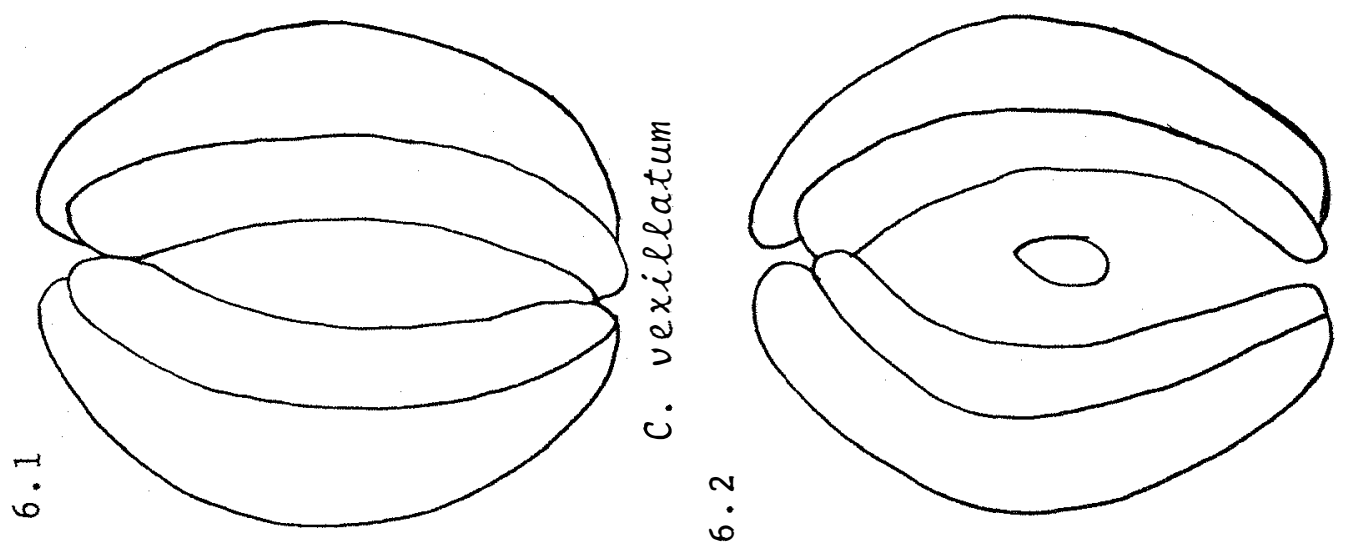

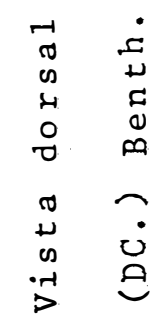



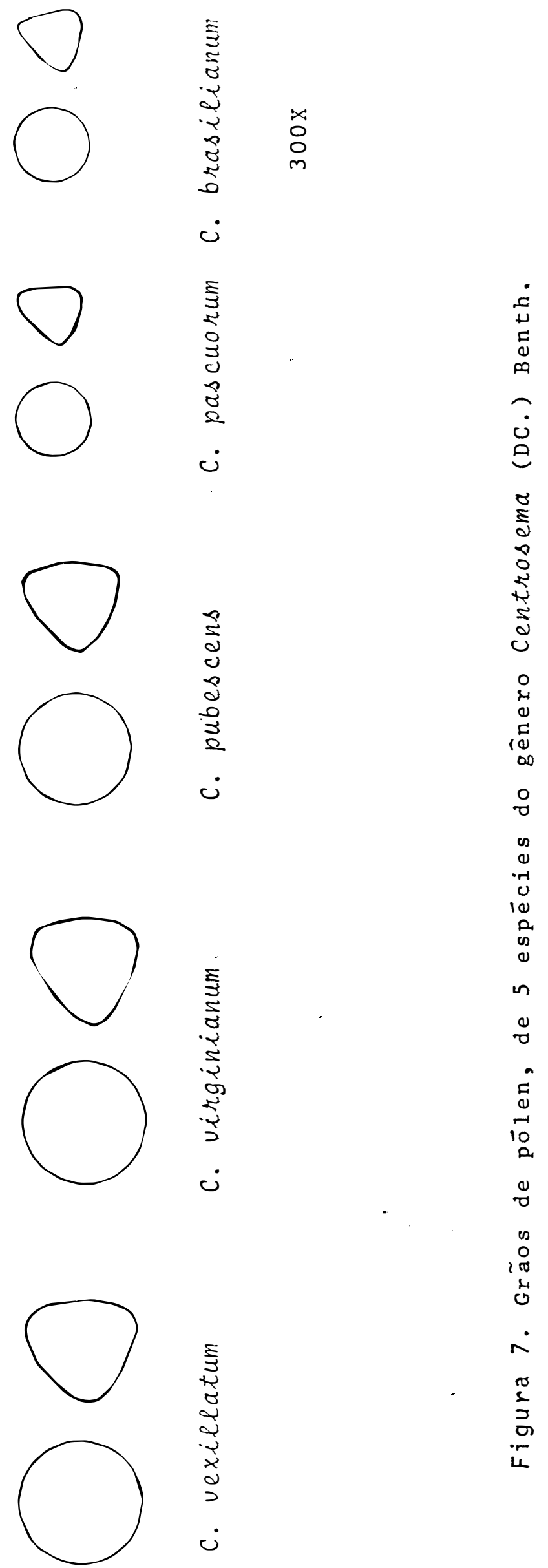

0
0
0
0
0
0
0
0
0
0
0
0
0
0
0
0
0
0
0
0
0
0
0
0
0
0
0
0
0
0
0
0
0
0
0
0
0
0
0
0
0
0
5
0




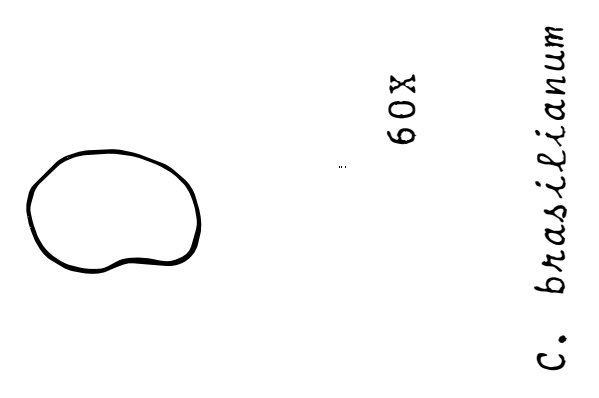

.115.
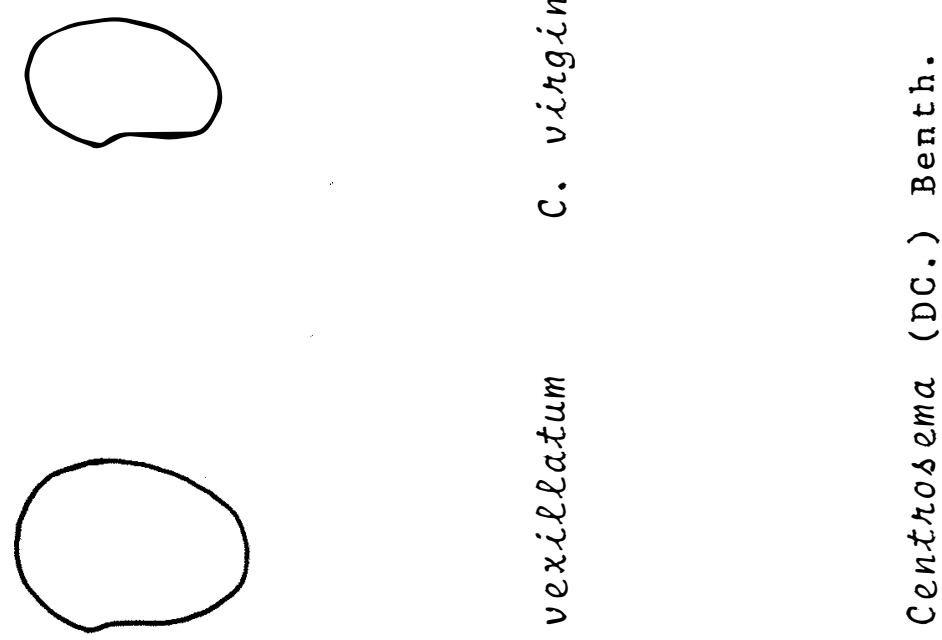

ن

ن

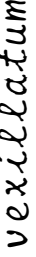

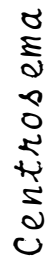

ci

0
4
0
1
0
0

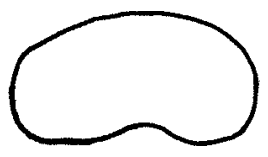

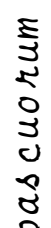

$\nabla$

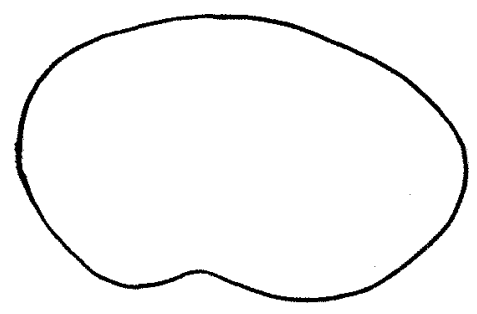

3
$\vdots$
0
0
2
$\vdots$
0
0
3
3
0

$\infty$

音

ن 

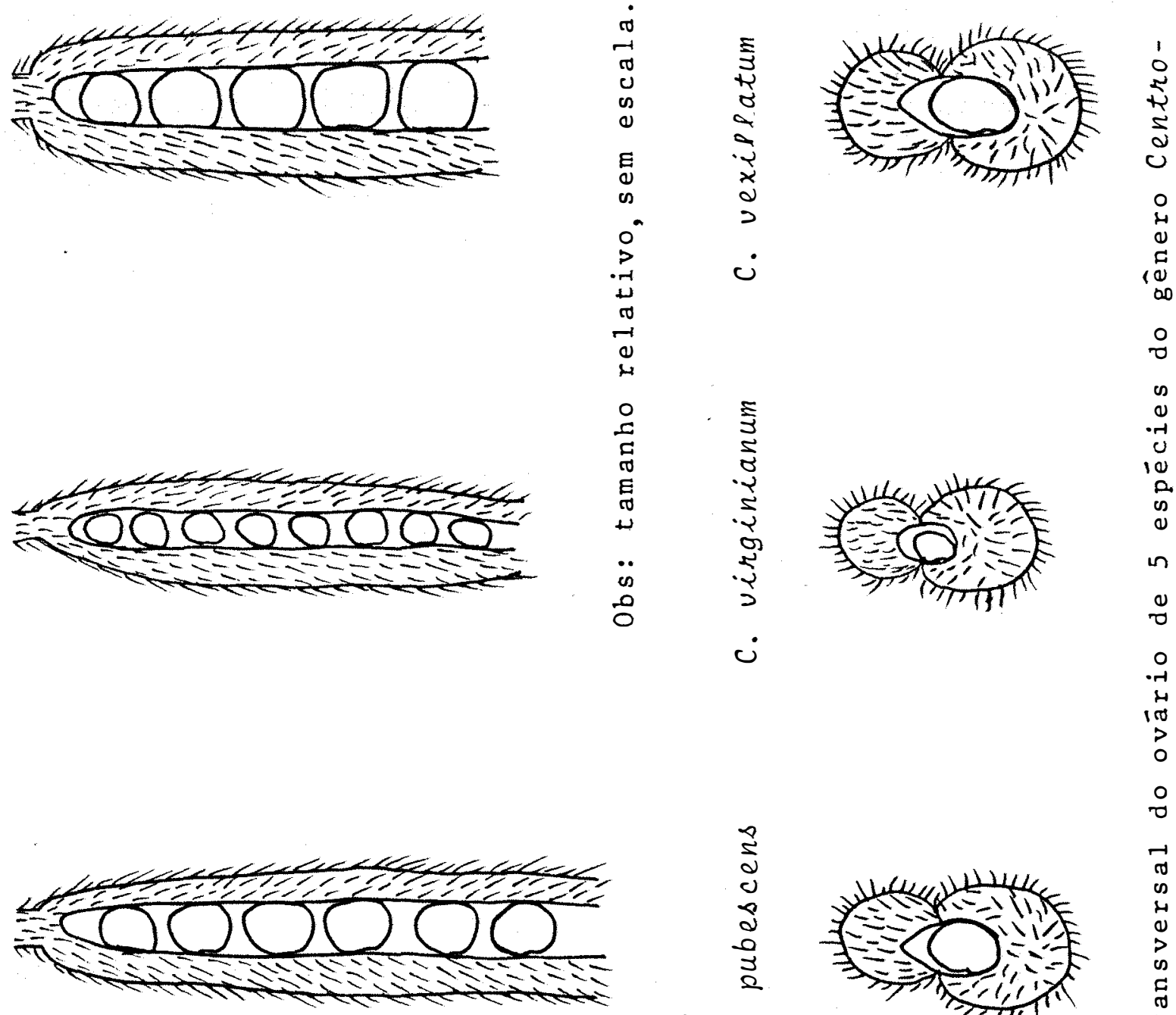

$a$
$\vdots$
0
0
$a$
0
0
3
2
0

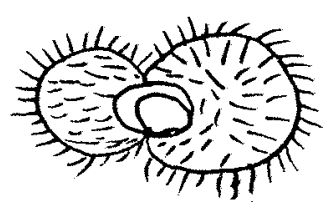

1
0
5
5
5
0
0
0
4
0
5
0
0
0
0
0
0
0
-1
0
0
0
0
0
0
0
0
0
0
0
0
0
0
0
0
0
0
0
0
0
4
0
0
0
5
0
4
1
0
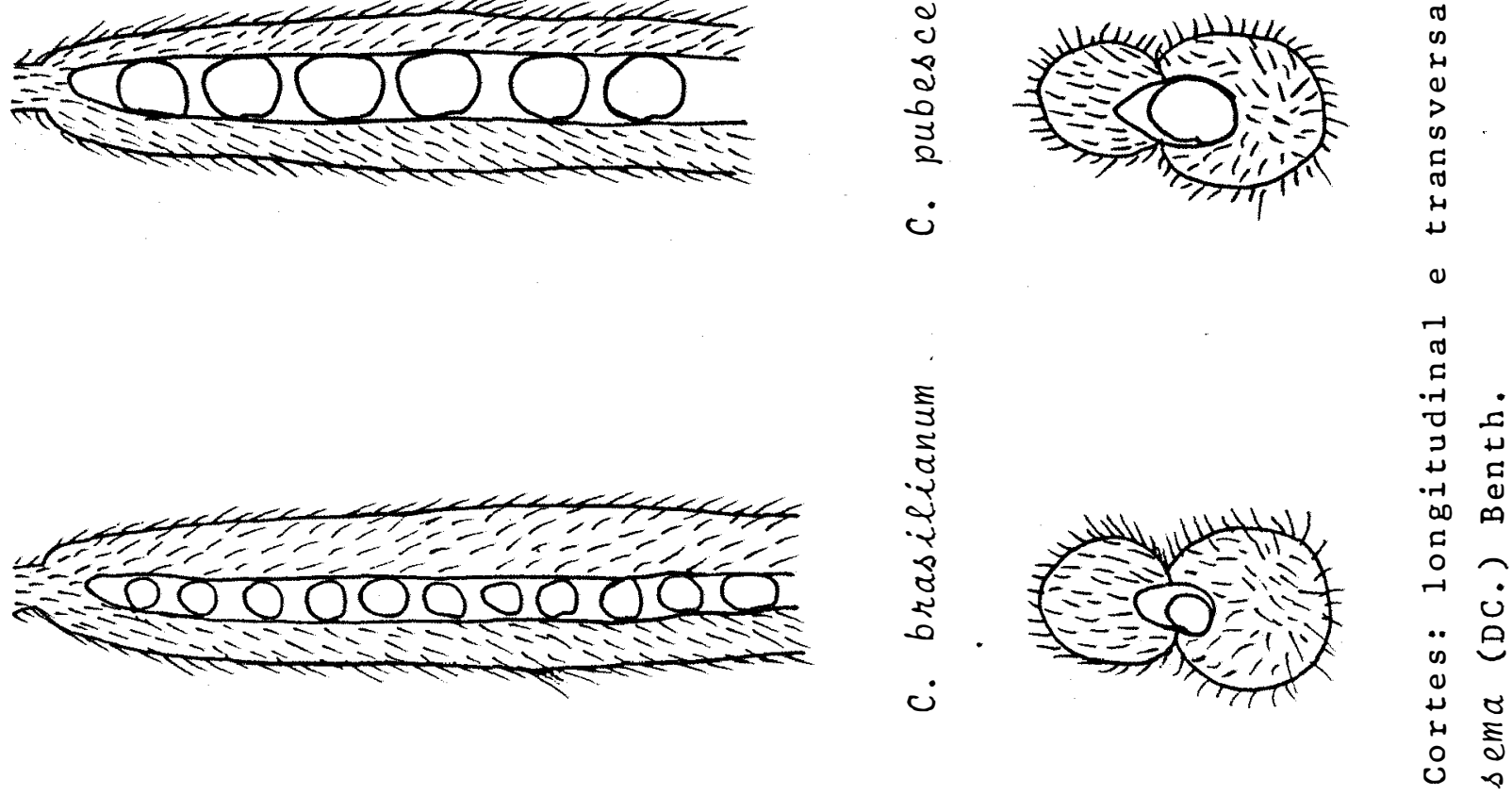

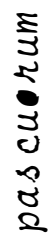

a
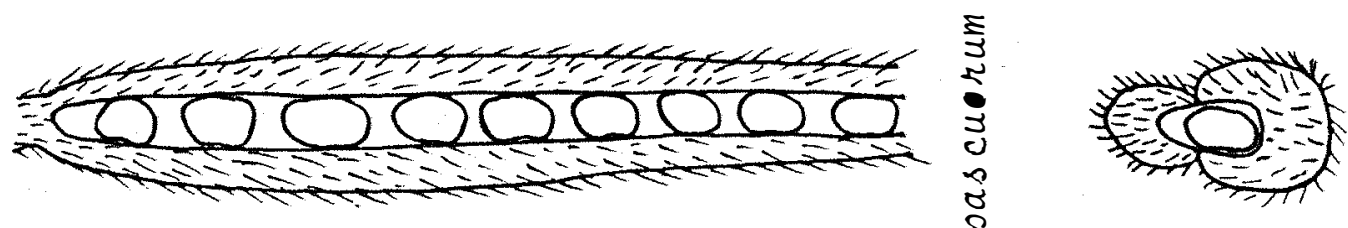

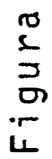




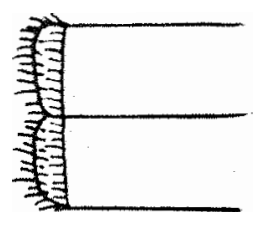

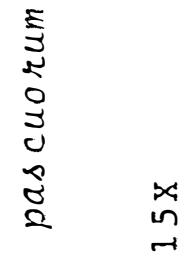

.117.
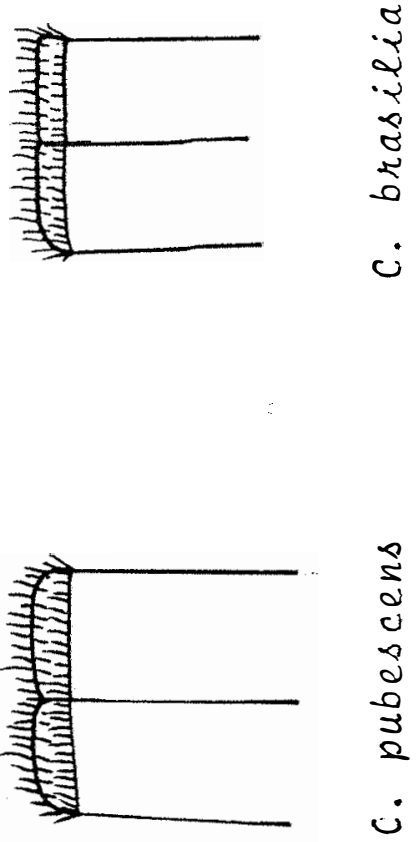

L
4
0
0
0
0
0

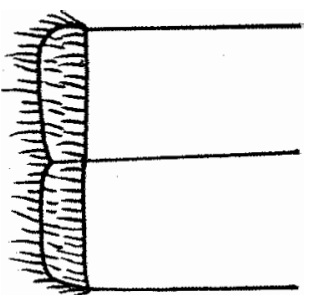

בٓ

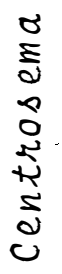

0
0
0
10
0
0

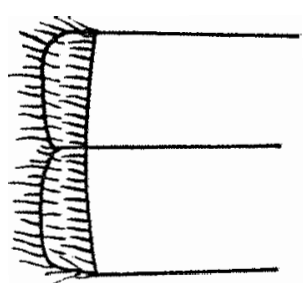

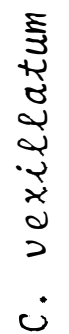

T

0
0
-1
0
10
0
0
0
0

ن

$\frac{0}{0}$

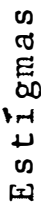

$\dot{0}$

0
2
5
0
11 


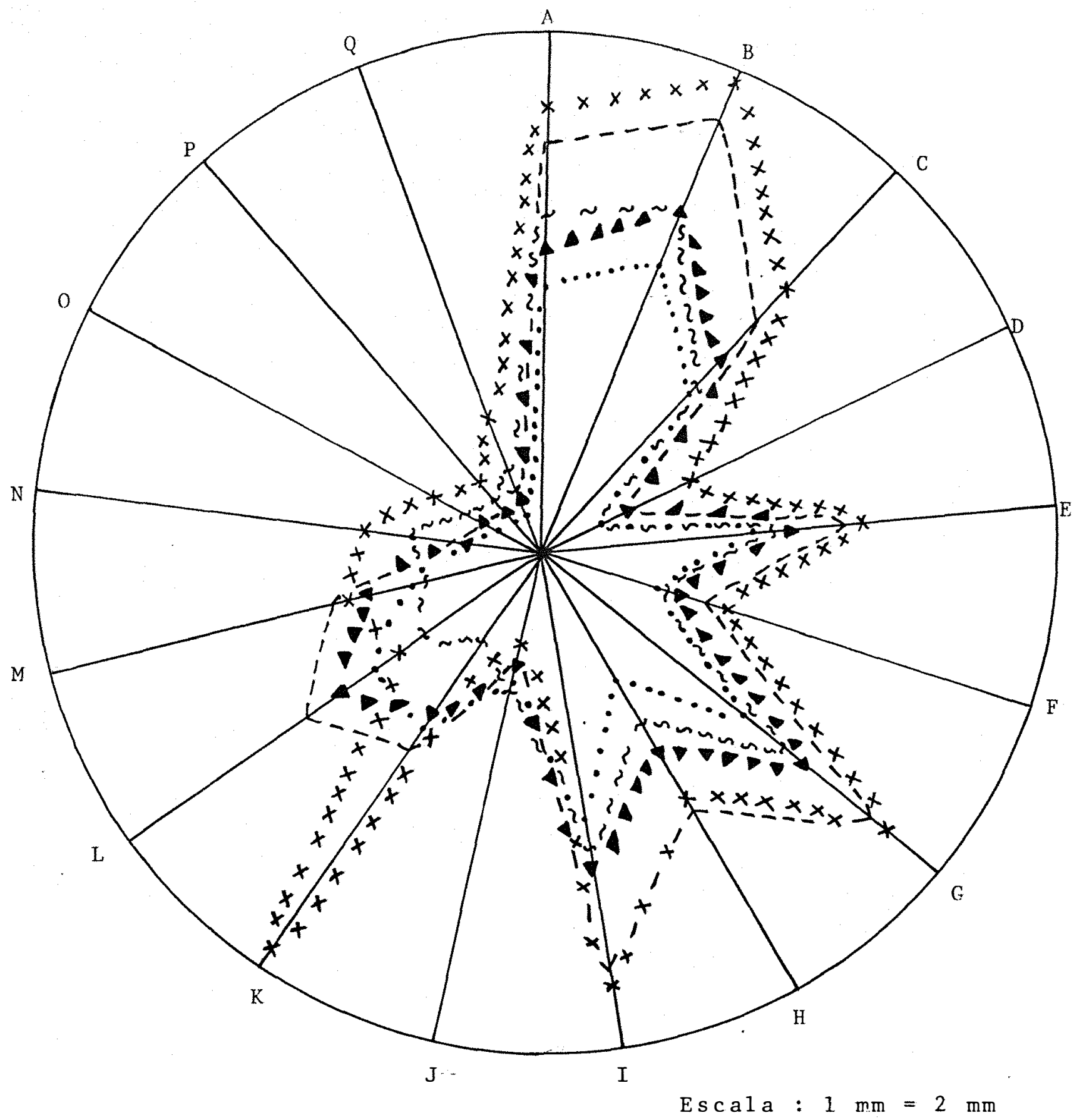

Figura 11. Distribuição dos caracteres florais: comprimento do estandarte (A); largura do estandarte (B); comprimento da asa (C); largura da asa (D); comprimento da quilha (E); largura da quilha (F); comprimento do androceu (G); comprimento do estame vexilar 1ivre (H); comprimento do gineceu (I); comprimento do ovário (J); comprimento do pedúnculo (K); comprimento do cálice (L); diâmetro do cálice (M); com primento da bracteola (N); largura da bracteolā (O); comprimento da bräctea (P); largura da bráctea (Q); das espécies; C. pubescens (-), C. brasilianum ( ), C. virginianum (•), C. vexillatum (X) e C. pascuorum $(\sim)$. ESLAQ/USP, Piracicaba - SP 1983. 


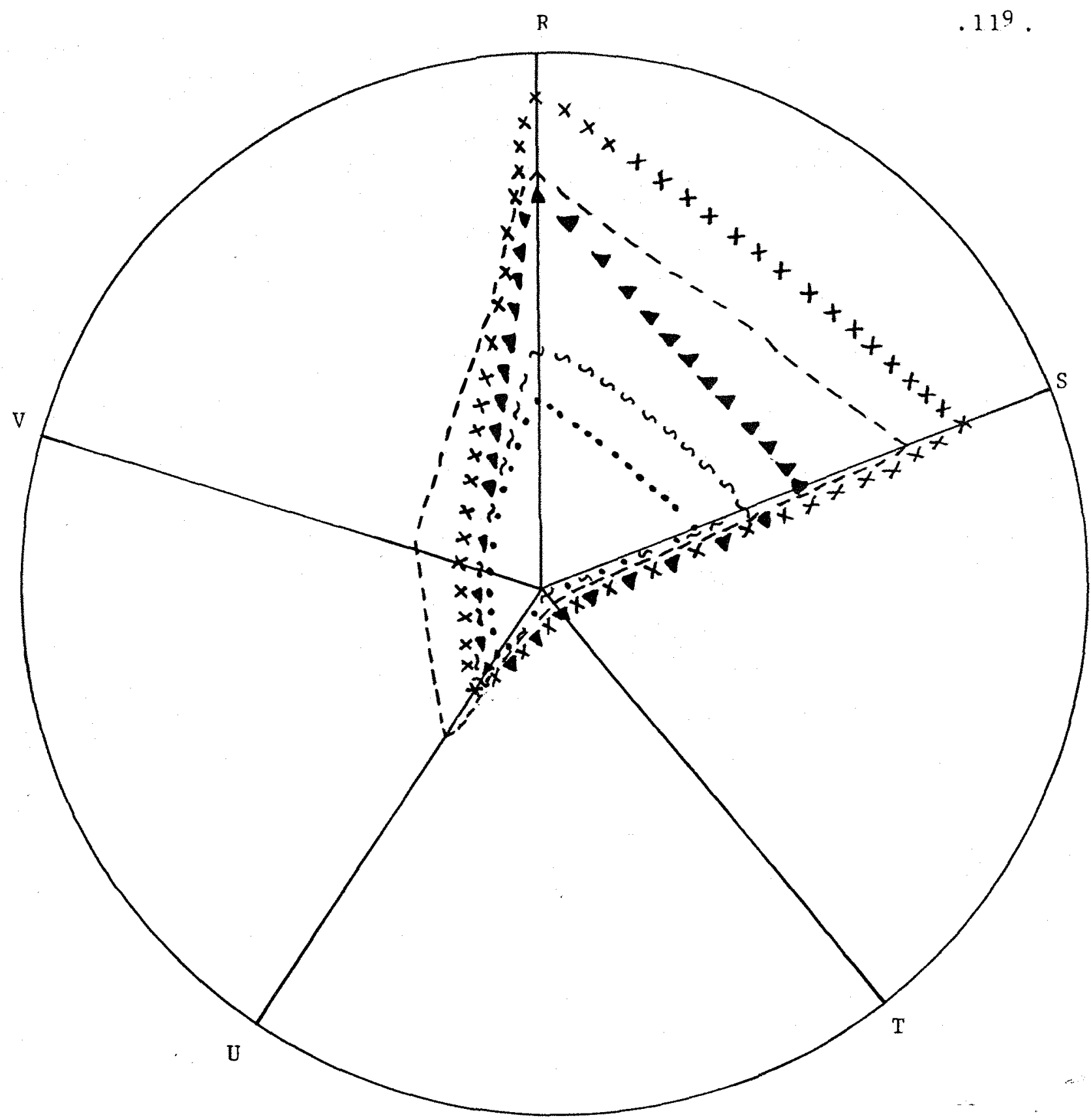

Escala : $1 \mathrm{~mm}=40 \mathrm{~mm}$

Figura 12. Distribuição dos caracteres f́lorais: comprimento da antera (R); largura da antera (S); diâmetro do grão de pólen (T); comprimento do óvulo (U); largura do óvulo (V); das espécies C. pubescens (-), C. brasilianum (•), c. virginianum (4), C. vexillatum $(x)$, C. pascuorum $(\sim)$. ESALQ/USP, PiracicabaSP. 1983. 